Energy Systems Environmental Restoration Program ORNL Environmental Restoration Program

\title{
Preliminary Evaluation of Liquid Integrity Monitoring Methods for Gunite and Associated Tanks at the Oak Ridge National Laboratory, Oak Ridge, Tennessee
}

Date Issued-February 1996

\author{
Prepared by \\ Vista Research, Inc. \\ Oak Ridge, Tennessee \\ under subontract T5-VR-JFA81C \\ Prepared for \\ U.S. Department of Energy \\ Office of Environmental Management \\ under budget and reporting code EW 20 \\ Environmental Management Activities \\ OAK RIDGE NATIONAL LABORATORY \\ Oak Ridge, Tennessee 37831-6285 \\ managed by \\ LOCKHEED MARTIN ENERGY SYSTEMS, INC. \\ for the \\ U.S. DEPARTMENT OF ENERGY \\ under Contract DE-AC05-840R21400
}




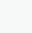




\section{PREFACE}

This report, Preliminary Evaluation of Liquid Integrity Monitoring Methods for Gunite and Associated Tanks at the Oak Ridge National Laboratory, Oak Ridge, Tennessee (ORNL/ER-349), was developed under Work Breakdown Structure 1.4.12.6.1.01.41.15.03 (Activity Data Sheet 3301, "WAGl"). This document provides the Environmental Restoration Program with an evaluation of the liquid integrity of the Gunite and Associated Tanks (GAAT) in the North and South Tank Farms at ORNL and of the monitoring methods for these tanks. Information provided in this report forms part of the technical basis for structural integrity, criticality safety, systems safety, engineering design, and waste management as they apply to the GAAT treatability study and remediation.

\section{DISCLAIMER}

- This report was prepared as an account of work sponsored by an agency of the United States Government. Neither the United States Government nor any agency thereof, nor any of their employees, makes any warranty, express or implied, or assumes any legal liability or responsibility for the accuracy, completeness, or usefulness of any information, apparatus, product, or process disclosed, or represents that its use would not infringe privately owned rights. Reference herein to any specific commercial product, process, or service by trade name, trademark, manufacturer, or otherwise does not necessarily constitute or imply its endorsement, recommendation, or favoring by the United States Government or any agency thereof. The views and opinions of authors expressed herein do not necessarily state or reflect those of the United States Government or any agency thereof. 


\section{CONTENTS}

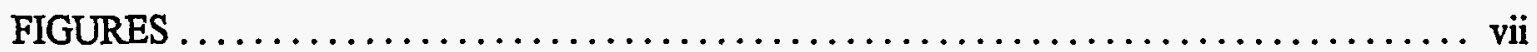

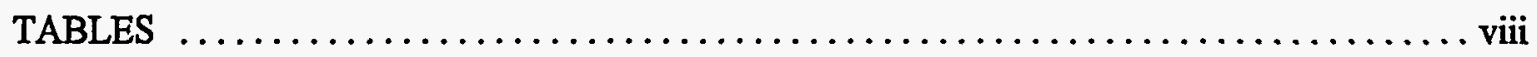

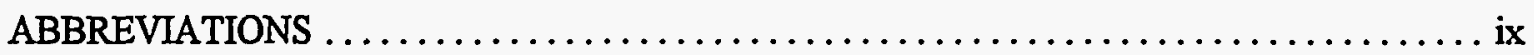

EXECUTIVE SUMMARY $\ldots \ldots \ldots \ldots \ldots \ldots \ldots \ldots \ldots \ldots \ldots \ldots \ldots \ldots \ldots \ldots \ldots \ldots$

1. INTRODUCTION $\ldots \ldots \ldots \ldots \ldots \ldots \ldots \ldots \ldots \ldots \ldots \ldots \ldots \ldots \ldots \ldots \ldots \ldots \ldots \ldots \ldots \ldots$

2. DESCRIPTION OF THE GUNITE TANKS AND DRY WELLS $\ldots \ldots \ldots \ldots \ldots \ldots \ldots$

3. EXTERNAL MONITORING METHOD $\ldots \ldots \ldots \ldots \ldots \ldots \ldots \ldots \ldots \ldots \ldots$

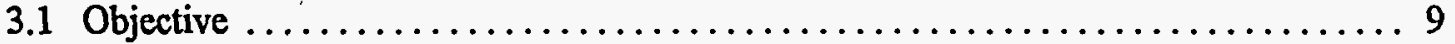

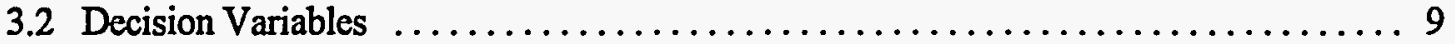

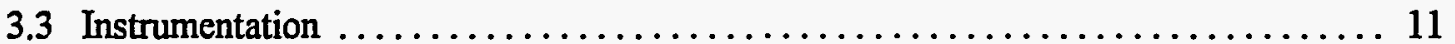

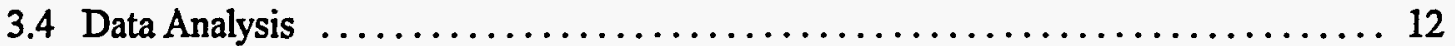

3.5 Results ............................................... 13

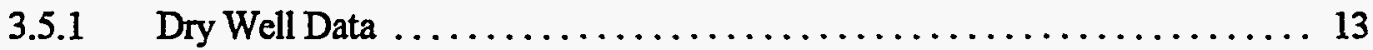

3.5.1.1 Conductivity/temperature data from the dry wells ......... 13

3.5.1.2 Water level data from the dry wells $\ldots \ldots \ldots \ldots \ldots \ldots \ldots \ldots 15$

3.5.1.3 Video data from the dry wells $\ldots \ldots \ldots \ldots \ldots \ldots \ldots \ldots \ldots 21$

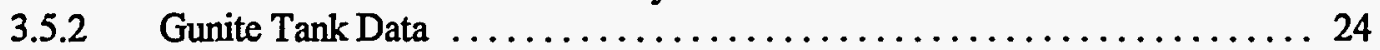

3.5.3 Calculation of the Leak Detection Threshold $\ldots \ldots \ldots \ldots \ldots \ldots . \ldots 28$

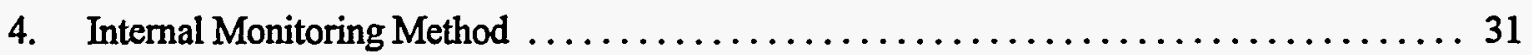

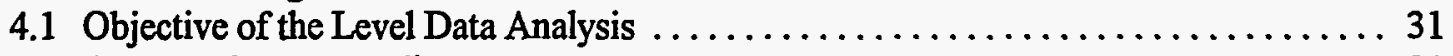

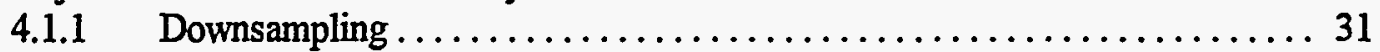

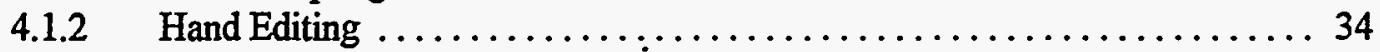

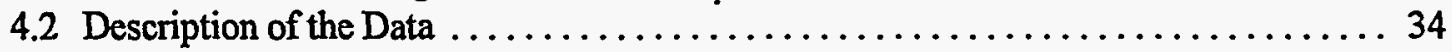

4.3 Approach to Level Data Analysis .............................. 35

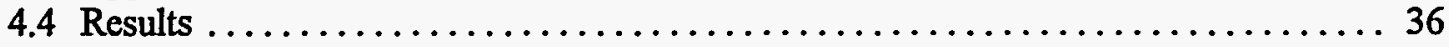

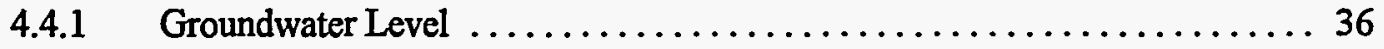

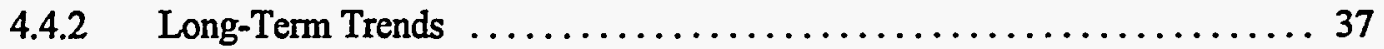

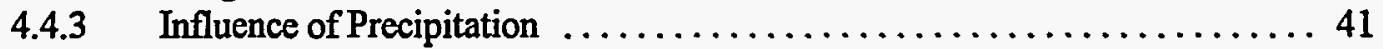

4.4.4 Statistical Inference Test .......................... 45

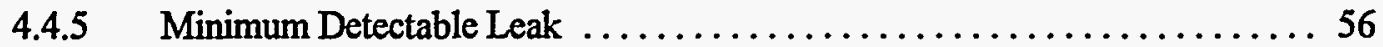

4.4.6 Evaporation and Condensation $\ldots \ldots \ldots \ldots \ldots \ldots \ldots \ldots \ldots \ldots \ldots$

5. CONCLUSIONS AND RECOMMENDATIONS $\ldots \ldots \ldots \ldots \ldots \ldots \ldots \ldots \ldots \ldots$

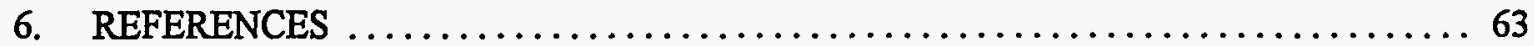

Appendix. ACCEPT/REJECT DIAGRAMS AND DATA USED IN STATISTICAL

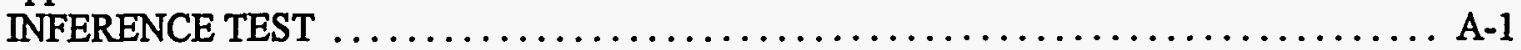




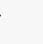




\section{FIGURES}

2.1 Map showing the location of the North and South tank farms at ORNL . . . . . . . . 4

2.2 Drainage and piping diagram for the Gunite tanks and dry wells in the North and South

Tank Farms

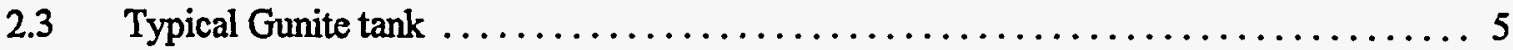

2.4 North-South cross section of Gunite tanks in the North and South Tank Farms ....... 7

2.5 East-west cross section of Gunite tanks in the South Tank Farm ............... 7

3.1 Cross-sectional diagram of a typical dry well $\ldots \ldots \ldots \ldots \ldots \ldots \ldots \ldots \ldots \ldots$

3.2 Conductivity and temperature in Dry Well D-3 from May 3-August 7, $1995 \ldots \ldots \ldots 14$

3.3 Cumulative and hourly rainfall at ORNL from May 3-August $7,1995 \ldots \ldots \ldots \ldots \ldots$

3.4 Conductivity and temperature in Dry Well D-4 from May 3-June 12, $1995 \ldots \ldots \ldots \ldots 16$

3.5 Conductivity and temperature in Dry Well D-8 from May 3-June 18, $1995 \ldots \ldots \ldots 17$

3.6 Water level in Dry Well D-3 and rainfall at ORNL from May 3-August 7, $1995 \ldots \ldots 17$

3.7 Water level in Dry Well D-3 and cumulative rainfall at ORNL from May 9-13, $1995 \ldots 18$

3.8 Water level in Dry Well D-4 and cumulative rainfall at ORNL from May 9-13, $1995 \ldots 18$

3.9 Water level in Dry Well D-8 and cumulative rainfall at ORNL from May 9-13, 1995 . . 19

3.10 Cross-sectional diagram of Dry Well D-3. The water in the dry well is at approximately the same level as the groundwater; the layer of sediment beneath

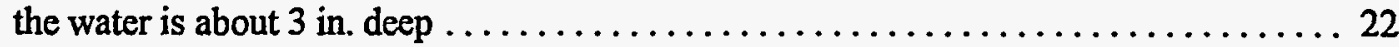

3.11 Cross-sectional diagram of Dry Well D-4. The water in the dry well is at approximately the same level as the groundwater; the layer of sediment beneath

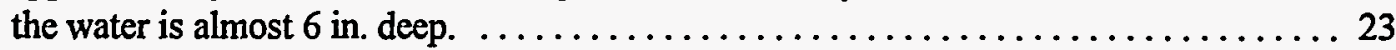

3.12 Cross-sectional diagram of Dry Well D-8. The water in the dry well is at approximately the same level as the the groundwater; the layer of sediment is about 12 in. deep, clogging the drainage piping into and out of the dry well . . . . . 23

3.13 Conductivity and temperature in Tank W-3 from May 3-June 12, 1995 ......... 25

3.14. Conductivity and temperature in Tank W-4 from May 3-June $12,1995 \ldots \ldots \ldots \ldots 25$

3.15 Conductivity and temperature in Tank W-8 from May 3-June 18, 1995 .......... 26

3.16 Conductivity below water level, measured at intervals of $0.5 \mathrm{ft}$, in (a) Tank W-3,

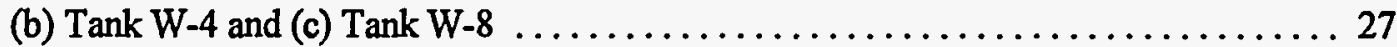

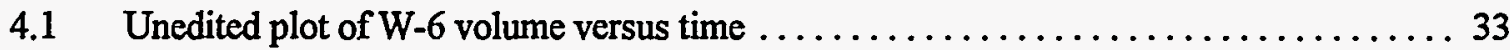

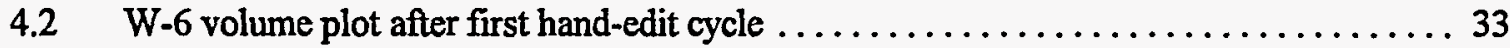

$4.3 \quad$ W-6 volume plot after final hand-edit cycle $\ldots \ldots \ldots \ldots \ldots \ldots \ldots \ldots \ldots \ldots \ldots \ldots$

4.4 Waste Operation Control Center (WOCC)-recorded volume in Tank W-5

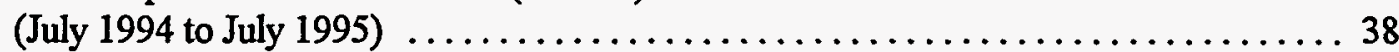

4.5 WOCC-recorded volume in Tank W-6 (July 1994 to July 1995) . . . . . . . . . . . . . 38

4.6 WOCC-recorded volume in Tank W-7 (July 1994 to July 1995) . . . . . . . . . . . . 39

4.7 WOCC-recorded volume in Tank W-8 (July 1994 to July 1995) . . . . . . . . . . . 39

4.8 WOCC-recorded volume in Tank W-9 (July 1994 to July 1995) . . . . . . . . . . 40

4.9 WOCC-recorded volume in Tank W-10 (July 1994 to July 1995) . . . . . . . . . . 40

4.10 Daily and cumulative rainfall at ORNL (April 1-30, 1994) .............. 42

4.11 Time series plot of volume in W-5 and rainfall at ORNL (April 1-30, 1994) ...... 42

4.12 Scatter plot of detrended rainfall data and detrended volume data for Tank W-5

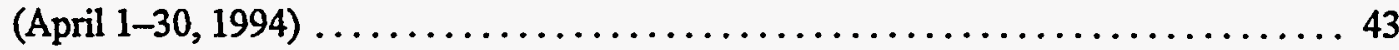


4.13 Time series plot of volume in W-8 and rainfall at ORNL (April 1-30, 1994) . . . . . 43

4.14 Time series plot of volume in W-9 and rainfall at ORNL (April 1-30, 1994) ........ 44

4.15 Time series plot of volume in W-10 and rainfall at ORNL (April 1-30, 1994) ...... 46

4.16 Time series plot of volume in W-7 and rainfall at ORNL (April 1-30, 1994) ....... 47

4.17 Time series plot of volume in W-3 and rainfall at ORNL (June 22-August 8, 1995) . . 47

4.18 Time series plot of volume in W-4 and rainfall at ORNL ((June 22-August 8, 1995) _. 48

4.19 Time series plot of volume in W-5 and rainfall at ORNL (March 28-July 30, 1995) ... 48

4.20 Time series plot of volume in W-6 and rainfall at ORNL (June 22-August 8, 1995) . . . 49

4.21 Time series plot of volume in W-7 and rainfall at ORNL (June 22-August 8, 1995) . . . 49

4.22 Time series plot of volume in W-8 and rainfall at ORNL (June 22-August 8, 1995) . . 50

4.23 Time series plot of volume in W-9 and rainfall at ORNL (June 22-August 8, 1995) . . 50

4.24 Time series plot of volume in W-10 and rainfall at ORNL (June 22-August 8, 1995) . . 51

4.25 Tank W-5: (a) CVR and noise analysis; (b) scatter plot of valid volume rate estimates .. 54

4.26 Evaporation and condensation as modeled in an liquid low level waste tank at ORNL (March 27-July 30, 1995) ............................. 60

4.27 Tank W-7 level (September 1, 1993-November 1, 1995) .................. 60

\section{TABLES}

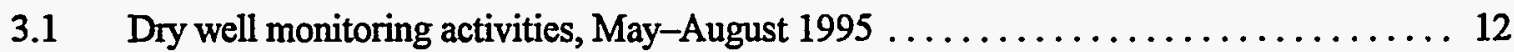

3.2 Water elevations in dry wells and tanks . . . . . . . . . . . . . . . . . . . 20

3.3 Conductivity measurements in the three tanks (August 14, 1995) ............. 24

3.4 Conductivity measurements in Dry Well D-3 (May 3-August 7, 1995) . ........ 28

4.1 Performance specifications for the Robertshaw Intel-185 sensor . . . . . . . . . 34

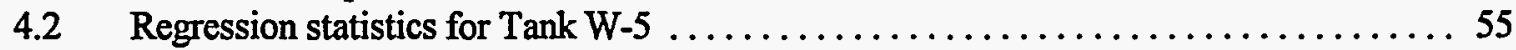

4.3 Summary of results from statistical inference test ................... 56

4.4 Performance estimates for 48-h integrity tests using the Gunite and Associated Tanks

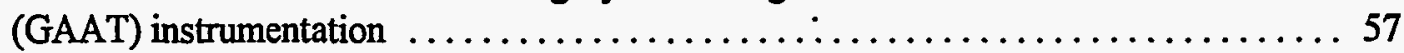




\section{ABBREVIATIONS}

EPA U.S. Environmental Protection Agency

HOG hot gas system

GAAT Gunite and Associated Tanks

LLLW liquid low-level waste tanks

NTF North tank farm

ORNL Oak Ridge National Laboratory

STF South tank farm

WOCC Waste Operation Control Center 



\section{EXECUTIVE SUMMARY}

The Gunite and Associated Tanks (GAAT) are inactive, liquid low-level waste (LLLW) tanks located in and around the North and South Tank Farms (NTF and STF) at Oak Ridge National Laboratory (ORNL). These tanks, which contain a supernatant over a layer of radioactive sludge, are the subject of an ongoing treatability study that will determine the best way to remove the sludge and remediate the tanks. As part of this study, a preliminary assessment of liquid integrity (or "tightness") monitoring methods for the Gunite tanks has been conducted. Both an external and an internal liquid integrity monitoring method were evaluated, and a preliminary assessment of the liquid integrity of eight Gunite tanks was made with the internal method.

The work presented in this report shows that six of the eight GAAT considered here are liquid tight and that, in the case of the other two, data quality was too poor to allow a conclusive decision. The analysis indicates that when the release detection approach described in this report is used during the upcoming treatability study, it will function as a sensitive and robust integrity monitoring system. Integrity assessments based on both the internal and external methods can be used as a means of documenting the integrity of the tanks before the initiation of in-tank operations. Assessments based on the external method can be used during these operations as a means of providing a nearly immediate indication of a release, should one occur.

The external method of release detection measures the electrical conductivity of the water found in the dry wells associated with each of the tanks. This method is based on the fact that the conductivity of the liquid in the GAAT is very high, while the conductivity of the groundwater in the dry wells and the underdrain system for the GAAT is very low. If a release occurs, the liquid that leaks out the tank will drain into the dry well, increasing the conductivity of the water there by a detectable amount. The internal method of release detection relies upon more traditional measurements and analyses of the changes in liquid level over time.

The evaluation of the external method involved inspection, instrument installation, and acquisition and analysis of data from the dry wells associated with Tanks W-3, W-4 and W-8 over a three-month period. The results of this work indicate that the external method can be a very sensitive release detection technique. The results also show, however, that construction rubble and sediment buildup in the STF dry wells can impede measurements. A considerable effort to clean out these wells may be required before they can be used for conductivity measurements.

The evaluation of the internal liquid integrity monitoring method and the assessment of the liquid integrity of Tanks W-3-W-10 were based on water level data from these tanks and on meteorological and groundwater records. These data were assembled, reviewed and analyzed. The analysis of the internal method utilized about five months' worth of data from the six Gunite tanks in the STF (W-5 -10 ) and one and one-half months' from the tanks in the NTF (W-3 and W-4). The results of the analysis indicate that W-3, W-4, W-5, W-6, W-8 and W-9 are tight. The level data obtained from W-7 and W-10, however, suffered from high noise, attributed to the measurement systems in these tanks; this greatly reduced the certainty of the assessments for these tanks. Despite the noise, the analysis suggests that W10 is also tight. Tank W-7 appears to exhibit a small but statistically significant volume loss over the period of the assessment. However, analysis of long-term water-level data and calculations of potential in-tank condensation and evaporation indicate that the changes in volume in Tank W-7 could be related to the seasonal changes in net evaporation and condensation occurring in that tank. 



\section{INTRODUCTION}

A treatability study is underway to investigate means to remediate the Gunite and Associated Tanks (GAAT) located in the North and South Tank Farms (NTF and STF) at the Oak Ridge National Laboratory (ORNL). Most of these tanks contain a supernatant (mostly water) over a layer of radioactive sludge. A part of the treatability study will entail sluicing-jetting water into a Gunite tank to loosen and suspend the sludge - so that the supernatant and the sludge can be removed. The current plans are to conduct a feasibility demonstration of the sluicing technique in Tanks W-3 and W-4, located in the NTF. The experience gained from this demonstration will be used to design and implement the remediation procedures for the Gunite tanks in the STF. In support of this demonstration and the long term remediation objectives for the GAAT, the integrity of the tanks is being evaluated. The two main components of the GAAT integrity analysis are the structural integrity assessment and the liquid integrity assessment. Although the two are interrelated, the former is being handled as part of a separate work effort. This report presents the results of a preliminary evaluation of internal and external methods to monitor the liquid integrity of the Gunite tanks.

The purpose of the preliminary evaluation is to show (1) that both internal and external monitoring techniques can be used to assess the liquid integrity of the tanks and (2) that a program to monitor the liquid integrity of tanks can effectively identify potential releases and changes in overall tank integrity during the treatability and remediation activities. An effective monitoring program will be essential in identifying changes in tank integrity that could result in the release of liquid. Two types of data were analyzed during this evaluation: existing data (i.e., data on liquid level in the tanks, meteorological conditions, and groundwater elevation) and new data collected for this effort (water level and conductivity data obtained from sensors placed in dry wells and Gunite tanks).

The internal monitoring method was evaluated by assembling and reviewing selected data files from the last several years that relate to the water level changes in the Gunite tanks. This includes the internal water level measurement data stored on the Waste Operations Control Center (WOCC) database system, and meteorological and groundwater data. The WOCC database contains water level data for the six Gunite tanks in the STF (W-5-W-10). For Tanks W-3 and W-4 in the NTF, water level data from newly installed pressure transducers were used. The internal monitoring method examines measurements of the liquid level in the tank to provide a precise estimate of the changes in volume over time. The assembled data were analyzed (1) to determine the threshold volume change that can be detected with the existing data, (2) to make a preliminary assessment of the liquid integrity of the tanks, and (3) to develop recommendations for implementation of an internal integrity monitoring program.

The external monitoring method was evaluated by collecting and analyzing new data from water level, electrical conductivity, and temperature sensors recently installed in the dry wells and tanks at W-3, W-4 and W-8. The external method makes use of the existing dry well system that is adjacent to each of the Gunite tanks. The data collected from the dry wells were analyzed to see if the chemistry and flow characteristics of the water that seeps into these wells can be used as an external means of monitoring the liquid integrity of the tanks. This method takes advantage of the fact that the conductivity of the liquid in the Gunite tanks is very high $(10,000$ to $20,000 \mu \mathrm{mhos} / \mathrm{cm})$ relative to the conductivity of the groundwater at the NTF and STF (200 to $400 \mu \mathrm{mhos} / \mathrm{cm}$ ). If liquid is released from one of the Gunite tanks it will drain into the dry well and change the conductivity of the water there. The ability of the external monitoring system to detect the release depends on conditions in the dry well, the volume rate of the release from the tank, and the sensitivity of the measurement system in the dry well. 
For the preliminary evaluation of the external monitoring technique, the response of the instruments in the dry wells and tanks as a function of time and rainfall events was monitored over a period of several months. These data were examined and analyzed to determine whether the dry well system, with some modifications, could be used as an external monitoring system that effectively augments the internal monitoring system. There were two main criteria for determining the suitability of the external system: the release detection threshold that could be achieved with the external system, and the degree to which the combining of the two independent systems, external and internal, improved detection sensitivity and reduced the false alarm rate.

This report presents the results of an evaluation of an internal and an external monitoring method that can be used together for making sensitive and robust release detection estimates in ORNL's Gunite tanks. Chapter 2 describes the Gunite tanks and dry well systems in the NTF and STF. Chapter.3 addresses the external monitoring technique, from data analysis to results. Chapter 4 does the same for the internal monitoring technique. Chapter 5 summarizes the results and presents the conclusions. 


\section{DESCRIPTION OF THE GUNITE TANKS AND DRY WELLS}

The Gunite and Associated Tanks, most of which were built in 1943 in pits excavated out of bedrock, are located in and around the North and South Tank Farms (NTF and STF) at Oak Ridge National Laboratory (ORNL). The tanks of primary interest in this investigation are the two Gunite tanks in the NTF (W-3 and W-4) and the six Gunite tanks in the STF (W-5, W-6, W-7, W-8, W-9 and W-10). A map showing the locations of these tanks within the NTF and STF is provided in Fig. 2.1. Tanks W-3 and W-4 are located in the southeast comer of NTF. Each is $25 \mathrm{ft}$ in diameter and approximately $12 \mathrm{ft}$ high (excluding the dome cover), with a capacity of 42,500 gal. The six tanks in the STF are arranged in two rows of three each and are lined up in an east/west direction. Each of these tanks is $50 \mathrm{ft}$ in diameter and approximately $12 \mathrm{ft}$ high (excluding the dome cover), with a capacity of 170,000 gal. Each of the tanks has an associated dry well that, via an inlet pipe and an outlet pipe, receives liquid from the excavation pits and drains it to a treatment facility. Figure 2.2 is a diagram that illustrates this dry well/drainage system.

Figure 2.3 is a schematic drawing of a typical Gunite tank and dry well. The dry wells, which were designed as part of an underdrain and leak detection monitoring system for the tanks, are $2 \times 2 \mathrm{ft}$ concrete wells that extend from the surface to about $2 \mathrm{ft}$ below the base of their respective tanks. Any water that collects on the tank base would be expected to drain out into the dry well and then be captured by the underdrain system. For both inventory and health and safety reasons, the water levels in all of the tanks in the NTF and STF are monitored on a routine basis. The tanks in the STF have an online water level monitoring system that provides a detailed database that was used in the preliminary liquid integrity analysis. Water levels in Tanks W-3 and W-4 have historically been monitored by manual reading of a staff gauge that was located in each tank. ${ }^{1}$ For the purposes of the liquid integrity analysis, data from pressure transducers were used in lieu of the type of WOCC level data available for the tanks in the STF. The proposed liquid integrity monitoring system is designed to take advantage of routine measurements of water level in the tanks and of the electrical conductivity of the water in dry wells, in effect combining them both into a sensitive, robust liquid integrity monitoring system.

When the tanks in the STF were removed from service, some of the lines leading into them were cut and capped in support of the requirements of the sluicing program; others remained intact and were taken out of service administratively. These tanks were all pumped down around 1983 as part of an earlier sluicing operation. Since then, however, they have been infiltrated by the slow seepage of rainwater and other shallow drainage that enters through and around the drain pipes in the domes of the tanks. The amount of water that has infiltrated the tanks varies considerably, with W-6 experiencing the most and W-7 the least. With the exception of W-7, the tanks are currently at their highest levels since they were pumped down in 1983.

As mentioned above, there is a dry well adjacent to each of the tanks (W-1-W-10) that is designed to collect liquid that infiltrates or seeps onto the concrete base under each tank. The tanks are all connected by a gravity-fed drain system that draws off water from both the dry wells and the backfill that surrounds the tanks. Each dry well was constructed with a 6-in.-deep sump located below the level at

${ }^{1}$ In June 1995 these staff gauges were removed; water levels are now being measured manually with a water level probe and are also being logged on an hourly basis with a submerged pressure transducer connected to a data recorder. There is no detailed and precise historical record, prior to June 1995, of water level for Tanks $\mathrm{W}-3$ and $\mathrm{W}-4$. However, there is a record for the six bigger tanks in the STF. 


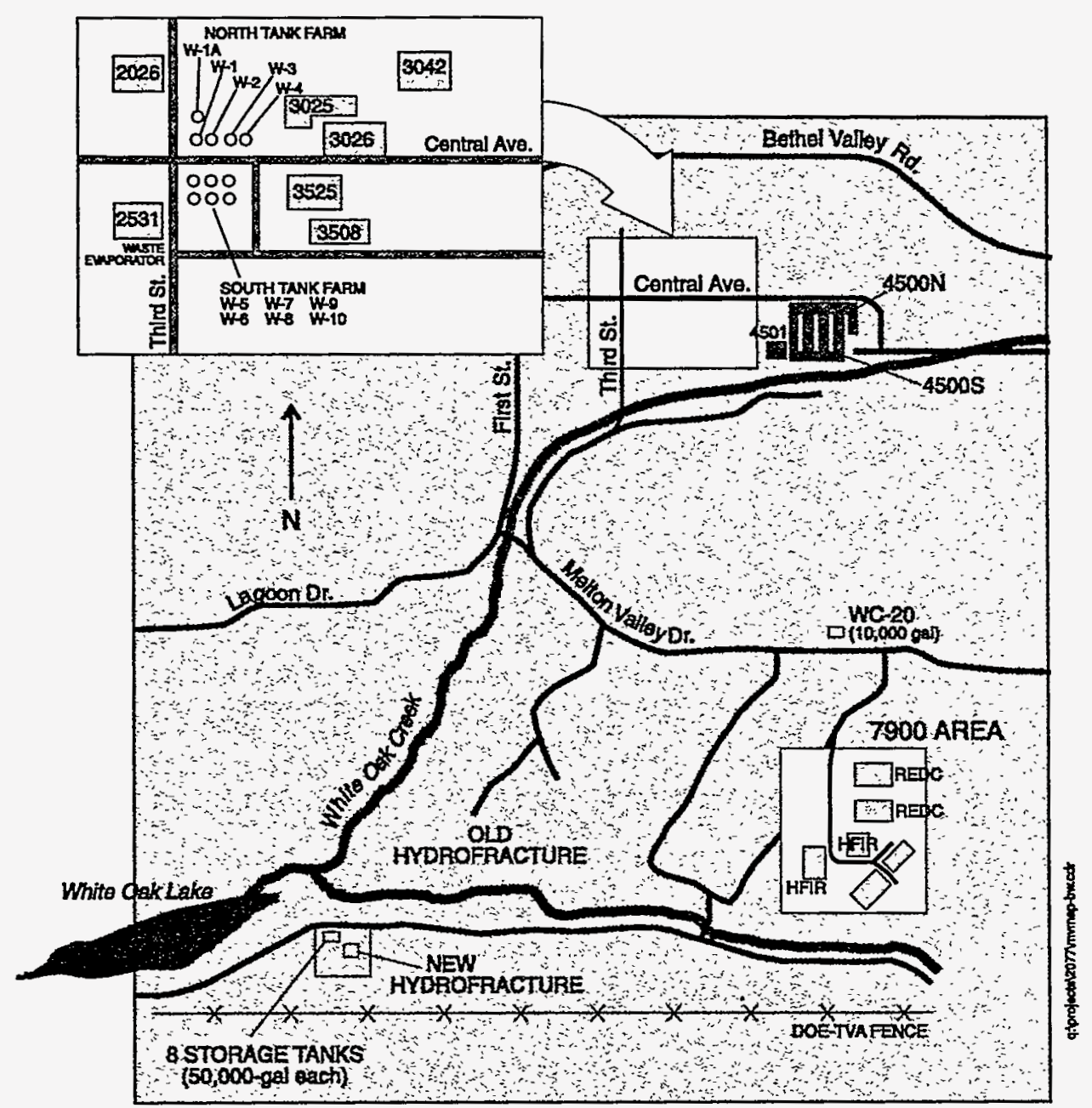

Fig 2.1. Map showing the location of the North and South Tank Farm at ORNL. 


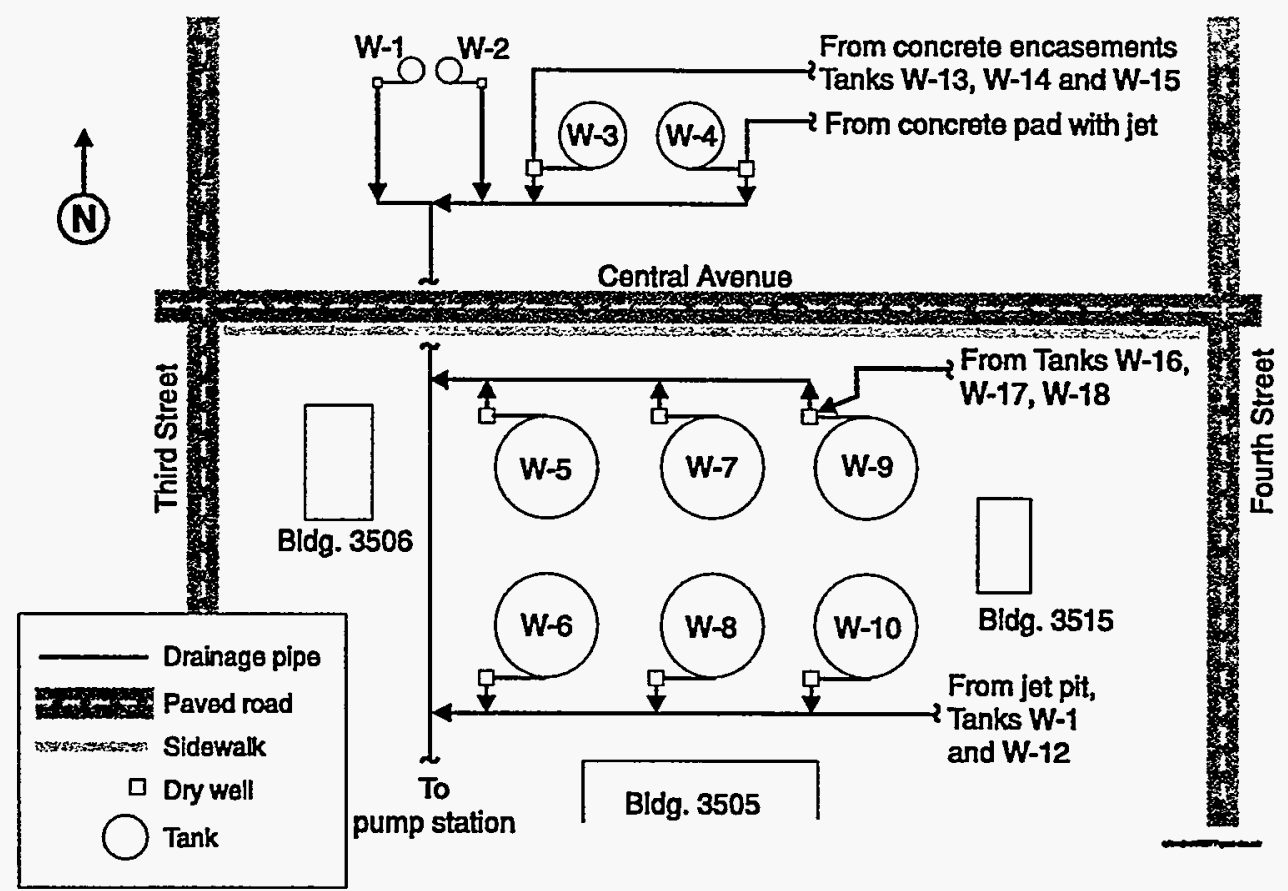

Fig. 2.2. Dry well and drainage piping for the gunite tanks in the North and South Tank Farms at ORNL.

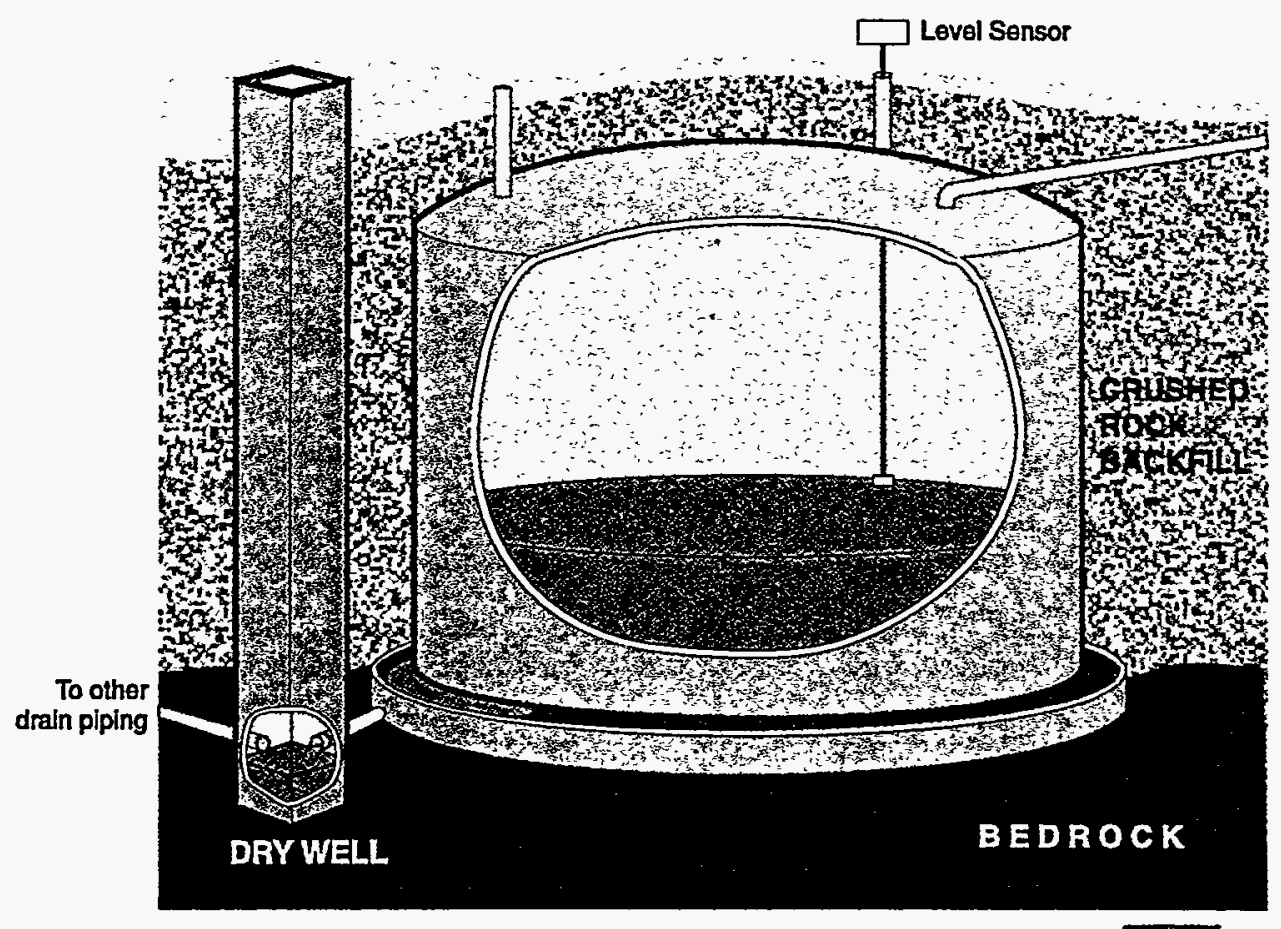

Fig. 2.3. Typical gunite tank. 
which the drain pipe from the concrete pad and the outlet pipe intersect the well. The relationship between the tank/dry-well/drain system and the surrounding groundwater is illustrated in Figs. 2.4 and 2.5.

Figure 2.4, a North-South crossectional view of the tanks in the NTF and STF, shows that the groundwater is kept depressed, below the bottom of the tanks, by the dry well and drain system. Figure 2.5 illustrates the same phenomenon from a different perspective, an east-west cross-sectional view of the tanks in the STF. Figures 2.4 and 2.5 are based on measurements and observations obtained through various investigations over the last several years and confirmed by the dry well data and the data on liquid level in the tanks collected during this study. (Figures 2.4 and 2.5 were adapted from engineering drawings prepared by Bechtel Corporation, Inc.)

Note that Figures 2.4 and 2.5 also show the approximate level of water in each tank. These levels are well above groundwater levels, indicating that groundwater is neither a source of leakage into the tanks nor a factor that would inhibit leakage out of the tanks (given a defect that would allow such a leak). The concrete pads are also above groundwater levels. Thus, if liquid did flow out of a tank and onto the pad, it would be expected to flow into the dry well rather than mix with the groundwater. This release would be detectable by an external monitoring system that was based on the contrast in conductivity between water from the tank and water in the dry well.

The construction of the dry wells, which have a 6-in.-deep sump below the bottom of the inlet and outlet drains (see Fig. 2.3), provides a convenient arrangement for the installation of external monitoring sensors. In the preliminary evaluation, the dry wells associated with Tanks W-3, W-4 and W-8 were instrumented with water level, conductivity and temperature probes. It was determined during the evaluation that sediment and other materials have collected in the bottom of the dry wells, in some cases to such an extent that it was difficult to install instruments and obtain useful measurements. This problem is discussed in Sect. 3.5.1.3. 


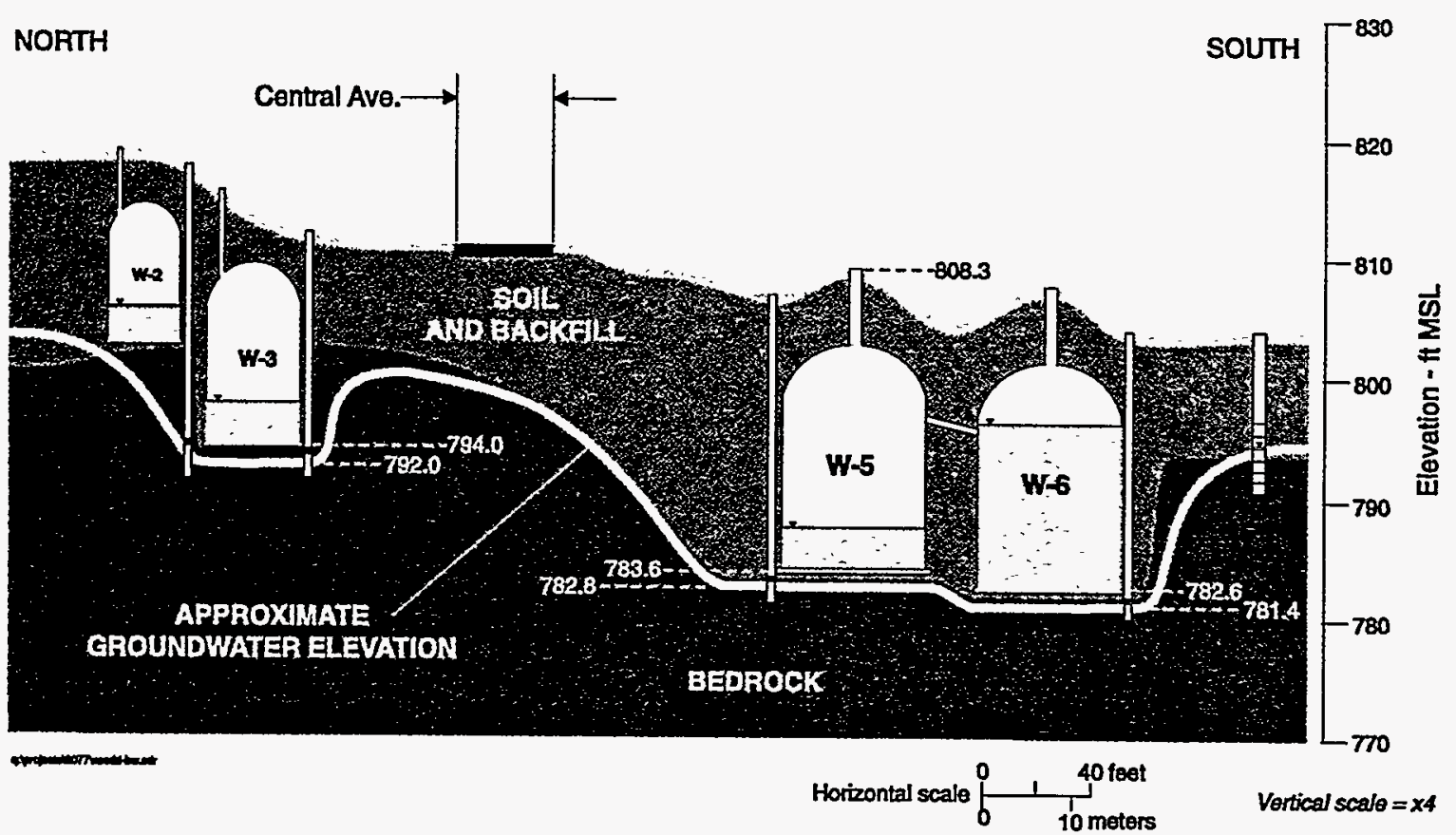

Fig. 2.4. North-south cross section of gunite tanks in the North and South Tank Farms.

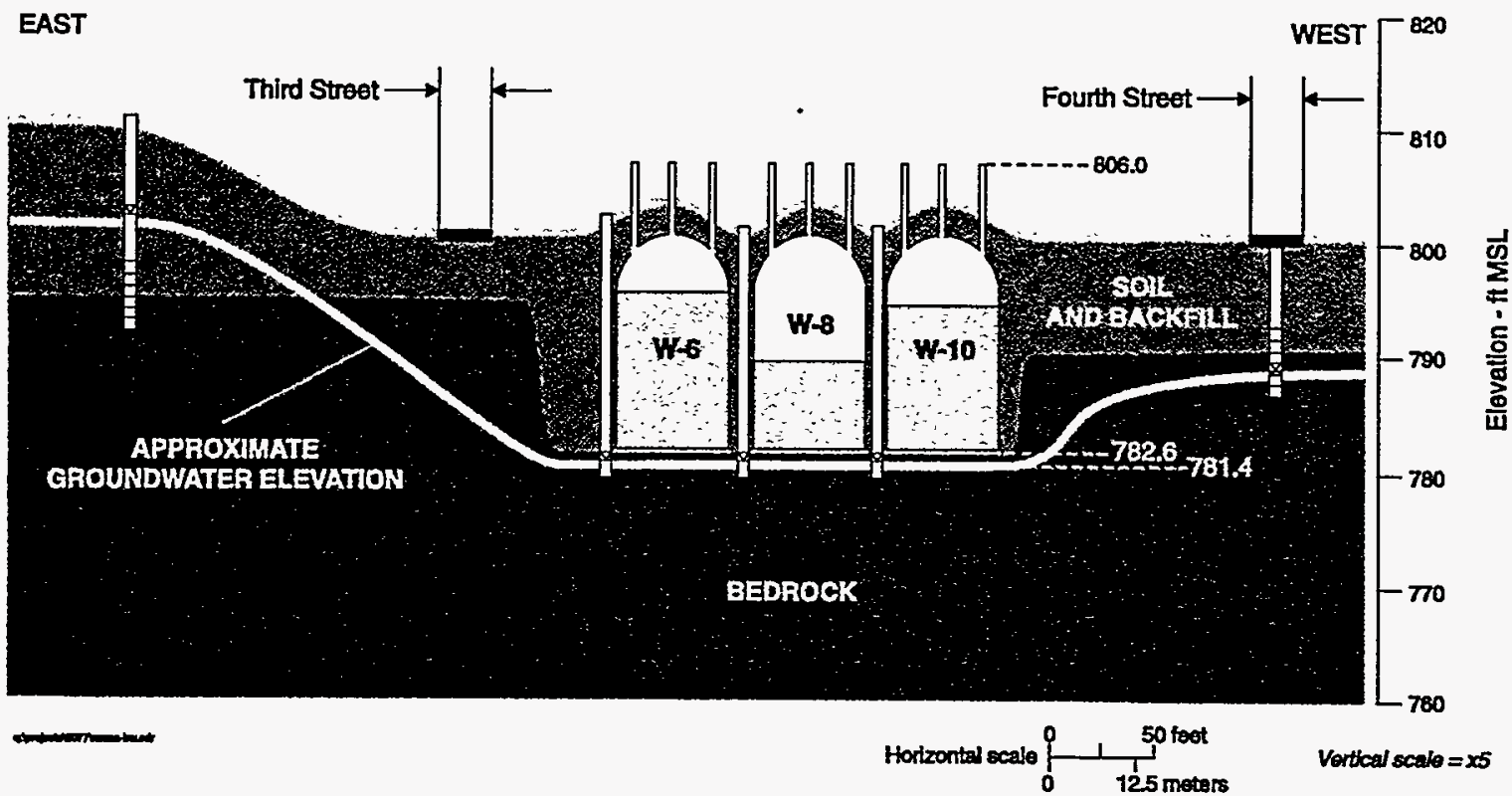

Fig. 2.5. East-west cross section of gunite tanks in the South Tank Farm. 


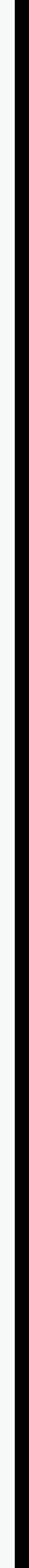




\section{EXTERNAL MONITORING METHOD}

The external monitoring method for assessing the liquid integrity of a tank (sometimes referred to as the "dry well monitoring" method) is based on conductivity measurements of the water in the dry well adjacent to that tank. Chapter 3 describes the preliminary evaluation of this technique.

\subsection{OBJECTIVE}

The principal objective of the preliminary evaluation of the dry well monitoring method was to determine the feasibility of using measurements of electrical conductivity-specifically, the difference in conductivity between the water in a Gunite tank and the water in its dry well-as an external means of monitoring that tank for leaks. Secondary objectives included determining sensor performance over an extended period of time, estimating a threshold value for the size of the detectable leak, and discovering what modifications (either to monitoring equipment or dry wells) might be required in order to install and operate such equipment in these wells.

Information from past sampling operations and other monitoring activities indicated that there is water at the bottom of the dry wells in the NTF and STF, and that there is a significant difference in electrical conductivity between the water in the dry wells and that in the tanks. However, no detailed analysis had been conducted on the depth of this water, on the relationship of the level of water in the wells to the level of the water table in the surrounding soil, or on the practicality of installing instruments at the bottom of the wells. The preliminary evaluation described here includes a detailed analysis of dry well conditions and groundwater levels done specifically to determine feasibility of the proposed method for external monitoring of the Gunite tanks.

As described in Chap. 2, the dry wells are constructed with inlet and outlet drains at the bottom. Figure 3.1 shows a typical dry well. The inlet pipe receives the water that drains from the concrete pad under the Gunite tank. The outlet drain is connected to a main drain header system designed to carry the water out of the NTF and STF and down to Pump Station 1. Both the inlet and outlet drains consist of 6-in.-diameter clay pipes positioned 6 in. from the bottom of the dry well. This design provides a 6-in. sump where water draining from the concrete pad can collect. The dry well sump thus offers a technique for monitoring tank-specific water quality parameters such as conductivity from a vantage point external to the tank, and for using this information to infer the liquid integrity of the tank. The data acquisition and analysis discussed in Sect. 3.4 provided information that was needed in order to evaluate this monitoring technique; specifically, the practicality of instrumenting the dry wells; the drain elevations and the condition of the dry well sumps, including any sediment of fill material contained therein; the changes in conductivity and water level in the sump as a function of time and rainfall events; and an estimate of the detection threshold that could be achieved given a release of liquid from a tank.

\subsection{DECISION VARIABLES}

The term "decision variables," as used here, refers to the parameters that support the analysis leading to a "decision" regarding a liquid integrity assessment based on the external monitoring method. 


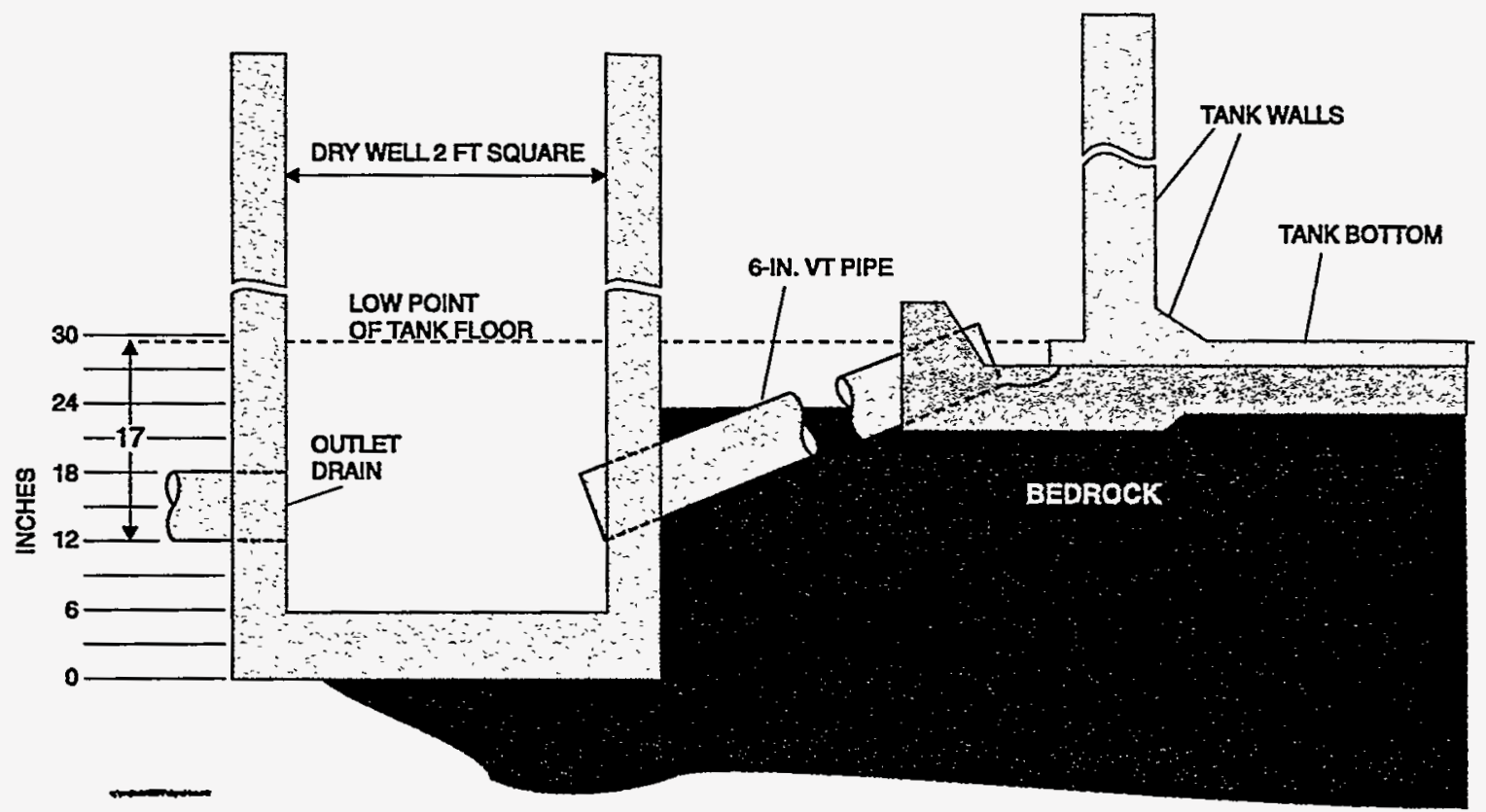

Fig. 3.1. Cross-sectional diagram of a typical dry well. 
The decision variables for the external dry well monitoring technique are as follows:

- Conductivity data from the dry wells. These data provided information on the average value of conductivity in a dry well, the standard deviation of the measurements, the change in value over time, and the general performance of the conductivity sensor.

- Temperature data from the dry wells. These data, obtained from the same sensor that provided the conductivity data, were recorded for later use in correcting conductivity values to reflect changes in temperature if necessary. They were also used to check for any significant changes in water temperature that might indicate other changes in the conditions within the dry well.

- Water level data from the dry wells. These data were used to determine whether there was any correlation between changes in water level and changes in conductivity. They also provided information on the response of the water level to rainfall events, on long-term changes in water level, and on the general relationship between the level of water in the well and the level of the water table in the surrounding soil.

- Conductivity data from the Gunite tanks. These data provided information on changes in conductivity in the water in a Gunite tank. The purpose of the conductivity profiles was to identify expected conductivity values as a function of both time and depth. Then, based on the contrast between the conductivity of the water in the tank and that in the dry well, these data were used in estimating the threshold at which a leak could be detected.

- Physical condition of the dry wells. A video camera was used to examine the bottoms of the dry wells. This information was used to evaluate instrumentation problems and to determine what modifications might be required to improve instrumentation of the dry wells.

\subsection{INSTRUMENTATION}

The instrumentation used in the preliminary evaluation of the external monitoring technique consisted of two types of sensors, each with a specific function. The sensor used to measure conductivity in the dry wells and tanks was a combined conductivity/temperature probe, Model CTS-200, manufactured by In-Situ, Inc. The probe used in the dry wells has a range of 0 to $1500 \mu \mathrm{mhos} / \mathrm{cm}$, and the one used in the tanks has a range of 0 to $20,000 \mu \mathrm{mhos} / \mathrm{cm}$. The selection of ranges was based on expected values of conductivity. The second type of sensor, whose function was to measure water level in the dry wells and tanks, was a pressure transducer, Model PXD-260, also manufactured by In-Situ. The pressure range used in making these measurements was between 0 and 5 psi, the lowest available and the one that provided the best accuracy and precision.

The instrumentation was installed in the dry wells and tariks on May 3, 1995. Dry Wells D-3, D-4 and D-8 were each equipped with a conductivity/temperature probe and a pressure transducer. Tanks W$3, W-4$ and W-8 were initially equipped only with a conductivity/temperature probe. Between June 12 and 18 , the instrumentation had to be removed temporarily to accommodate sampling and other activities at the tanks. When it was re-installed on June 22, pressure transducers were added to the three tanks. Data from all these sensors were collected hourly by the data logger and downloaded weekly from May-August, at which time the instrumentation was removed to accommodate construction activities for the treatability study.

The conductivity/temperature probes and the pressure transducers that were placed in the dry wells were submerged as far as possible below the water line in an effort to ensure their proper operation. All the sensors at a given tank farm were connected to an in situ data logger, which was set to record measurements from each sensor hourly. 
NTF Tanks W-3 and W-4 and their respective dry wells, D-3 and D-4, were selected for instrumentation because they are the first tank systems scheduled for the sluicing demonstration portion of the treatability study. Tank W-8 and its dry well, D-8, were selected because they are representative of systems in the STF.

\subsection{DATA ANALYSIS}

The approach to the data analysis was to evaluate the overall changes and trends in the data as a function of time and as a function of environmental influences such as rainfall. Selected data sets were downloaded from the data loggers and put into standard Excel spreadsheets. From the spreadsheets, a series of plots was generated that showed changes in conductivity and water level in the dry wells as a function of time; in conjunction with the conductivity and water level data, rainfall data obtained from the ORNL meteorological station were also plotted. The general characteristics of the collected data became clear from an examination of these plots. Statistics on the conductivity measurements-average, minimum and maximum values as well as the standard deviation-were developed from these data. This information on the dry wells, along with similar information obtained from data on the tanks, was used in estimating a conservative threshold value representing the size of the leak that could be detected with the external monitoring technique.

The type of data collected for analysis includes the following:

- data from conductivity/pressure transducers in three dry wells and three tanks;

- data from pressure transducers in three dry wells and three tanks;

- rainfall data for the period from May-August 1995 at ORNL;

- videotapes of the three dry wells; and

- separate conductivity profiles of the three tanks.

Table 3.1 provides a chronology of the data collection activities.

Table 3.1. Dry well monitoring activities, May-August 1995

\begin{tabular}{lrrl}
\hline \multicolumn{1}{c}{ Date } & \multicolumn{1}{c}{ Tank } & Dry Well & \multicolumn{1}{c}{ Activity } \\
\hline May 3 & & D-3, D-4, D-8 & $\begin{array}{l}\text { Dry wells instrumented with conductivity, } \\
\text { temperature and pressure (water level) sensors }\end{array}$ \\
& W-3, W-4, W-8 & ans instrumented with conductivity and \\
& & $\begin{array}{l}\text { Tanks } \\
\text { temperature sensors }\end{array}$ \\
June 12-18 & W-3, W-4, W-8 & D-3, D-4, D-8 & Instruments removed temporarily \\
June 22 & W-3, W-4, W-8 & D-3, D-4, D-8 & $\begin{array}{l}\text { Instruments re-installed } \\
\text { Pressure transducers added to existing } \\
\end{array}$ \\
& W-3, W-4, W-8 & & instrumentation in tanks
\end{tabular}


Table 3.1. (continued)

\begin{tabular}{|c|c|c|c|}
\hline Date & Tank & Dry Well & Activity \\
\hline 19 July & & & $\begin{array}{l}\text { Status meeting held to discuss early results, } \\
\text { modifications, and data requirements }\end{array}$ \\
\hline 8-11 August & & D-3, D-4, D-8 & Dry wells videotaped \\
\hline 30 August & $W-3, W-4, W-8$ & & $\begin{array}{l}\text { Instruments removed from tanks to accommodate } \\
\text { construction activities }\end{array}$ \\
\hline
\end{tabular}

\subsection{RESULTS}

The results of the preliminary evaluation of the external (dry well) monitoring technique come from two sources: (1) data collected from the dry wells and (2) data collected from the Gunite tanks associated with these wells.

\subsubsection{Dry Well Data}

As discussed in Sects. 3.3 and 3.4, conductivity/temperature and water level data on Dry Wells D-3, D-4 and D-8 were collected from May-August 1995. During the installation of the sensors, it was observed that there was only a thin layer of water in Dry Wells D-4 and D-8. After several weeks of data collection it became apparent that in D-4 and D-8 neither the conductivity/ temperature probes nor the pressure transducers were sufficiently submerged to produce reliable readings. Only the sensors in D-3 provided consistent measurements of conductivity and water level. Data collection continued in all three wells nevertheless, so that the influence of rainfall and other environmental factors on conductivity and water level could be gauged. Preparations were made to further investigate conditions in the dry wells by means of a video camera.

\subsubsection{Conductivity/temperature data from the dry wells}

The conductivity probe in D-3 provided a fairly complete set of hourly measurements from May 3-August 7, 1995, with the exception of a break in June when the instruments were temporarily removed. Figure 3.2 plots the conductivity of the water at the bottom of D-3 during this period. It shows that the conductivity, ranging from 300 to $400 \mu$ mhos, was relatively stable during most of the monitoring period. From 20 July on, the data seem to drop off in value. This decrease may have been caused by inadvertent moving of the probe during various sampling and construction activities around Tanks W-3 and W-4. Figure 3.2 also plots the temperature of the water. A small increase in temperature seems to correlate fairly well with the increase in conductivity values until about $20 \mathrm{July}$, when, as stated, other activities may have interfered.

The blips, or spikes, on both plots in Fig. 3.2 seem to coincide and are generally correlated with rainfall events. Cumulative and hourly rainfall data from the ORNL meteorological station are plotted in Fig. 3.3, which covers the same time interval as Fig. 3.2. A comparison of the two figures shows that the spikes in the conductivity and temperature data are related to rainfall events. However, not all of the rainfall events shown in Fig. 3.3 result in spikes in Fig. 3.2. This may be because rainfall at ORNL is sometimes very localized. Rain does not always occur at the same time or in the same amounts at the 


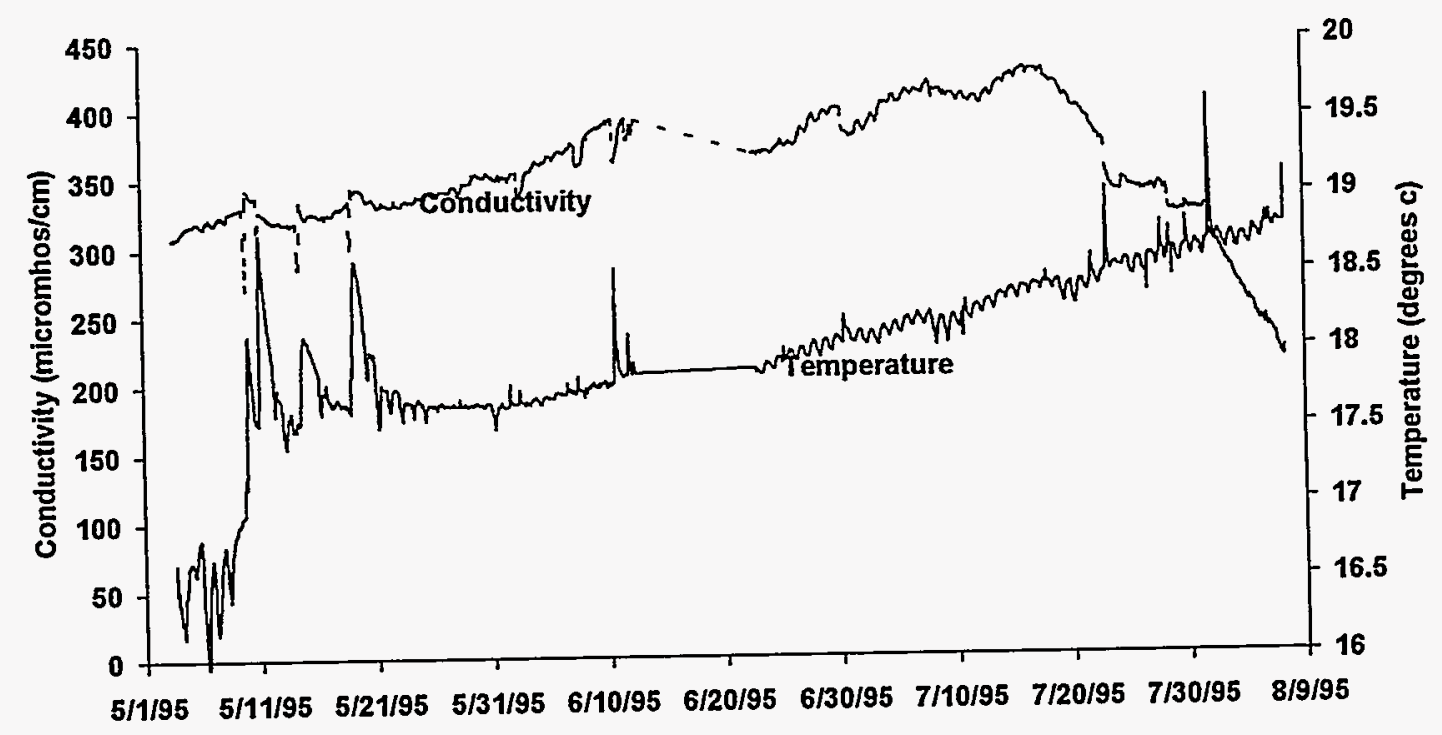

Fig. 3.2. Conductivity and temperature in Dry Well D-3 from 3 May through 7 August 1995.

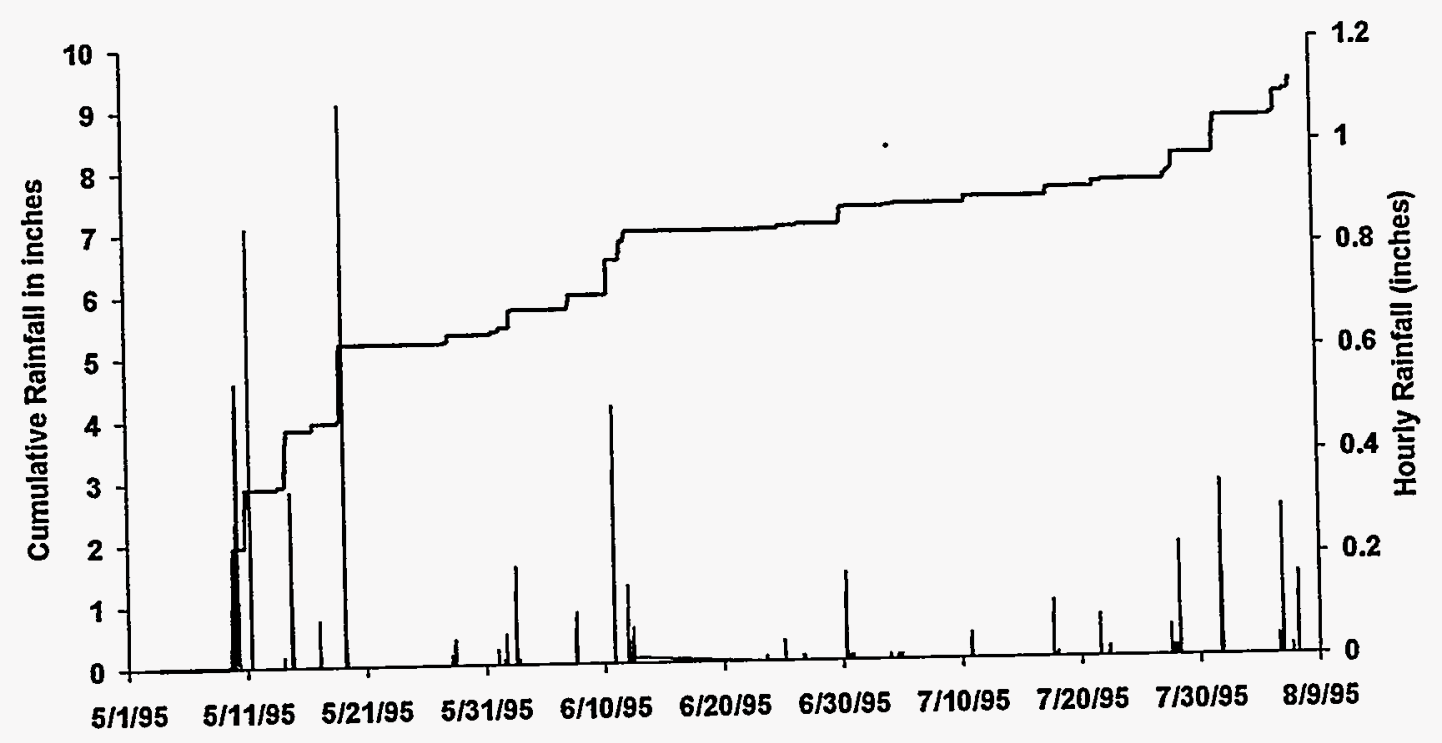

Fig. 3.3. Cumulative and hourly rainfall at ORNL from 3 May through 7 August 1995. 
weather station, the NTF and the STF. Thus, some caution must be used when one compares rainfall data to the measurements made at the NTF and STF.

As stated earlier, the conductivity/temperature probes in D-4 and D-8 yielded only sporadic readings due to the fact that they were inadequately submerged (water depth prevented adequate submersion of the instruments). These sporadic readings are illustrated in the two sets of conductivity and temperature plots, one for D-4 and the other for D-8, shown in Figs. 3.4 and 3.5, respectively. Figure 3.4 shows the period from May 1- June 12, and Fig. 3.5 the period from May 1-June 18. During most of this time, conductivity values are essentially zero (indicating that the instrument was not in the water) with occasional spikes that generally correlate with rainfall events. Temperature data from the conductivity/temperature probe are more consistent, because it does not matter whether the probe is submerged.

The spikes associated with D-8 are more significant than those associated with D-4. This is presumably related to the relatively large amount of water that drains into D-8 when it rains. This inflow of water also causes a rapid rise in level, on the order of 2 to $4 \mathrm{ft}$, that is not observed in D-3 or D-4. This is discussed below.

\subsubsection{Water level data from the dry wells}

Figure 3.6 provides a plot of water level data from Dry Well D-3 during the period May 3-7 August, 1995. Also shown is the hourly rainfall data. The plot of water level is quite smooth, indicating that the water level is very stable. The small fluctuations that are visible appear to be correlated with rainfall events. The overall change in water level is approximately $0.072 \mathrm{ft}$ over the three months shown in the plot, a very small amount. This plot indicates that conditions in D-3 are stable and thus suitable for making the conductivity measurements associated with the external monitoring technique.

Water level data from Dry Wells D-4 and D-8 were sporadic because of the difficulty in submerging the sensors. Certain intervals of time, however, yielded data useful in examining the comparative responses of the dry wells to rainfall. For example, Figs. 3.7, 3.8, and 3.9 plot the water levels in D-3, D-4 and D-8, respectively, from May 9-13, 1995. During this period it rained several times. The water level changes in D-3 and D-4, in the NTF, are significantly different from those in D-8, in the STF. All three figures use the same scale for plotting water level data, and all three include a plot of cumulative rainfall data. As shown in Figs. 3.7 and 3.8, the responses of D-3 and D-4 to rainfall (i.e., increases in cumulative rainfall) are very slight; changes in water level appear as small bumps on the plots. Figure 3.9, in contrast, shows that the response of D-8 is much greater, with a pronounced recovery time. As stated earlier, this response is due to the inflow of water through drains at the top of D-8. This inflow creates an environment that is less stable than those of D-3 and D-4 and therefore less conducive to making conductivity measurements. The long response time suggests that the drainage for this dry well is not as free-flowing as for D-3 and D-4.

In addition to the water level data collected with the pressure transducers, two separate sets of water level measurements were made in the dry wells in May and August. These data are presented in Table 3.2. Water depth measurements in all three dry wells and in Tanks W-3 and W-4 were made with 


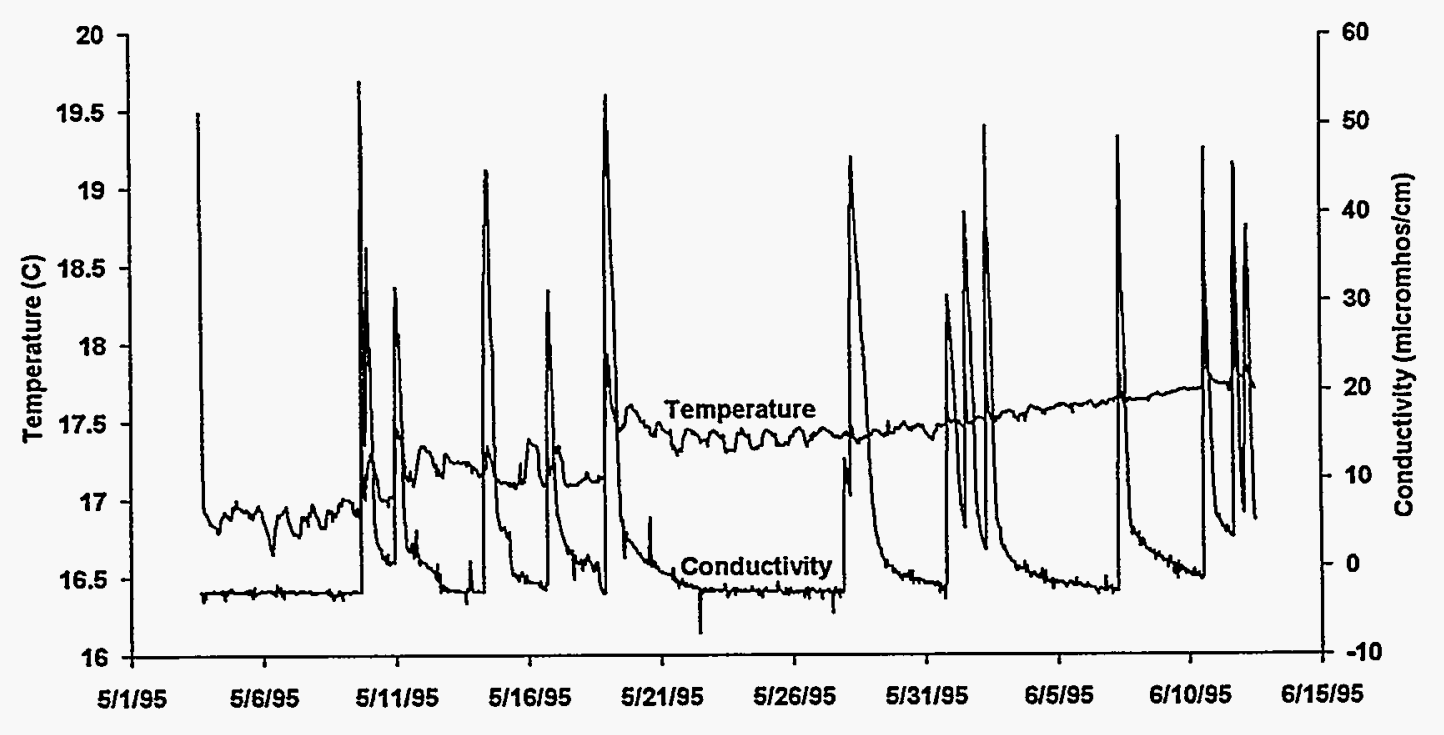

Fig. 3.4. Conductivity and temperature in Dry Well D-4 from 3 May through 12 June 1995. 


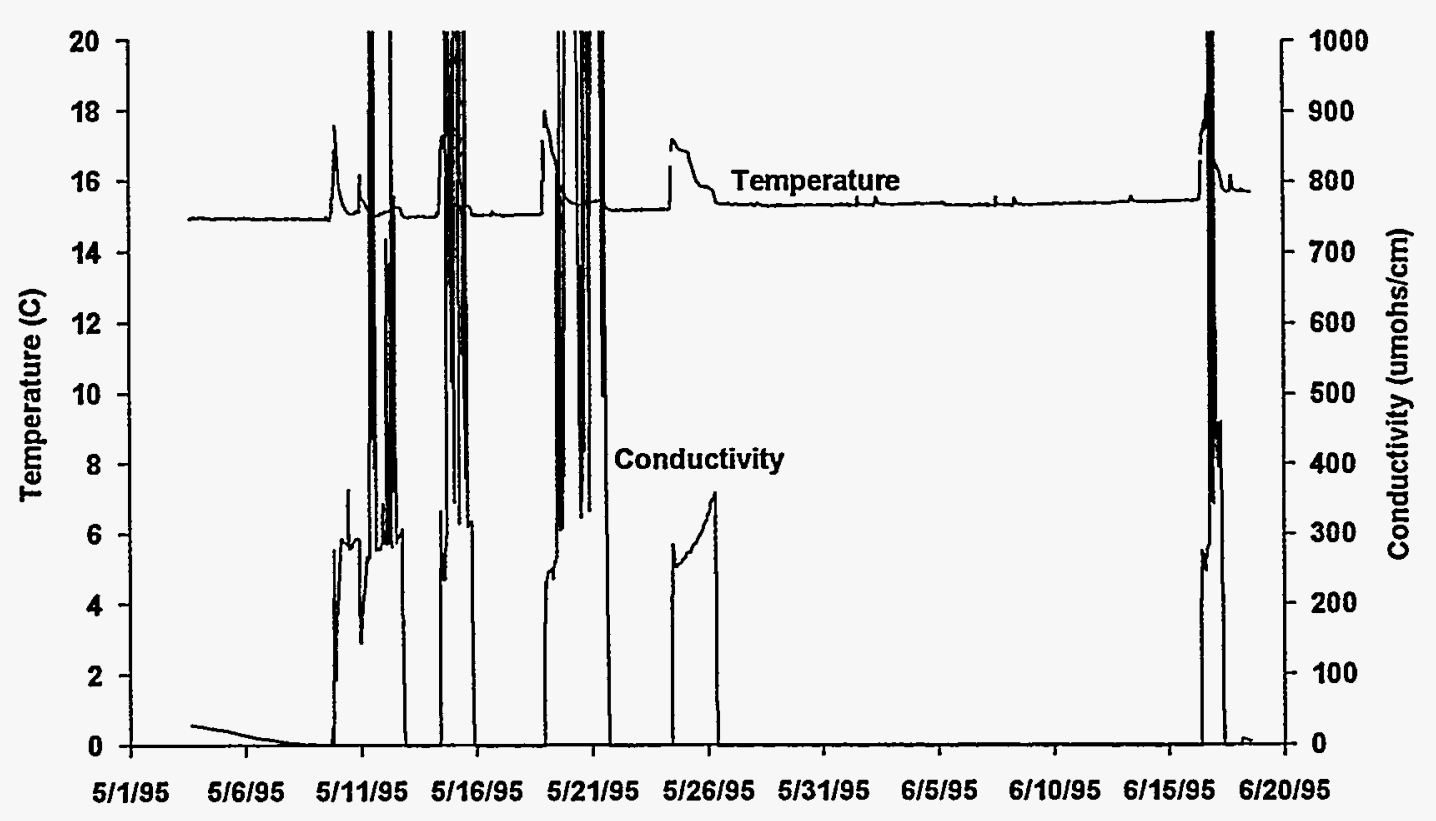

Fig. 3.5. Conductivity and temperature in Dry Well D-8 from 3 May through 18 June 1995.

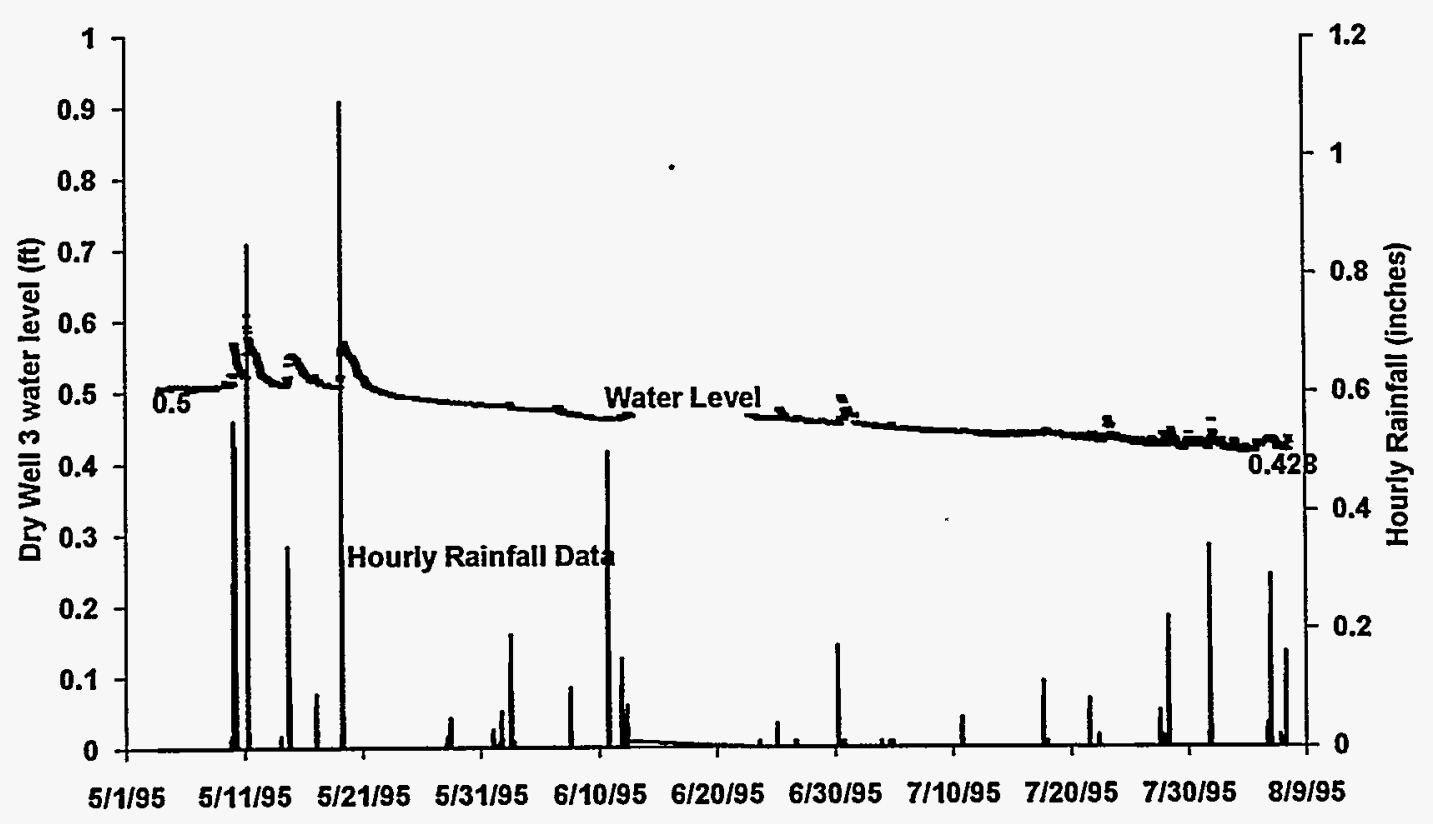

Fig. 3.6. Water level in Dry Well D-3 and rainfall at ORNL from 3 May through 7 August 1995. 


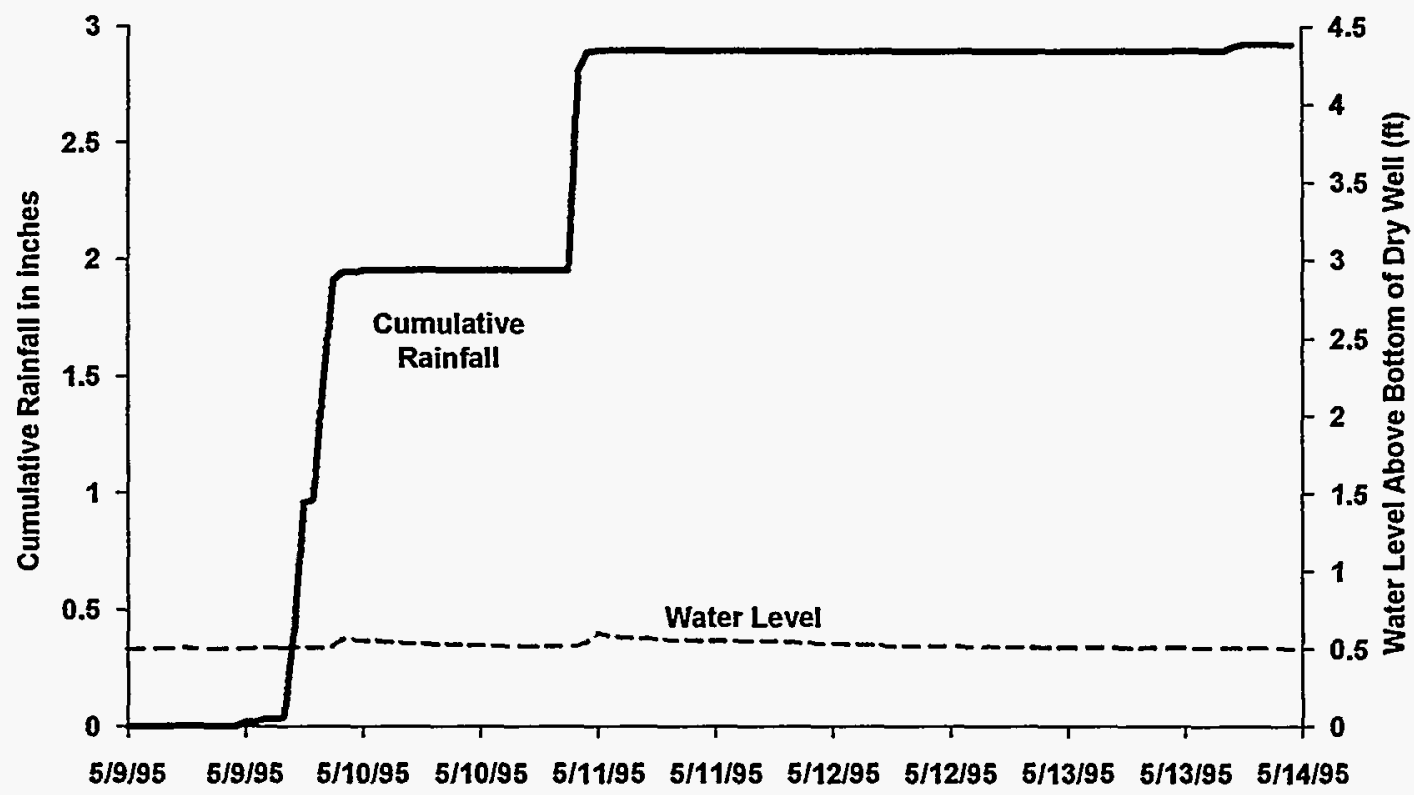

Fig. 3.7. Water level in Dry Well D-3 and cumulative rainfall at ORNL from 9 through 13 May 1995.

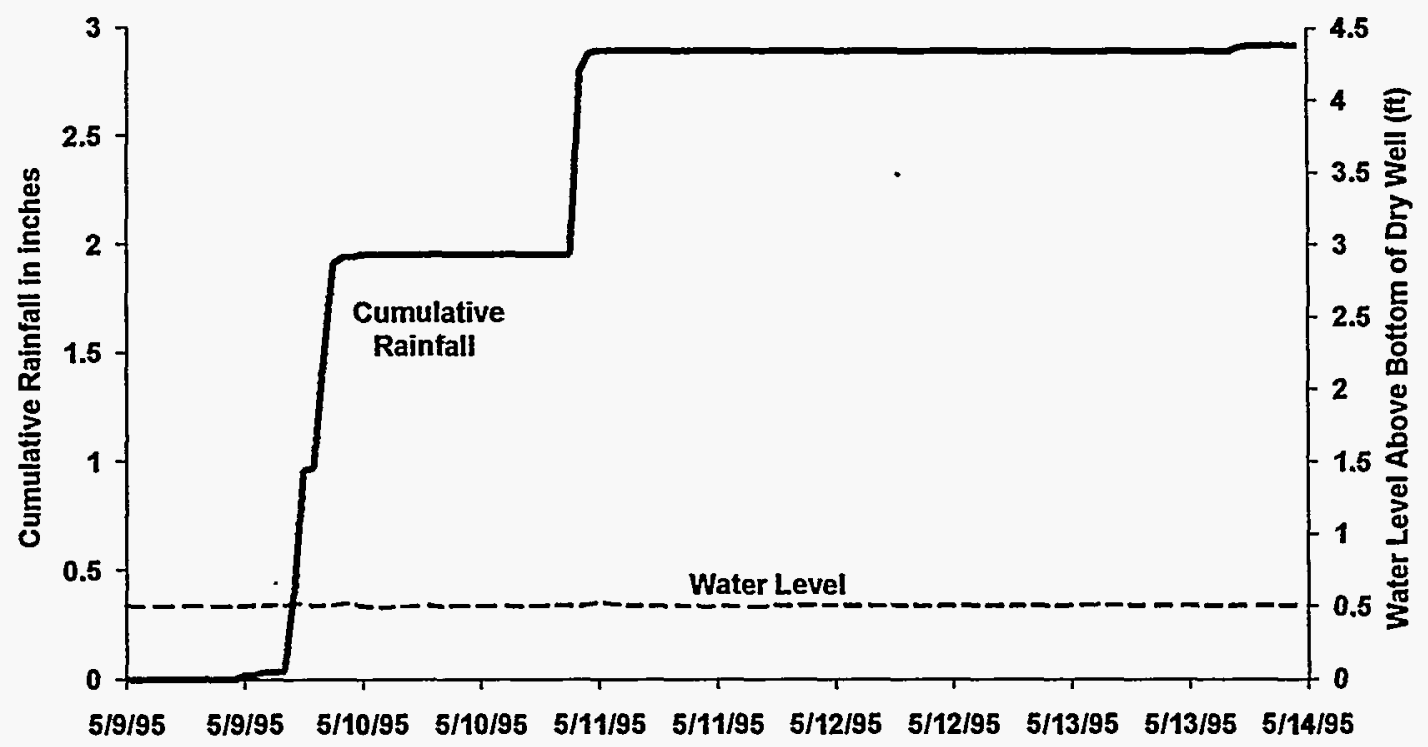

Fig. 3.8. Water level in Dry Well D-4 and cumulative rainfall at ORNL from 9 through 13 May 1995. 


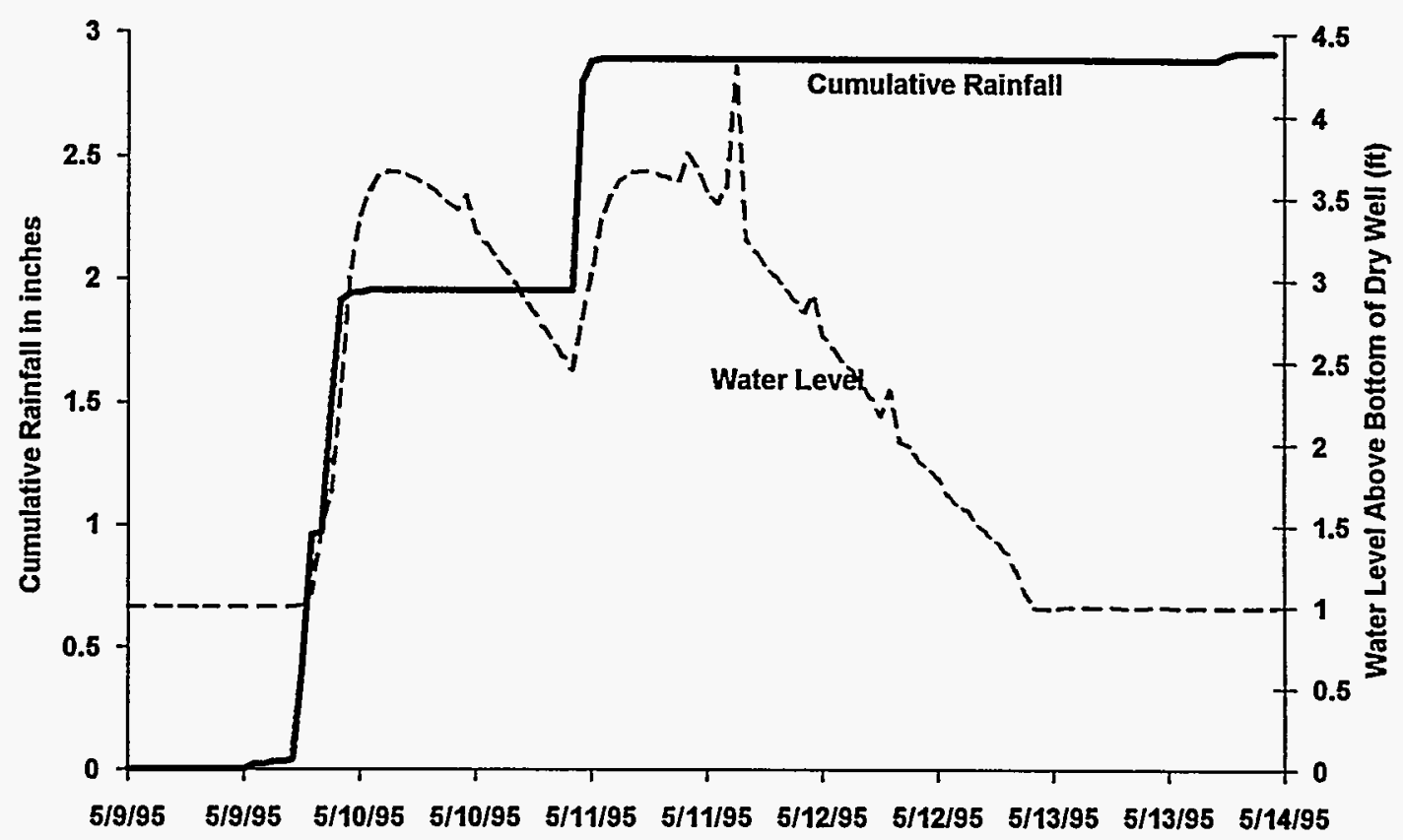

Fig. 3.9. Water level in Dry Well D-8 and cumulative rainfall at ORNL from 9 through 13 May 1995. 
Table 3.2. Water elevations in dry wells and tanks*

\begin{tabular}{ccccccc}
\hline & D-3 & W-3 & D-4 & W-4 & D-8 & \multicolumn{1}{c}{ W-8 } \\
\hline Measuring Point Elevation & 813.52 & 813.40 & 813.38 & 813.10 & 802.00 & NA \\
May 3, 1995 & & & & & & \\
Depth to Water & 20.91 & 15.52 & no data & 11.83 & 19.85 & NA \\
Water Elevation & 792.61 & 797.88 & NA & 801.27 & 782.15 & $786.57 * *$ \\
Bottom Elevation* & 792.11 & 794.78 & 792.11 & 794.78 & 780.18 & 782.60 \\
August 8-11, 1995 & & & & & & \\
Depth to Water & 20.92 & 15.45 & 20.79 & 11.75 & 20.57 & 19.30 \\
Water Elevation & 792.60 & 797.95 & 792.59 & 801.35 & 781.42 & $786.63 * *$ \\
Bottom Elevation* & 792.11 & 794.78 & 792.11 & 794.78 & 780.18 & 782.60 \\
\hline
\end{tabular}

* Bottom elevations estimated from drawings and dry well measurements

** Water elevation estimated from Robertshaw instrument

water-level interface probe; the water level data from Tank W-8 were extrapolated from the Robertshaw in-tank level-measuring instrument. The measuring point elevation for each tank and dry well is noted in Table 3.2. Water level was calculated by subtracting the water depth value from the measuring point elevation. The bottom elevations for the tanks and dry wells were determined from depth measurements and design drawings.

The data in Table 3.2 show three important results. The first is that the water level in Dry Well D-3 on 8 August is essentially the same as it was on May 3, indicating that it remained more or less constant during the intervening three-month period. This is consistent with data obtained from the pressure transducer in D-3 (Fig. 3.6), which showed a very small change of approximately $0.072 \mathrm{ft}$. Given the expected range of measurement error $( \pm 0.1 \mathrm{ft})$, these two data sets are essentially the same, indicating that the water level in D-3 is very stable.

The second important result is that the water level in D-3 on 8 August is approximately the same as that in D-4 on the same date. (No comparison could be made with May 3 because there was no water depth measurement available.) In addition, the water level in both wells is flush with the bottom of the drain holes. This suggests that D-3 and D-4 are interconnected in terms of water and water level, and that water level is controlled by the drain system, which is, in turn, in equilibrium with the surrounding groundwater. The water levels measured in D-3 and D-4 are, therefore, an indication of the level of the groundwater around Tanks W-3 and W-4, immediately adjacent to these wells.

The third significant result is the difference in water levels between the dry wells and the tanks. The water level in each of the three dry wells is below the floor of the adjacent tank. This is consistent with previous measurements and observations. The drain system for the dry wells ensures that groundwater stays below the tanks. The level of water in the dry wells is, in general, a measure of the equilibrium between the dry well/drain system and the surrounding groundwater. The importance of this finding is that groundwater (1) is not considered a source of the water found in the tanks and (2) would not be expected to affect the water level data collected as part of the internal monitoring technique. 


\subsubsection{Video data from the dry wells}

The interiors of Dry Wells D-3 and D-4 were videotaped on 8 August 1995, and that of D-8 on 11 August. The purpose was to make a visual assessment of the water levels in relation to the drains at the bottom of the wells and also to determine what actions might be taken to improve the way the wells are monitored. The results of the video inspections are presented schematically in Figs. 3.10-3.12. In D-3 (Fig. 3.10), the water level was flush with the bottom of the drain holes. Although there was a layer of sediment at the bottom of the well, it was not very deep, and there was a sufficient amount of water above it ( 0.2 to $0.3 \mathrm{ft}$ in depth) to submerge the instrumentation. In D-4 (Fig. 3.11), the water level was again flush with the bottom of the drain holes, but the layer of sediment was much deeper; there was hardly any water above it. It is evident why the instrumentation could not be submerged. A possible solution would be to use a long-handled augering device to move the sediment out of the way and then to reinstall the instrumentation in a protective well screen. This would ensure both proper submersion and protection from the sediment.

The video inspections of D-3 and D-4 also showed shallow drain pipes near the top of each dry well. A hole was observed in the north wall of D-3, about $8 \mathrm{ft}$ from the top; the wall also showed some minor staining. This is consistent with NTF drawings that show that a drain had been added at some time to receive water from one of the tank vaults. (The drain line into the north side of D-3 was added in the 1950s; this drain line receives water from vaults for Tanks W-13, W-14 and W-15.) Based on the water level data presented above, this drain does not appear to contribute much water during rainfall events. A drain pipe was also observed protruding from the east wall of D-4, about $10 \mathrm{ft}$ from the top. This drain, originally installed to receive water from a tanker unloading pad, was subsequently abandoned. Based on the data, it does not appear to contribute water to D-4 during rainfall events.

The video inspection of D-8 (Fig. 3.12) showed a considerable amount of sediment and concrete rubble at the bottom. The inlet and outlet drains were not visible; they are covered by the fill material, which, based on "depth-to-sediment" measurements (from the top of the well to the top of the sediment layer), is estimated to be approximately 1.0 to $1.5 \mathrm{ft}$ deep.A shallow layer of water was observed at about the same level as the sediment layer. Again, it is evident why the instrumentation could not be submerged. It is assumed that the water level is located at the plain at which equilibrium develops between the dry well/drain system and the surrounding groundwater. The most likely source of the concrete rubble in D-8 is from the construction of two drains, approximately $10 \mathrm{ft}$ from the top of the well, designed to drain water from several valve pits in the STF. Chunks of concrete drilled out of the walls while the drains were being installed fell to the bottom of the well. Staining and a buildup of scale were observed on the walls below these two drains, indicating that they admit significant amounts of water to D-8. This is confirmed by the rise in water level observed in D-8 during rainfall events (see Fig. 3.9). Since the time of the inspection, the north end of this pipe has been excavated and is to be capped and abandoned in place.

The significant rise in water level in D-8 during periods of rainfall can most likely be explained thus: not only does water enter in significant amounts through he shallow drains at the top of the well, but there is already a thick layer of sediment and rubble at the bottom. This may also explain why it takes approximately two days for the water level in the dry well to return to a static state. (See Fig. 3.9.) It is assumed that the observed rise in water level is confined to the dry well and that it is not indicative of a general rise in water level in the backfill material throughout the STF. Nevertheless, videotape inspections should be made of the other dry wells in the STF, and water level measurements taken, in order to better understand the hydrological dynamics of the dry well and drain system in that area. Current conditions in D-8 are not conducive to the use of this well as an external monitoring method for 


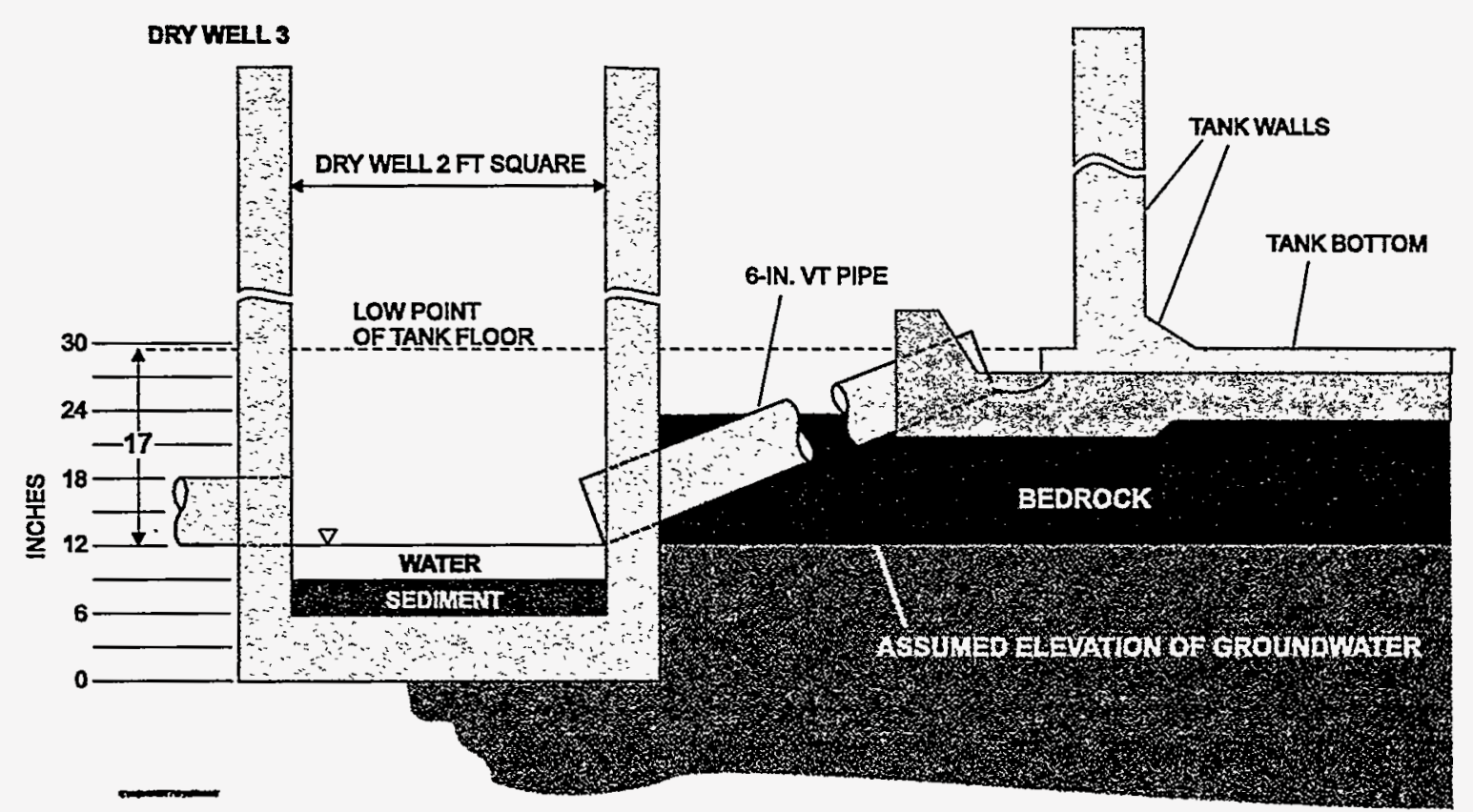

Fig. 3.10. Cross-sectional diagram of Dry Well D-3. The water in the dry well is at approximately the same level as the groundwater; the layer of sediment beneath the water is about 3 in. deep. 


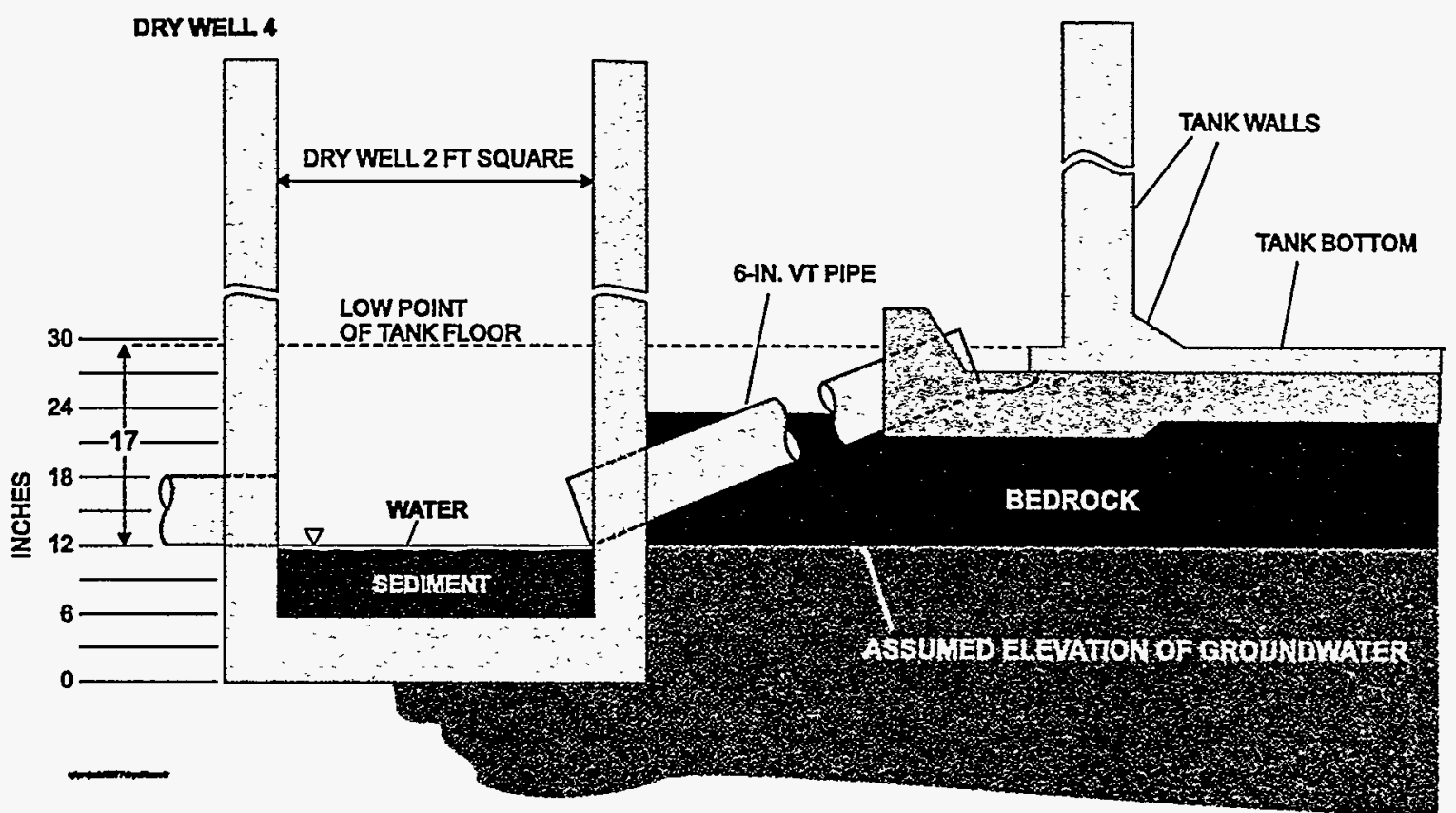

Fig. 3.11. Cross-sectional diagram of Dry Well D-4. The water in the dry well is at approximately the same level as the groundwater; the layer of sediment beneath the water is almost 6 in. deep.

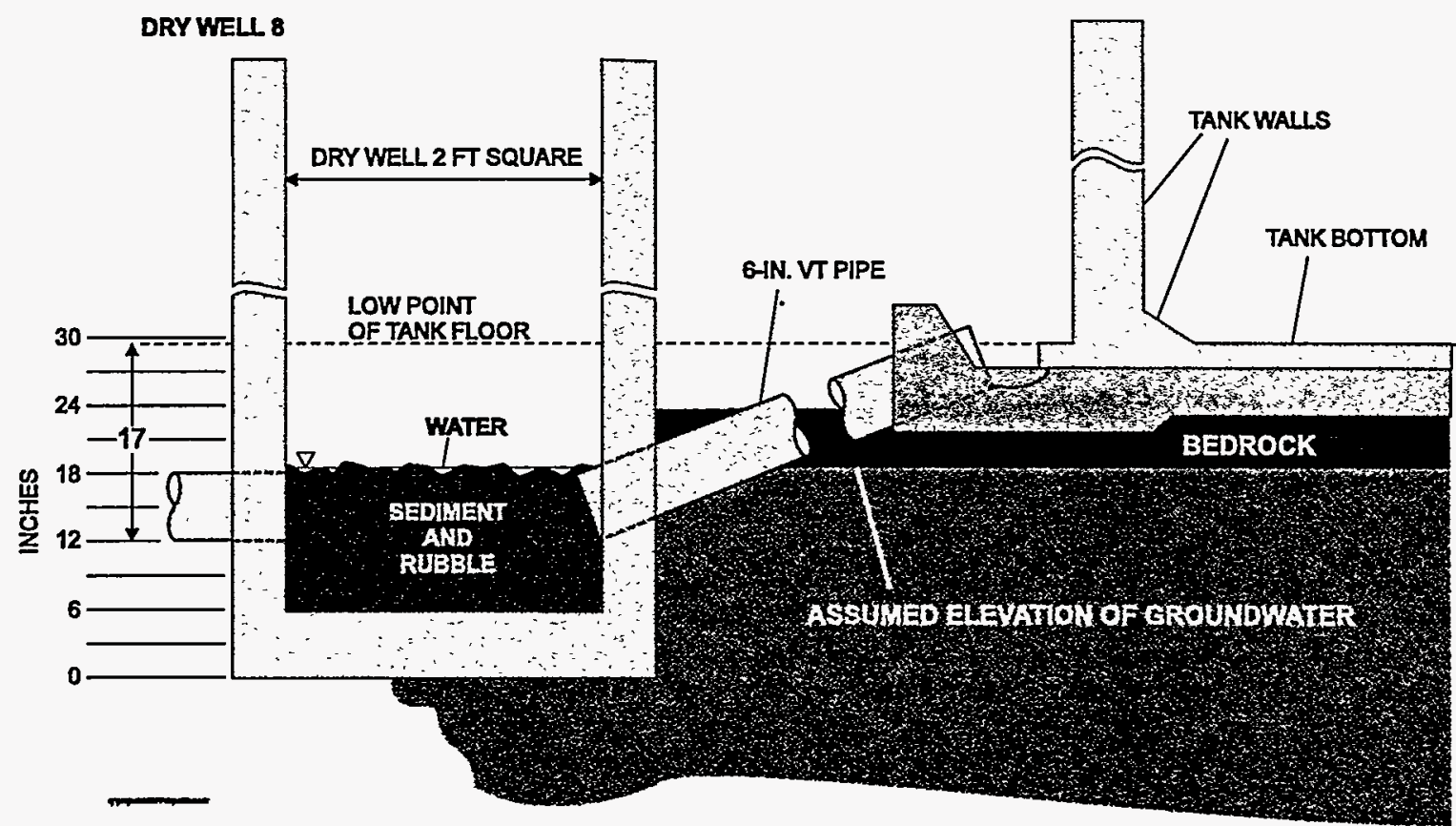

Fig. 3.12. Cross-sectional diagram of Dry Well D-8. The water in the dry well is at approximately the same level as the groundwater; the layer of sediment is about 12 in. deep, partially clogging the drainage piping into and out of the dry well. 
Tank W-8. Making D-8 usable in this context may require significant modifications or may not be feasible at all. The results of further inspections and additional data collection activities in the STF will be extremely useful in making this determination.

\subsubsection{Gunite Tanks}

Each of the three Gunite tanks associated with the dry wells (Tanks W-3, W-4 and W-8) was instrumented and monitored during this evaluation. On May 3, 1995, each tank was equipped with a conductivity/temperature probe whose range was 0 to $20,000 \mu \mathrm{mhos} / \mathrm{cm}$. (This range was selected because it is compatible with the expected conductivity of the water in the tanks, i.e., 5,000 to 15,000 $\mu \mathrm{mhos} / \mathrm{cm}$.) On June 22 , pressure transducers were also installed. These provided hourly data on water levels in W-3 and W-4 that would not have been available otherwise. (These data were used in the analysis of the internal monitoring technique, discussed in Sect. 4.2.)

The primary reason for instrumenting the tanks was to determine the variability in the conductivity of the water in these as a function of time. A secondary objective was to evaluate the performance of the conductivity/temperature probe under the harsh conditions imposed by the quality of the water. Conductivity and temperature data from W-3 and W-4 are shown in Figs. 3.13 and 3.14, respectively, covering the period from May 3-June 12, 1995. The sensors in both tanks appear to perform satisfactorily. Conductivity in W-3 was about $2500 \mu \mathrm{mhos} / \mathrm{cm}$ and in W-4 about $5000 \mu \mathrm{mhos} / \mathrm{cm}$. Conductivity and temperature data from the third tank, W-8, are shown in Fig. 3.15. Conductivity values started at about $5000 \mu \mathrm{mhos} / \mathrm{cm}$, increased abruptly to about $20,000 \mu \mathrm{mhos} / \mathrm{cm}$, and then continued to range between the initial value $(5000)$ and the limit of the instrument $(20,000)$. The reason for this kind of instrument response is believed to be either a faulty sensor of the sensor's coming into contact with water having a much higher conductivity.

On 22 June 1995, the conductivity/temperature probes in W-3 and W-4 were reset. The probe in W-8, which had been giving erratic readings, was replaced. It continued to produce the same erratic results. The probes in W-3, which initially gave readings of about $7000 \mu \mathrm{mhos} / \mathrm{cm}$ and $5000 \mu \mathrm{mhos} / \mathrm{cm}$ respectively, also started to respond erratically. Because of these problems, a conductivity profile was run on each tank. The results of these measurements are given in Table 3.3. The same results are presented as plots, one for each tank, in Fig. 3.16. This figure illustrates the difference in conductivity profiles from one tank to another. The starting point on each plot (conductivity zero) corresponds to the water level ("height" in feet). The data from all three tanks are stratified, with the lowest values of conductivity found in the upper regions of the water layer, and with these values increasing with depth.

Table 3.3. Conductivity measurements in the three tanks (14 August 1995)

\begin{tabular}{cccccc}
\hline \multicolumn{2}{c}{$\begin{array}{c}\text { W-3 } \\
\text { (Water Depth 4.3 ft) }\end{array}$} & \multicolumn{2}{c}{$\begin{array}{c}\text { W-4 } \\
\text { (Water Depth 7.6 ft) }\end{array}$} & \multicolumn{2}{c}{$\begin{array}{c}\text { W-8 } \\
\text { (Water Depth 4.2 ft) }\end{array}$} \\
$\begin{array}{c}\text { Conductivity } \\
(\mu \text { mhos/cm) }\end{array}$ & $\begin{array}{c}\text { Measurement } \\
\text { Depth* } \\
\text { (ft) }\end{array}$ & $\begin{array}{c}\text { Conductivity } \\
(\mu \text { mhos/cm) }\end{array}$ & $\begin{array}{c}\text { Measurement } \\
\text { Depth* } \\
\text { (ft) }\end{array}$ & $\begin{array}{c}\text { Conductivity } \\
(\mu \text { mhos/cm) }\end{array}$ & $\begin{array}{c}\text { Measurement } \\
\text { Depth* } \\
\text { (ft) }\end{array}$ \\
\hline 538 & 3.8 & 5400 & 7.1 & 9510 & 3.7 \\
7490 & 3.3 & 5530 & 6.6 & 14000 & 3.2 \\
8920 & 2.8 & 6320 & 6.1 & 18680 & 2.7 \\
\hline
\end{tabular}




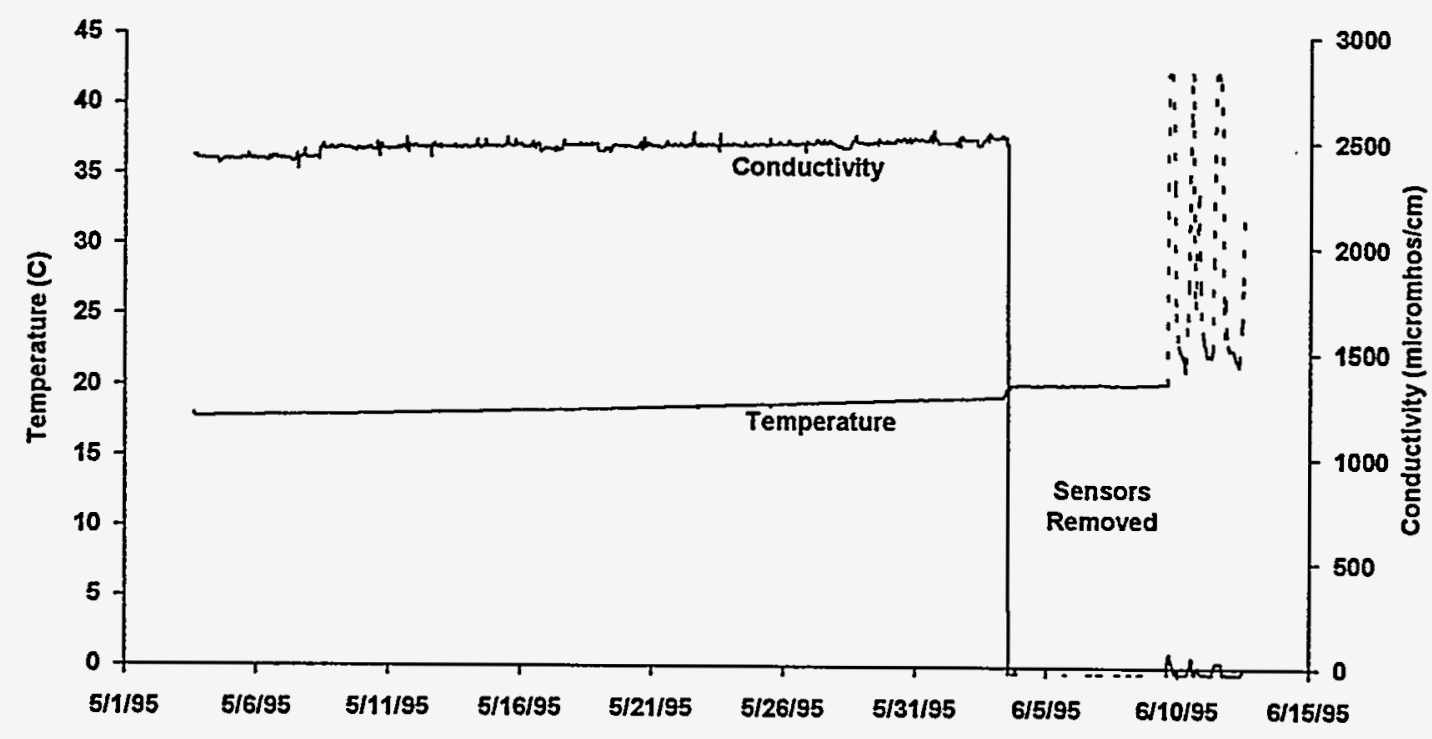

Fig. 3.13. Conductivity and temperature in Tank W-3 from 3 May through 12 June 1995.

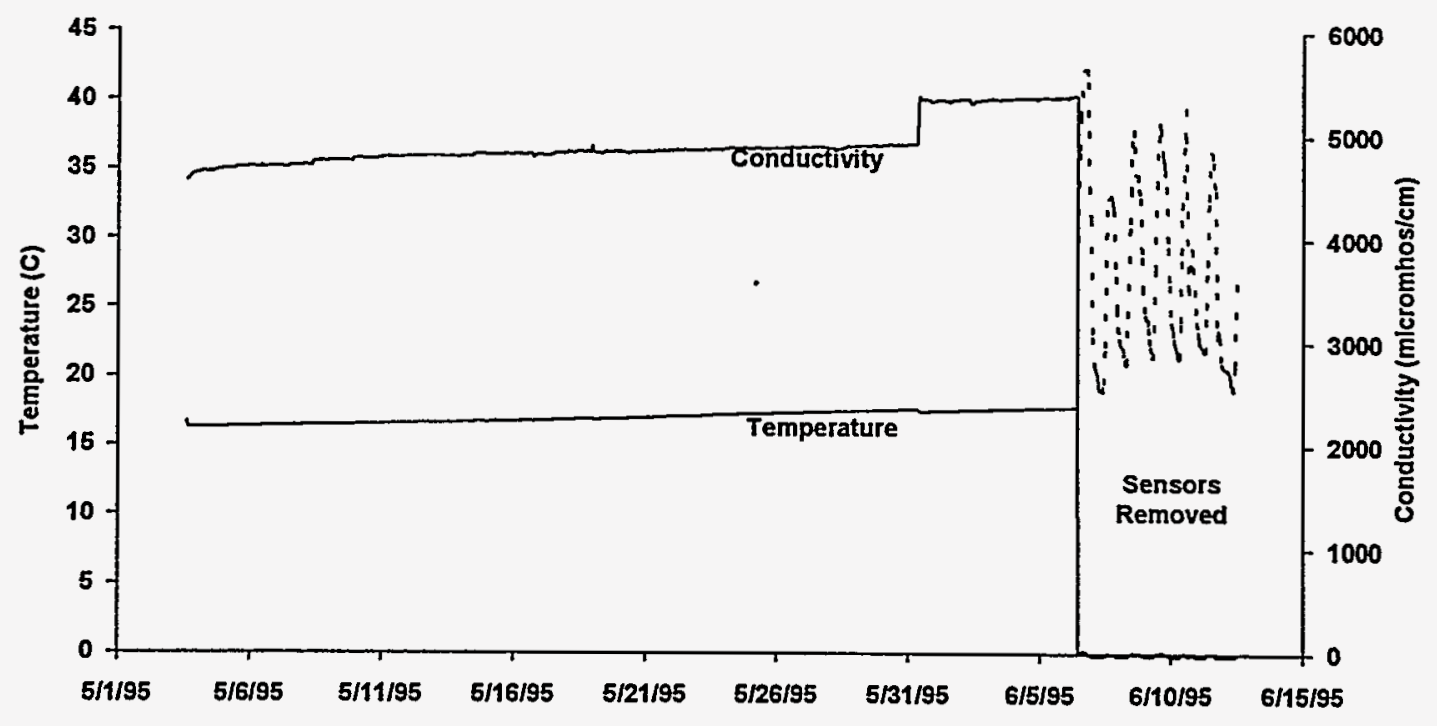

Fig. 3.14. Conductivity and temperature in Tank W-4 from 3 May through 12 June 1995. 


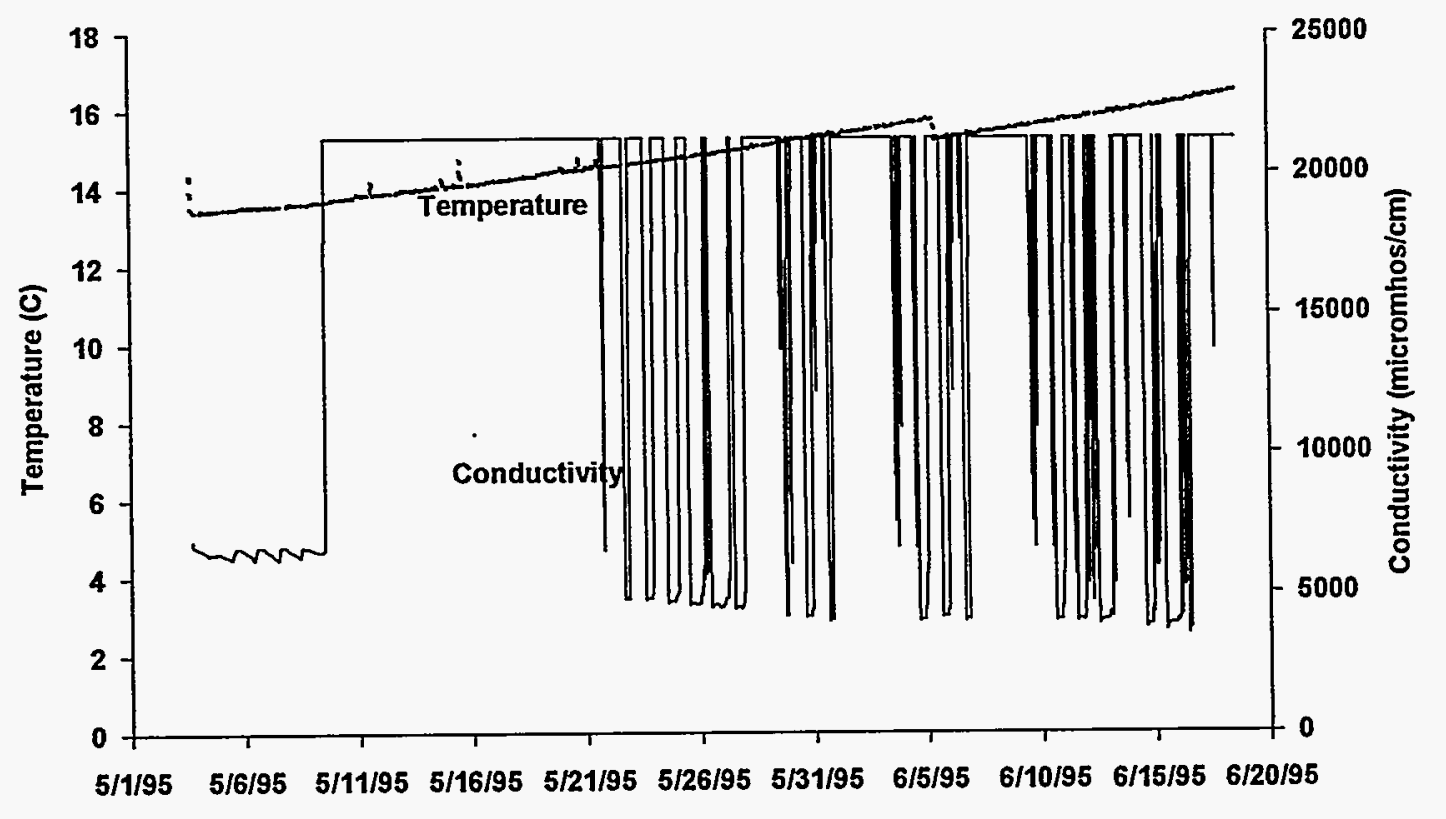

Fig. 3.15. Conductivity and temperature in Tank W-8 from 3 May through 18 June 1995. 


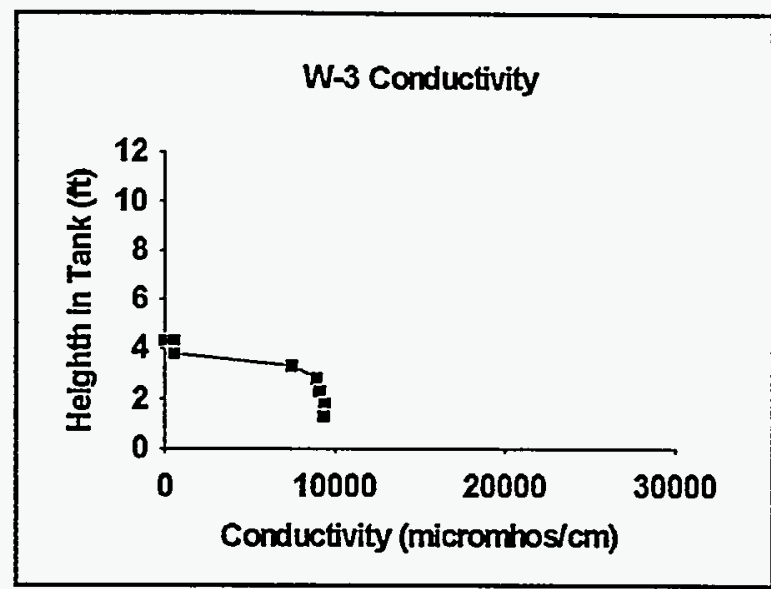

a

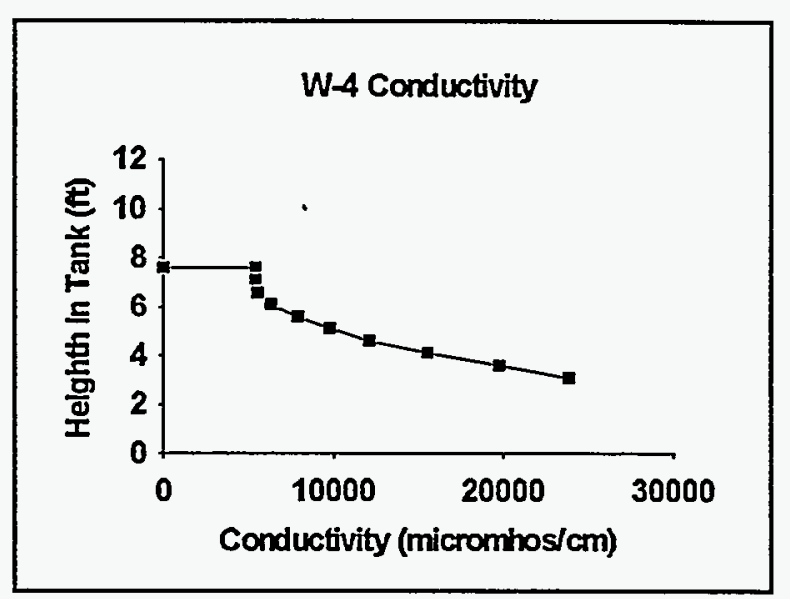

b

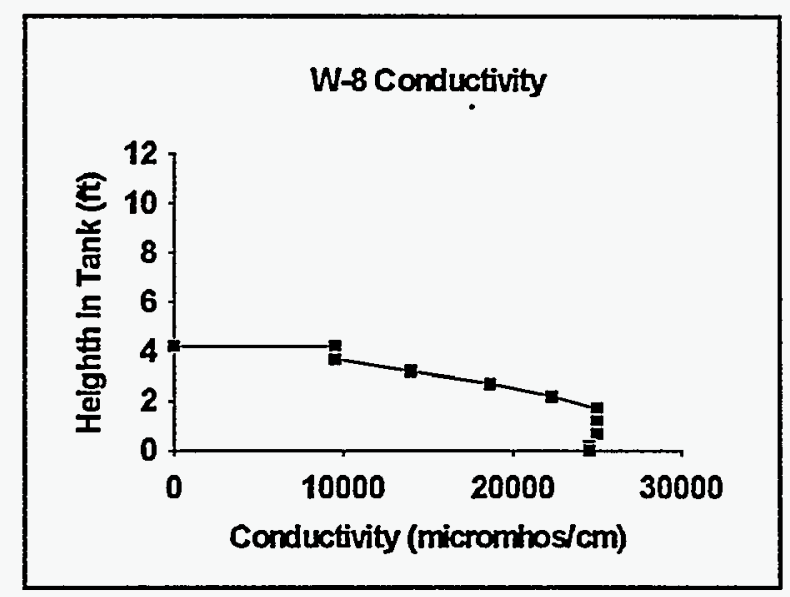

C

Fig. 3.16. Conductivity below water level, measured at intervals of $0.5 \mathrm{ft}$, in (a) Tank W-3, (b) Tank W-4 and (c) Tank W-8. 
Table 3.3. (continued)

\begin{tabular}{|c|c|c|c|c|c|}
\hline \multicolumn{2}{|c|}{$\begin{array}{c}\text { W-3 } \\
\text { (Water Depth } 4.3 \mathrm{ft} \text { ) }\end{array}$} & \multicolumn{2}{|c|}{$\begin{array}{c}\text { W-4 } \\
\text { (Water Depth } 7.6 \text { ft) }\end{array}$} & \multicolumn{2}{|c|}{$\begin{array}{c}\text { W-8 } \\
\text { (Water Depth } 4.2 \mathrm{ft} \text { ) }\end{array}$} \\
\hline $\begin{array}{l}\text { Conductivity } \\
(\mu \mathrm{mhos} / \mathrm{cm})\end{array}$ & $\begin{array}{c}\text { Measurement } \\
\text { Depth* } \\
\text { (ft) }\end{array}$ & $\begin{array}{l}\text { Conductivity } \\
(\mu \mathrm{mhos} / \mathrm{cm})\end{array}$ & $\begin{array}{c}\text { Measurement } \\
\text { Depth* } \\
\text { (ft) }\end{array}$ & $\begin{array}{l}\text { Conductivity } \\
(\mu \mathrm{mhos} / \mathrm{cm})\end{array}$ & $\begin{array}{l}\text { Measurement } \\
\text { Depth* } \\
\text { (ft) }\end{array}$ \\
\hline 9090 & 2.3 & 7890 & 5.6 & 22320 & 2.2 \\
\hline 9380 & 1.8 & 9800 & 5.1 & 25040 & 1.7 \\
\hline \multirow[t]{4}{*}{93390} & 1.3 & 12090 & 4.6 & 25040 & 1.2 \\
\hline & & 15540 & 4.1 & 25040 & 0.7 \\
\hline & & 19760 & 3.6 & 24570 & 0.2 \\
\hline & & 23820 & 3.1 & 24550 & 0.0 \\
\hline
\end{tabular}

One possible explanation for the generally lower conductivity values in Tank W-3 would be that the contents of this tank are periodically pumped into the liquid low level waste (LLLW) system, and the tank refills as liquid infiltrates it. The other two tanks had not been pumped down.

Because of the stratification of data seen in Fig. 3.16, it is important to look at the overall range of conductivity in a tank rather than a set of readings at only a single level of water. The data also showed that the sensors did not perform well under the harsh conditions in the tanks. These conditions probably led to the buildup of a coating on the sensor, in effect degrading its performance and causing the erratic readings. The external monitoring technique does not require continuous data on the conductivity of water in the tank. When the external monitoring technique is employed, periodic conductivity profiles of the tank should be made (semiannually is the recommended interval). The data from these conductivity profiles will be used to estimate the detection threshold.

\subsubsection{Calculation of the Leak Detection Threshold}

The conductivity data collected in Dry Well D-3, which provided fairly consistent and reliable results, can be used to estimate the threshold of the external monitoring technique's ability to detect a leak. Statistics on the conductivity measurements in Dry Well D-3 appear in Table 3.4. These are based on data presented in Fig. 3.2.

Table 3.4. Conductivity measurements in Dry Well D-3 (May 3-August 7, 1995)

\begin{tabular}{ll}
\hline Statistic & \multicolumn{1}{c}{ Value } \\
\hline Average & $355 \mu \mathrm{mhos} / \mathrm{cm}$ \\
Standard Deviation & $44 \mu \mathrm{mhos} / \mathrm{cm}$ \\
Maximum & $429 \mu \mathrm{mhos} / \mathrm{cm}$ \\
Minimum & $216 \mu \mathrm{mhos} / \mathrm{cm}$ \\
\hline
\end{tabular}


The threshold is calculated from the following equation, which yields the volume of liquid from Tank W-3 that would increase the conductivity of the water in the dry well by approximately three standard deviations (150 $\mu$ mhos):

$$
V_{t}=\frac{V_{d} C_{i}}{C_{t}-\left(C_{d}+C_{i}\right)}=0.5 \mathrm{gal}
$$

where

$$
\begin{array}{ll}
\mathrm{C}_{\mathrm{i}}=\text { increase in conductivity in Dry Well D-3 } & (150 \mu \mathrm{mhos} / \mathrm{cm}) \\
\mathrm{V}_{\mathrm{t}}=\text { calculated threshold volume from W-3 } & (0.5 \mathrm{gal}) \\
\mathrm{C}_{\mathrm{t}}=\text { conductivity in Tank W-3 } & (5000 \mu \mathrm{mhos} / \mathrm{cm}) \\
\mathrm{V}_{\mathrm{d}}=\text { volume of Dry Well D-3 } & (15 \mathrm{gal}) \\
\mathrm{C}_{\mathrm{d}}=\text { conductivity in Dry Well D-3 } & (428 \mu \mathrm{mhos} / \mathrm{cm})
\end{array}
$$

A change in conductivity of $150 \mu$ mhos would be significantly greater than the normally observed fluctuations and would be readily seen in the data. This is evident from the conductivity plot in Fig. 3.2, which shows that changes over a one-day or one-week period are very small. The results of the calculation in the equation above indicate that 0.5 gal of liquid from Tank W-3 would be sufficient to increase the conductivity in D-3 by $150 \mu$ mhos. The underlying assumption in this analysis is that the water in the dry well is isolated from the surrounding groundwater by the concrete walls and floor of the dry well. Based on an analysis of conductivity data over periods ranging from one day to one week, it is assumed that the diluting effect of groundwater as it flows into and out of the well through the drain lines is negligible. Dilution of the water in the dry well may occur, however, during periods of heavy rainfall.

These estimates indicate that external monitoring in a dry well such as D-3 can be a very sensitive leak detection method. The utility of the external monitoring technique, however, is dependent on (1) the stability and characteristics of the water in the sump of the dry well, (2) the effects of inflows from shallow drains, and (3) the effects of fill material at the bottom of the well. 


\section{INTERNAL MONITORING METHOD}

The internal monitoring method for assessing the liquid integrity of a tank is based on measurements of water level in the tank. Chapter 4 describes the preliminary evaluation of this technique.

\subsection{OBJECTIVE OF THE LEVEL DATA ANALYSIS}

Liquid level in the tanks was one of the two types of data that were of potential use in assessing the liquid integrity of the GAAT (the other was the electrical conductivity of the liquids in the dry wells, as noted above). The objective of analyzing the liquid level data was to determine whether they were of sufficient quality and quantity for making an estimate of tank integrity, and, if so, to determine whether selected Gunite tanks ${ }^{2}$ have sufficient integrity to contain liquids. The format of the WOCC data made it possible, with only a modest increase in effort, to assess all of the tanks in the STF, W-5-W-10. In addition, Tanks W-3 and W-4 in the NTF were outfitted with piezoelectric-type pressure sensors to measure liquid level. Accordingly, the analysis of level data was applied to Tanks W-3-W-10, and, in such cases as data quality allowed, a preliminary liquid integrity assessment of the integrity of these tanks has been made.

The data analysis leading to the liquid integrity assessments entailed three distinct steps. First there was a downsampling step wherein the raw, 1 min-sampled, tank-volume time series data files were downsampled to $1 \mathrm{~h}$ samples. This allowed large quantities of data to be analyzed with little or no loss of accuracy or precision. After downsampling, the data were hand-edited to remove obvious errors in the data stream. After editing, and after selecting portions of the data to be analyzed to avoid gaps and rain-related influences, the data were statistically analyzed. In particular, a regression analysis was performed on the selected data to measure the volume rate (in gallons per hour) over a number of blocks of data $48 \mathrm{~h}$ in duration. A null hypothesis test (using the student's t-test) was performed on the ensemble of volume rates for each tank. Based upon the volume rates and the standard deviation of the y-estimates of the time series data, a release detection threshold was calculated, based upon a $5 \%$ probability of false alarm $\left(\mathrm{P}_{\mathrm{FA}}\right)$, and the minimum detectable release rate (in gallons per hour) was calculated for a $95 \%$ probability of detection $\left(\mathrm{P}_{\mathrm{D}}\right)$. In addition, evaporation and condensation were briefly examined as potential contributors to the volume losses and gains observed in the tanks. Each of these steps is explained in detail below.

\subsubsection{Downsampling}

Downsampling of the data was essential to the outcome of this work because of the sheer quantity of raw data. It was determined from a cursory examination of the data that several months of time series data would need to be analyzed to assure a meaningful result. For each of the GAAT to be assessed, 90 days of data represents 129,600 time samples $(90 \times 24 \times 60=129,600)$. The format of the data as downloaded from the WOCC computer system is

\section{MM/DD/YY HH:MM XXXXXX.XX}

for each of the time samples, where "XXX" represents the volume value in gallons. The month/day/year,

\footnotetext{
${ }^{2}$ More precisely, the Statement of Work specifically called for a preliminary assessment of Tanks W-3, $\mathrm{W}-4$ and W-8.
} 
the time in hours and minutes, and the volume value are each tab-delimited. When the data are averaged to $1 \mathrm{~h}$ samples, 90 days' worth of volume data is reduced to 2,160 data samples, a format that was much easier to handle and process.

Downsampling was accomplished using a program called AVGDOWN.EXE. This program was written in $\mathrm{C}++$, specifically for this effort, by Vista Research. AVGDOWN.EXE reads in the (typically) 1-week-long data files created at WOCC, ${ }^{3}$ averages the volumes from one hour's worth of data about an on-the-hour time point from $30 \mathrm{~min}$ (samples) prior to the point and $29 \mathrm{~min}$ (samples) after the point, and appends the newly averaged data to the end of the previously averaged data to create a single data file with a format of

\section{MM/DD/YY HH:MM XXXXX.XX}

where $M M=00$ and XXX represents the averaged volume value in gallons. If and when AVGDOWN.EXE encounters data gaps or spurious data such as non-numeric characters in the data stream, it generates the appropriate time stamps for the data file and places a null character in the volume value place to denote missing or unreliable data.

As a dedicated program with limited use, AVGDOWN.EXE was not subjected to any rigorous or formal quality assurance tests. Rather, the program was run using the WOCC data files and the output data were compared to the input data for a number of cases, including data with missing or non-numeric values in both the volume and date/time locations. This ensured that the code was properly averaging the data and generating and placing the averaged data at the proper time locations.

\subsubsection{Hand-Editing}

Hand-editing of the data was required because AVGDOWN.EXE was not designed or coded to catch volume discrepancies other than non-numeric or missing values, and because much of the data contained significant volume discrepancies. Figure 4.1 illustrates volume discrepancies commonly found in the data averaged by AVGDOWN.EXE that required hand-editing. These data, a plot of the hourly samples of volume in Tank W-6 as a function of time over a four-month interval from March 28-July 28,1995 , show that there are at least three anomalous points in the data stream. These spikes occurred on April 4, June 10, and July 7. The spikes obviously do not represent the actual volume in the tank and are thus undependable data points that would interfere with or contaminate the analysis results if they were left in the data.

Hand-editing of spurious points can remove the worst of the unusable points, but other such data may be revealed, as illustrated in Fig. 4.2. Additional rounds of hand-editing may be required, resulting in a final, usable data set such as the one shown in Fig. 4.3. Some such points may remain, however, either because they cannot be readily identified or because the method of correction cannot be justified from a technical point of view. Consider, in Fig. 4.3, the volume discontinuity on April 4 or the sudden volume transitions that occur numerous times over the four-month span of the W-6 data. Even though these manifestations are not valid, there are no clear rules that would allow alterations.

${ }^{3}$ The data files obtained from WOCC included the volume samples from all of the tanks in the STF: W-5, W-6, W-7, W-8, W-9, and W-10. AVGDOWN.EXE downsampled these files simultaneously, which made the liquid integrity analysis for all of these tanks a relatively simple extension of the analysis that would be done for a single tank. 


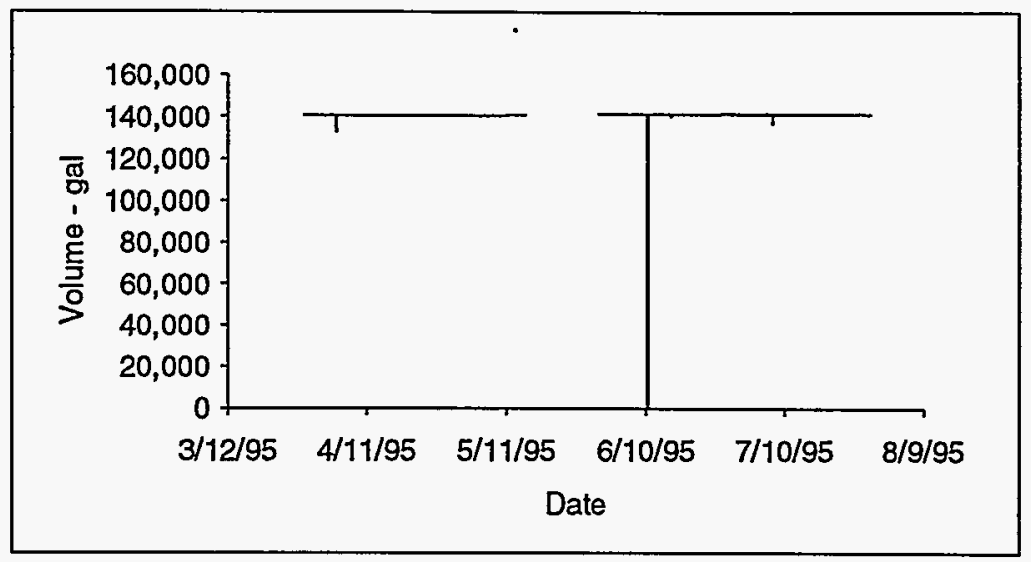

Fig. 4.1. Unedited plot of $W-6$ volume versus time.

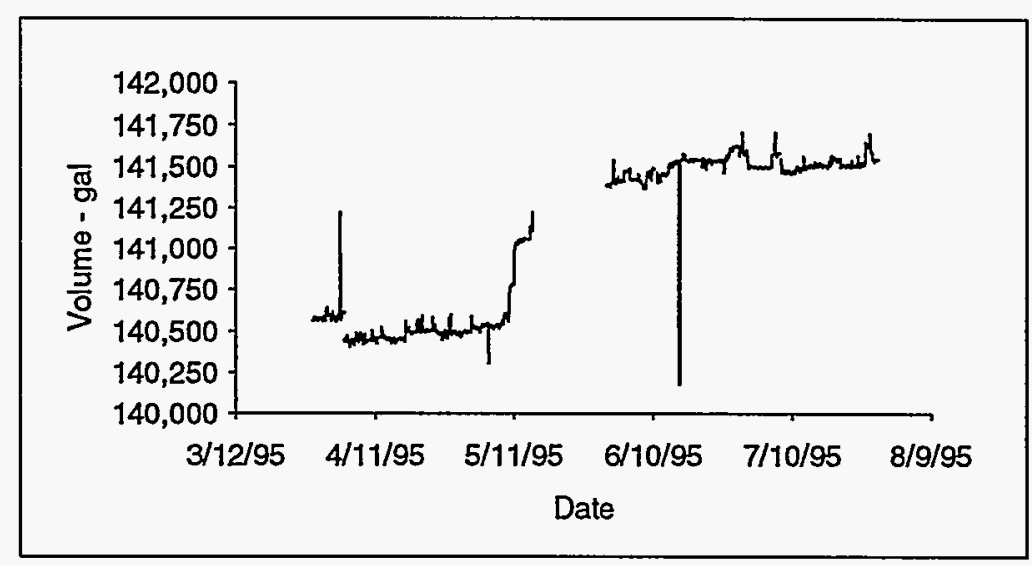

Fig. 4.2. W-6 volume plot after first hand-edit cycle.

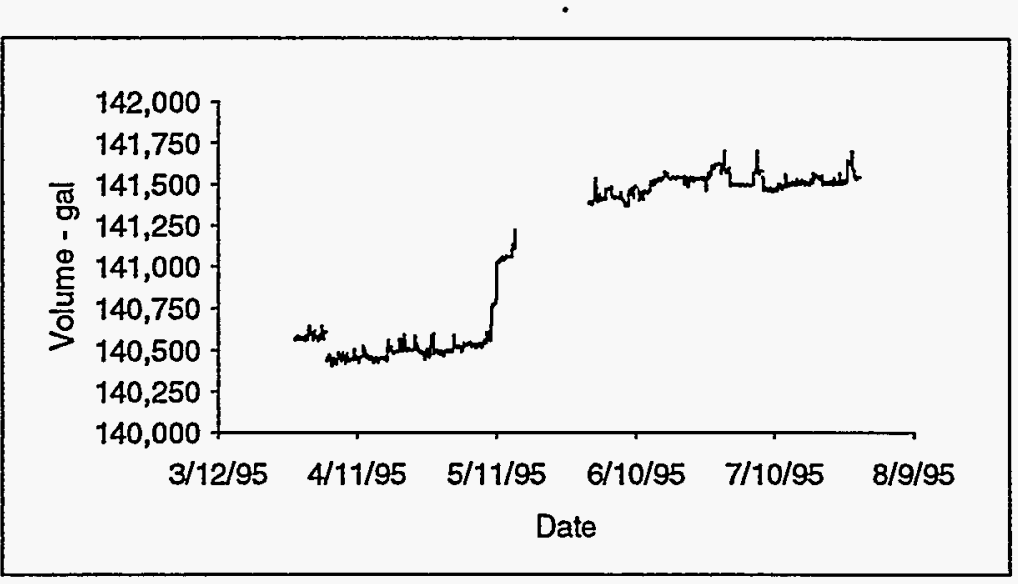

Fig. 4.3. W-6 volume plot after final hand-edit cycle. 
Accordingly, after the obviously bad data are removed, the remaining fluctuations must be considered part of the noise of the system. (It will be shown in Sect. 4.4.3 that the volume increase seen to occur around May 11 is due to rain water entering the tank.)

\subsection{DESCRIPTION OF THE DATA}

There were three essential sources of data used in assessing the internal monitoring method: liquid level in the tank, precipitation, and temperature and relative humidity. The rainfall and atmospheric data were obtained from the X-10 Meteorological Tower, which is located immediately to the northeast of the upper parking lot serving Building 1000 at X-10 and approximately $1,500 \mathrm{ft}$ west-northwest of the NTF and STF. In addition to relative humidity and precipitation this tower measures wind speed, wind direction, and air temperature at 10,30, and $100 \mathrm{~m}$ above the ground. All data are sampled hourly. The accuracy and precision of the various sensors are not known, but are presumed to be sufficient for the purposes of the analysis described below.

Liquid level data for the tanks in the STF (W-5-W-10) were obtained from conductivity probes that are permanently installed in these tanks. The level sensor is an Intel-185 manufactured by Robertshaw. This device lowers a probe from a servomotor-driven reel until an electrical contact is made at the liquid surface. At that point, the length of wire reeled out is recorded and the reel is partially withdrawn. The liquid depth is calculated as the length of wire reeled out subtracted from a 0 -reference datum. The volume of liquid in the tank is calculated as the liquid depth times a height-to-volume scaling ratio. Table 4.1 lists the performance specifications for the Robertshaw Intel-185.

Assuming a height-to-volume conversation ratio of $1224 \mathrm{gal} / \mathrm{in}$. for the STF GAAT, a 12-ft span for the servomechanism that drives the contact probe, and a change in temperature of $50^{\circ} \mathrm{F}$ over the analysis period, the Robertshaw level sensor is expected to provide an overall accuracy of about 210 gal, together with a standard deviation (precision) of about 21 gal. In addition, there is an unknown offset in the data that affects the absolute accuracy of the device; this offset represents the 0 -reference point for the measurement, which may or may not correspond to the bottom of the tank.

Table 4.1. Performance specifications for the Robertshaw Intel-185 sensor

\begin{tabular}{ll}
\hline \multicolumn{1}{c}{ Specification } & \multicolumn{1}{c}{ Value } \\
\hline Accuracy & $0.1 \%$ of span \\
Resolution & $0.012 \mathrm{in}$. \\
Repeatability (taken as precision) & $0.06 \mathrm{in} . / 100 \mathrm{ft}$ \\
Temperature & $0.25 \%\left(-50^{\circ}\right.$ to $\left.250^{\circ} \mathrm{F}\right)$ \\
\hline
\end{tabular}

Level data in the STF are sampled at a rate of once per minute for each tank. The sampled data are recorded and archived at the WOCC at the same rate. These data were downsampled to hourly samples, as described in Sect. 4.1.1. 
Unlike the tanks in the STF, Tanks W-3 and W-4 in the NTF do not have permanently installed liquid level sensors. Thus, In-Situ piezoelectric pressure transducers, Model PDX-260, were installed at the bottom of W-3 and W-4 for a short period so that level data could be obtained. The PDX-260 pressure transducer infers liquid depth by measuring the head pressure of the liquid above it and converts this pressure to inches. For the purpose of this analysis, the precision of the PDX-260 is assumed to be 0.01 in. For this precision, and for a tank with a height-to-volume ratio of $306 \mathrm{gal} / \mathrm{in}$. (appropriate for W-3 and W-4), and assuming a specific gravity of 1.0, the calculated measurement precision (standard deviation) is expected to be approximately 3 gal. These PDX-260 pressure transducers were connected directly to the in situ data logger at the NTF. The data were recorded at hourly intervals.

The data used in this report spanned several time periods. The WOCC volume data for Tanks W-5-W-10 were from the periods March 1-May 31, 1994, and March 27-July 30, 1995. The three-month-long 1994 data set was selected because the first half of April in that year was more rainy than any other two-week period at ORNL, based on rainfall data during the 5-year period from 1990 to 1995. The four-month-long 1995 data set was selected because it was the most recent that was available for analysis. Level data for Tanks W-3 and W-4 were obtained from a 5-week period beginning on June 22,1995 , and ending on 31 July 1995. Rainfall data were obtained from ORNL archives on a year-byyear basis; hourly samples were obtained for the period 1990- July 1995. The need for air temperature and relative humidity data (to support the evaporation and condensation analysis) was identified late in the program. These data were obtained from the Met Tower archives. These data, spanning the period March 27 through about 10 July 1995, only partly overlapped the 1995 WOCC data set; there were several time gaps in the data.

\subsection{APPROACH TO LEVEL DATA ANALYSIS}

The analysis utilized all of the data described in Sect. 4.2, in addition to information from other sources. It consisted of the following six steps:

- Make a qualitative determination of the likely elevation of the groundwater in the vicinity of the GAAT. The importance of this step is that if it.can be shown that the groundwater is below the bottom of a tank, then (taking into account head pressure in the tank) the leakage into the tank cannot be attributed to groundwater seeping in through a hole in the tank. Similarly, if the groundwater can be shown to be above the top of the tank, any leakage from the tank cannot be attributed to liquid released from the tank through such a hole. This step is also important because groundwater that located at intermediate levels along the tank's height can mask releases.

- Observe and note any long term trends in the liquid level data. This is useful to qualitatively assess the tank and observe any overall trends that may be occurring, or long-term data quality problems.

- Correlate any observed inflows with rainfall effects, to attempt to bound the level analysis task. To the extent that leakage into the tank can be attributed to rainfall, it means that when it is not raining, the level data are not being influenced by precipitation and are thus amenable to analysis. This correlation analysis was accomplished by constructing a scatter plot of the detrended cumulative rainfall as the independent variable plotted against the detrended changes in tank volume. A regression line was then calculated as the least squares fit to the data in the scatter plot. The slope of this line defined the "rain influence coefficient," while the regression correlation provided a measure of whether the regression analysis was useful for predicting leakage into the tank from the amount of rainfall. 
- Conduct a statistical inference test. This step began with a regression analysis of segments of volume data abstracted from the time serial tank volume data record. Segments were selected that were free of the effects of leakage into the tank due to rain. The duration of the segment was long enough that it would be free of short-term sampling and would mitigate most effects of noise, but short enough that a significant number of segments could be selected for analysis between rainfall events. While a systematic study could have been done to optimize the segment duration, in terms of minimizing the standard deviation of the ensemble of data going into the test suite, a segment duration of $48 \mathrm{~h}$ was chosen for this work. This duration was chosen largely because it is the one used at the Waste Management Division of ORNL in testing tanks greater than 3,000 gal in capacity for leaks.

For each tank, a regression line was fit to each of the data segments; the slope and the standard deviation of the y-estimate were tabulated. After the statistics from each segment had been determined, an ensemble statistic was calculated as the mean of the slopes (the average volume rate) and the mean and variance of the standard deviation of the y-estimates (the precision of the estimate). After "wild points" had been identified and had been removed from this data set, the residual data were subjected to a null hypothesis test. This was repeated for the data from each tank.

The null hypothesis test is done by applying the Student's t-test to the average volume rate and precision data. The test asserts that there is no difference between the average volume rate and a volume rate of $0 \mathrm{gal} / \mathrm{h}$. Based upon the results of the test we either accept the null hypothesis or we reject it. This test allows a measure of the liquid integrity of the tank to be estimated. If the null hypothesis is accepted, it means that the tank is likely sealed; if the null hypothesis is rejected, it means that the tank is likely not sealed.

- Utilize the regression data from the statistical inference test to estimate the minimum detectable release, at a probability of detection of $95 \%$. The results of this analysis were used to assess the performance of the level sensing instruments that are presently installed in the GAAT. The analysis is similar to the Student's t-test described above and follows the procedures developed by the EPA for estimating the performance of leak detection systems,

- Examine the potential for evaporation and condensation to be the major contributors to non-rain-elated volume increases and decreases observed in the GAAT. This analysis utilized the relative humidity and air temperature measured at the X-10 Meteorological Tower, together with some assumptions about the hot off-gas air flow through the GAAT, brought into an idealized evaporation/condensation model. This model was developed by Vista to support the active-tanks leak testing program at X-10, and is described in the Sect. 4.4.6 of this report.

\subsection{RESULTS}

As noted above, the internal liquid level monitoring portion of the integrity assessment considered six individual elements that, taken together, provide information regarding the liquid integrity of the Gunite tanks. These elements are discussed below:

\subsubsection{Groundwater Level}

Tanks W-3 and W-4 in the NTF and Tanks W-5 though W-10 in the STF were installed in tank pits that were excavated from the native soil. Anecdotal information indicates that, after tank 
construction was complete, the space between the tanks was filled with crushed rock and other highly permeable materials to allow surface and perched water to drain from the excavations through a French drain system installed in the pits during construction. Groundwater levels in the vicinity of the Gunite tanks were estimated from a 1992 workshop, a review of 1995 groundwater level data, and water level measurements in the NTF and STF dry wells made during this investigation. In 1992 ORNL put on an observational approach workshop to summarize the information then available on the inactive LLLW system. Presented as part of this workshop were cross-sectional drawings showing the relationship between the soil, bedrock and groundwater in the area of the Gunite tanks in the NTF and STF. These drawings had been generated from geologic descriptions and from data on groundwater level obtained from a number of monitoring wells and borings surrounding the tanks.

The two crossectional drawings from the 1992 workshop have been updated to include the recent data collected from the dry wells during this investigation; they were shown in Figs. 2.4 and 2.5. The north-south crossection, which cuts through both the NTF and the STF, is shown in Fig. 2.4, where the estimated elevation of the groundwater appears as a thick white line sloping generally downward from north to south, with depressions around the excavation pits where the tanks are located. The groundwater in these depressions is below the bottoms of the tanks. The east-west crossection, illustrating the southern portion of the STF, is shown in Fig. 2.5. Tanks W-6, W-8 and W-10 are shown in their respective positions in the excavation pit. In this figure, the estimated elevation of the groundwater-again denoted by a thick white line-extends from about $8 \mathrm{ft}$ beneath the surface at the western end of the drawing, drops to the bottom of the excavation pit, and rises to about $9 \mathrm{ft}$ below the surface at the eastern end.

The data shown in Figs. 2.4 and 2.5 indicate that the dry well and drain system in the NTF and STF is working as intended and is keeping the local groundwater from rising higher than the bottom of the tanks. A key inference that can be drawn from the data is that if there were any holes or defects in the side or bottom of a tank, there is no hydrostatic pressure on the liquid contents of the tank that would mask or impede either leakage into or out from the tank. Thus, in a tank with a finite liquid level, any defects at or below the liquid level should be evidenced by leakage from the tank. Similarly, any observed leakage into the tank is not coming from defects in the side or bottom of the tank.

\subsubsection{Long-Term Trends}

The observation of long-term tank level trends reveals a useful overview of the tank volume as a function of time, even though it does not directly provide any evidence of liquid integrity. Figures 4.5 31 show plots of the one-year volume history of Tanks W-5-W-10, respectively, from July 1994-July 1995. These data were obtained from the WOCC system, which routinely records the tank level as described above. Figure 4.4 shows that Tank W-5 had about 27,000 gal of liquid in it at the end of July 1994 , with a very slow volume decrease in the winter of 1994-95, followed by a volume increase to about 28,000 gal in July 1995 . (The gap in data during the early May to early June period was a data dropout in the WOCC plot, not a real volume change.) Figure 4.5 shows that Tank W-6 is nearly full, with a volume of about 140,000 gal; this tank shows a volume-change history much like that for Tank W-5. As seen in Fig. 4.6, however, Tank W-7 shows a much different volume history. The starting volume of about 4,500 gal, as measured in July 1994, decreased to about 3,500 gal by the spring of 1995 and then remained more or less constant through July 1995. (The dropout in late August 1994 is a data artifact and not reflective of the tank volume changes.) Figures 4.7 and 4.8 show that Tanks W-8 and W-9, from a base of about 58,000 and 43,000 gal, respectively, had a nearly constant level in the 1994 portion of the plot, followed by a slow increase in level in 1995. Tank W-10, shown in Fig. 4.9, demonstrates a very slow volume increase with time, starting with about 104,000 gal in 1994 and ending with about 106,000 gal. 


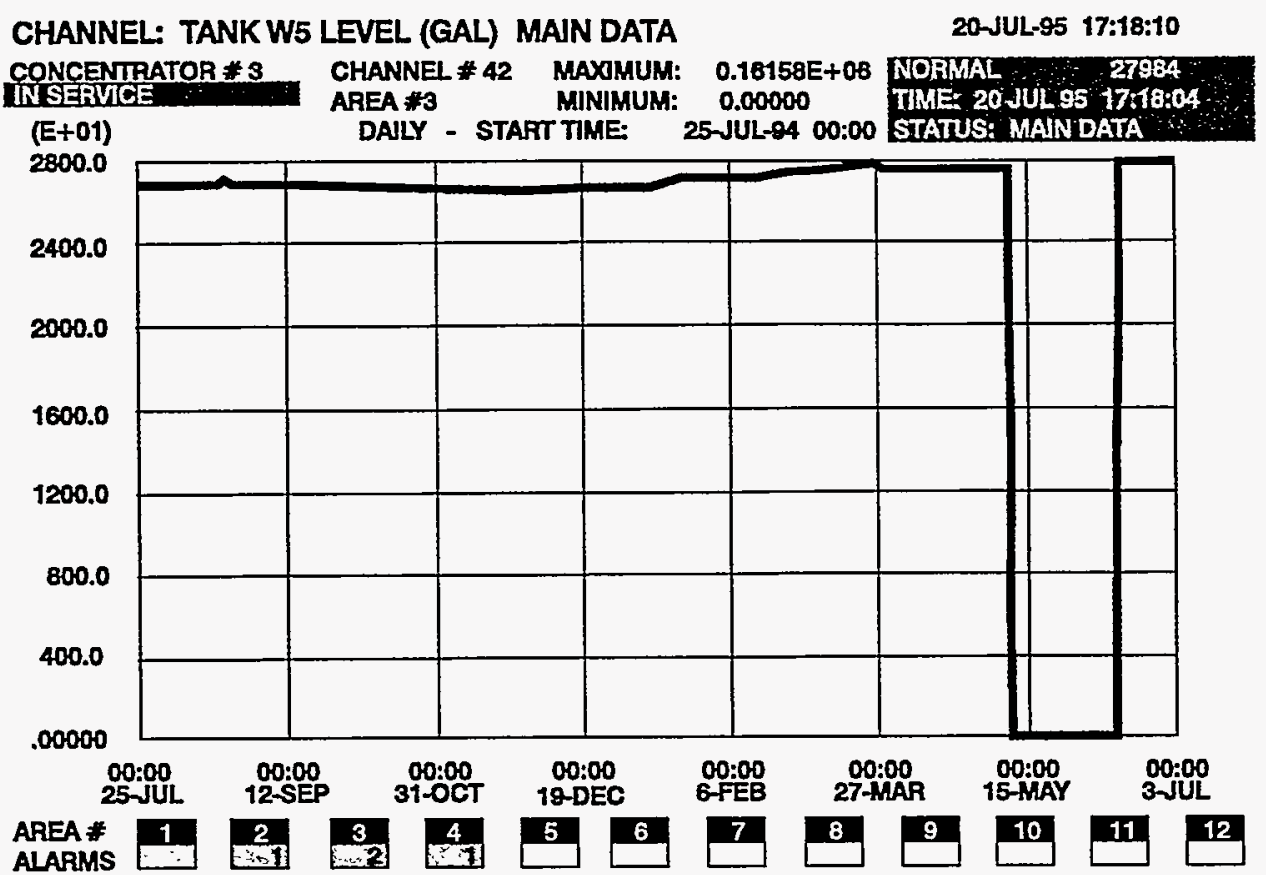

DISPLAY:

Fig. 4.4. WOCC-recorded volume in Tank W-5 (July 1994 to July 1995).

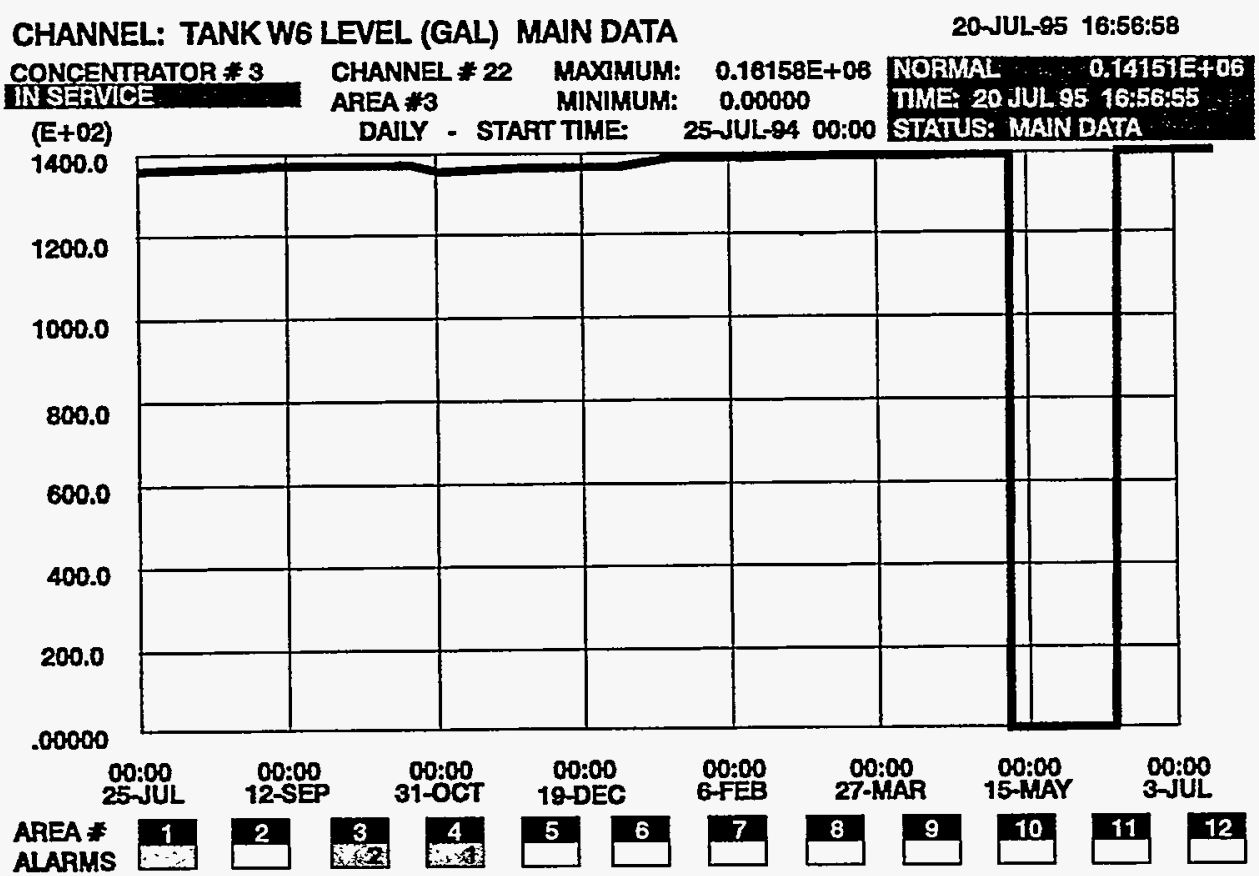

DISPLAY:

Fig. 4.5. WOCC-recorded volume in Tank W-6 (July 1994 to July 1995). 
CHANNEL: TANK W7 LEVEL (GAL) MAIN DATA

20-JUL-95 17:22:24

CONCENTRATOR $* 3$ CHANNEL * 43 MAXIMUM AREA :B

TORIMAL 3747.6

DAIIY - START TTHE.

$T M=20$ JUL 85 17.22021

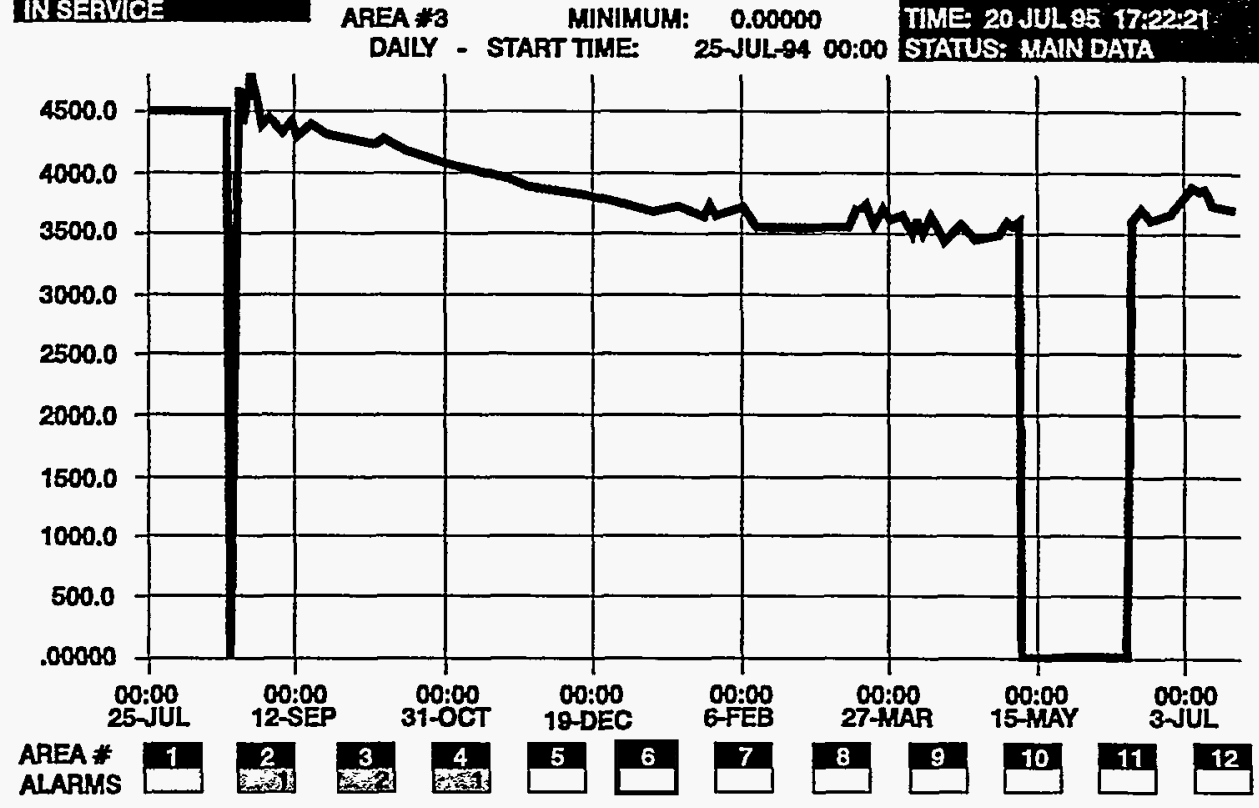

DISPLAY:

Fig. 4.6. WOCC-recorded volume in Tank W-7 (July 1994 to July 1995).

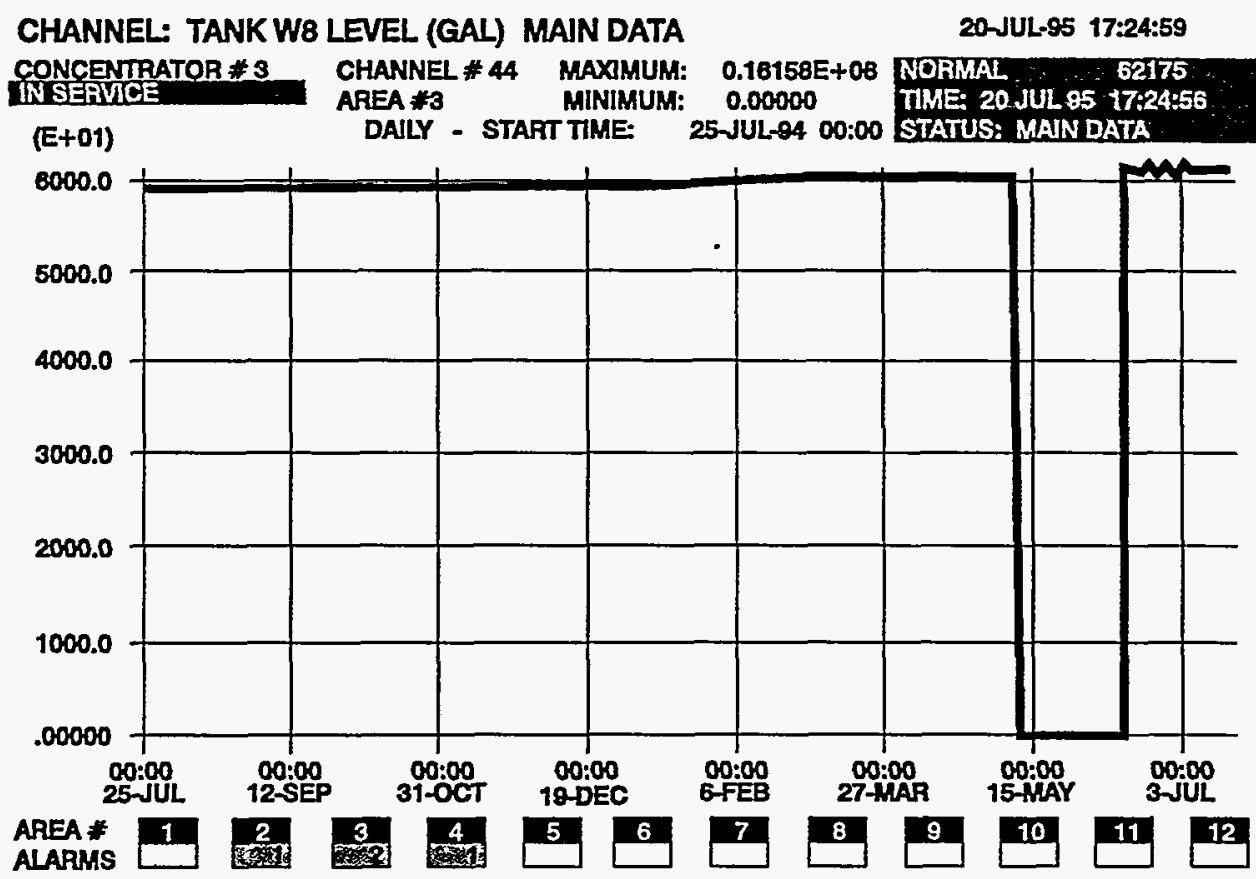

DISPLAY:

Fig. 4.7. WOCC-recorded volume in Tank W-8 (July 1994 to July 1995). 


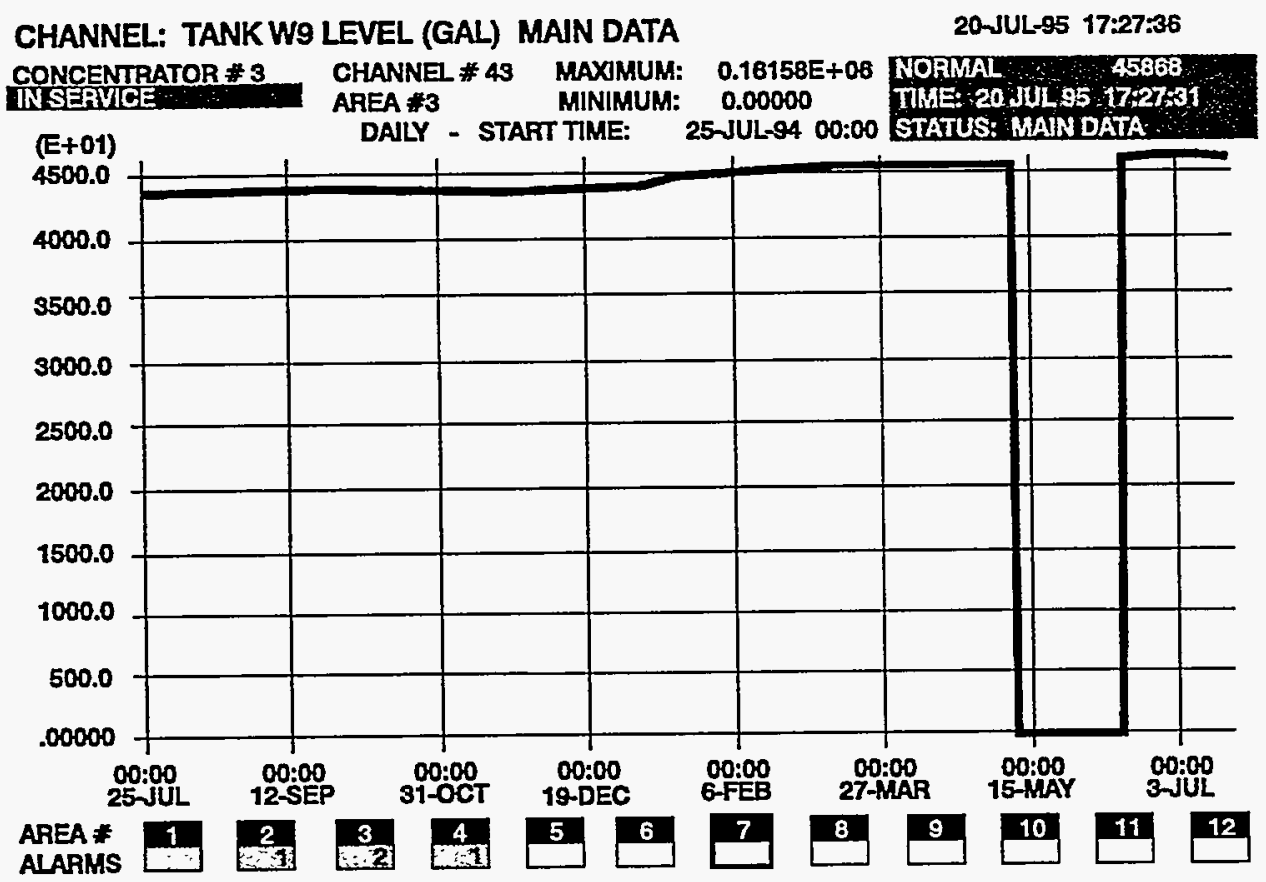

DISPLAY:

Fig. 4.8. WOCC-recorded volume in Tank W-9 (July 1994 to July 1995).

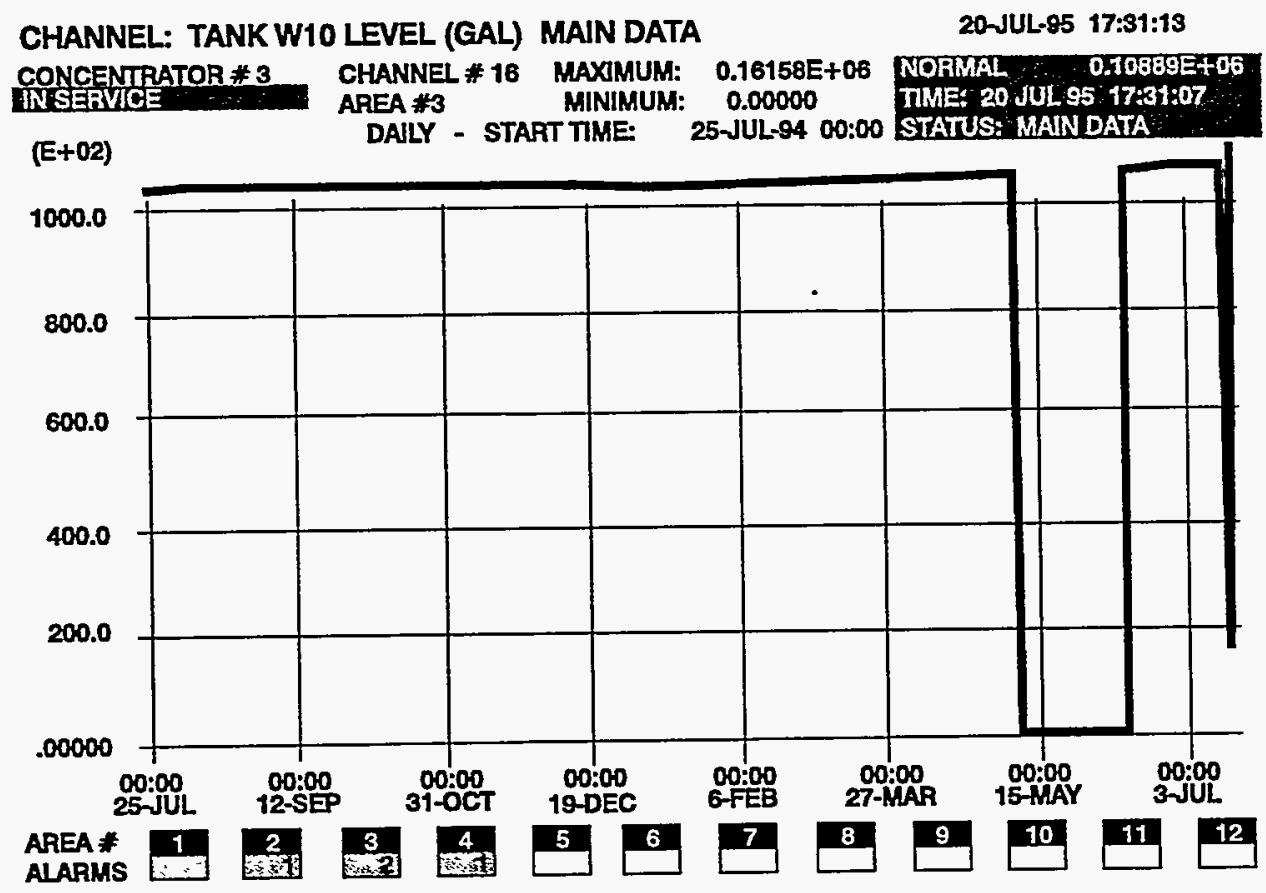

DISPLAY:

Fig. 4.9. WOCC-recorded volume in Tank W-10 (July 1994 to July 1995). 
These data show a wide disparity in tank volume, with some disparity in trends. Since these tanks are inactive and not being used, there should be no abrupt level changes in the data, such as would occur if the tank volume changed due to a transfer of product to or from another tank. The one-year plots confirm the inactive nature of the tank and suggests that, except for data dropouts, spikes and other data quality restrictions, and environmental effects, there should be few limitations to using the data for integrity assessment purposes.

\subsubsection{Influence of Precipitation}

Rainwater entering LLLW tanks is not an unusual circumstance. In the case of the active tanks, many of the associated valve and pump pits have sumps that pump accumulated water into the LLLW tank. In inactive tanks, abandoned lines and openings into the top can be conduits for the inflow of rainwater. Both active and inactive tanks can receive water due to local drains that collect infiltrating rainfall, and in some cases direct surface runoff, and drain it into the tank. Since this inflow of water contributes to the tank volume and can mask outflows, it is important to understand the volume data from the perspective of rain-related effects. During the first half of April 1994, there were a number of days of heavy rains, followed by a period of almost no rain during the last two weeks of the month. This contrast in precipitation conditions made this period a good one for examining the effects of rain on tank volume. The rain record for April 1994 at ORNL is illustrated in Fig. 4.10, which shows the daily and cumulative rainfall for this period. The column plot shows the daily rainfall measured at X-10, read on the left-hand ordinate. The cumulative rainfall (measured from January 1,1994) is shown as the line plot, and read on the right-hand ordinate. This figure shows that about 8 in. of rain fell during the first half of April, with a single rain day in the last half of April that contributed about $1 / 3 \mathrm{in}$. To assess the effect of this rain on tank volume, the change in tank volume was correlated with the change in cumulative rain, as discussed below.

Figure 4.11 shows a time series plot of the volume in Tank W-5 for the month of April (read on the left ordinate) and the cumulative April rainfall (read on the right ordinate). A qualitative correlation can be observed in the plots: when a modest rain occurs, a same-day increase in tank volume is observed that is more or less proportional to the amount of rain that has fallen. In an attempt to quantify this effect, the trend line through the cumulative rain data was subtracted from the cumulative rain data to obtain a data set of detrended cumulative rain. Similarly, the volume trend line was subtracted from the volume data to obtain a set of detrended volume data. Then, a scatter plot was made of the detrended volume as the dependent variable, against the detrended cumulative rain as the independent variable. This scatter plot, shown in Fig. 4.12, shows a clear correlation. A regression line placed through the scatter of data points (shown as the dashed line in the figure) indicates that, for the April 1994 data, Tank W-5 experienced a rain influence of about $135 \mathrm{gal} /$ in.; that is, for every $1 \mathrm{in}$. of rainfall, the tank showed approximately a 135 gal increase in volume. ${ }^{4}$ The correlation coefficient of the regression estimate was 0.85 (as shown in the figure), sufficiently high to suggest that the rain influence coefficient (135 gal/in.) is at least helpful in predicting the volume change in W-5 due to rain, if not definitive.

The rain influence correlation analysis was repeated for each of the tanks in the STF. Figure 4.13 shows the Tank W-8 volume time series and cumulative rainfall for the April 1994 period. As for Tank $\mathrm{W}-8$, a volume increase proportional to the amount of rainfall is observed in the W-8 data. The analysis of the detrended data resulted in a rain influence coefficient of $175 \mathrm{gal} / \mathrm{in}$. of rain, with a regression

\footnotetext{
${ }^{4}$ Not all of the rainwater enters the tank. There is a "field wetting" effect that must occur before the tank's volume shows an increase. This effect is created when frequent and/or heavy rain saturates the soil, allowing the rainwater to run off instead of being absorbed.
} 


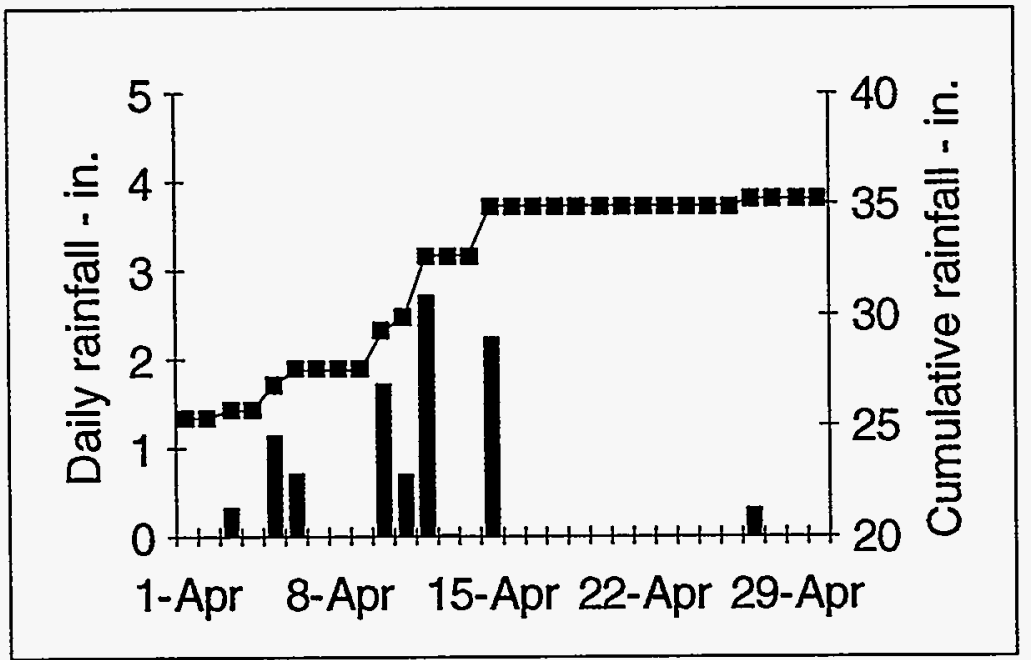

Fig. 4.10. Daily and cumulative rainfall at $\mathrm{ORNL}$ (1 to 30 April 1994).

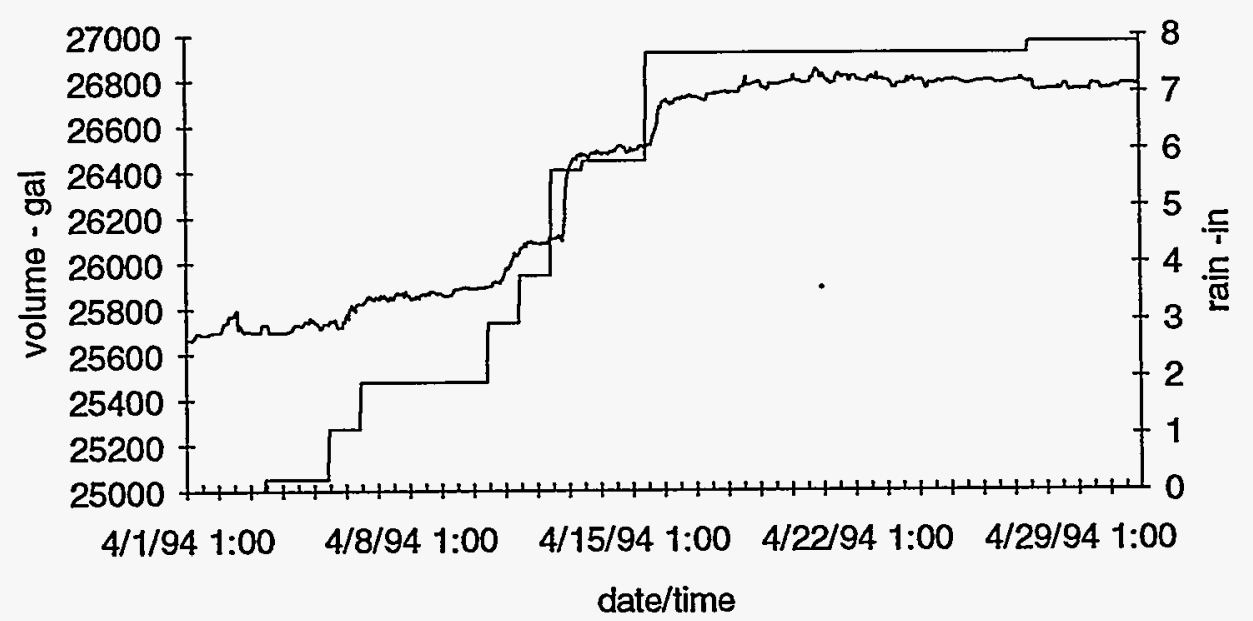

Fig. 4.11. Time series plot of volume in W-5 and rainfall at ORNL ( 1 to 30 April 1994). 


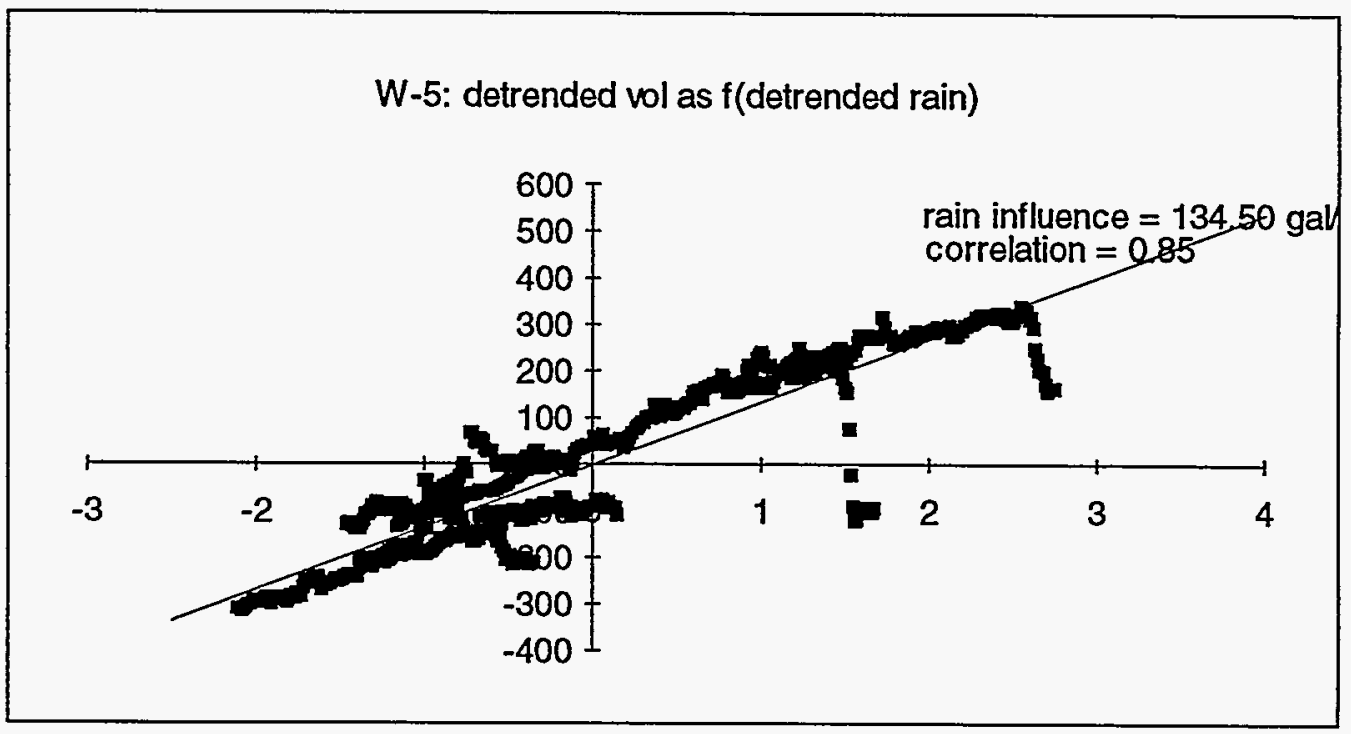

Fig. 4.12. Scatter plot of detrended rainfall data and detrended volume data for Tank W-5 (1 to 30 April 1994).

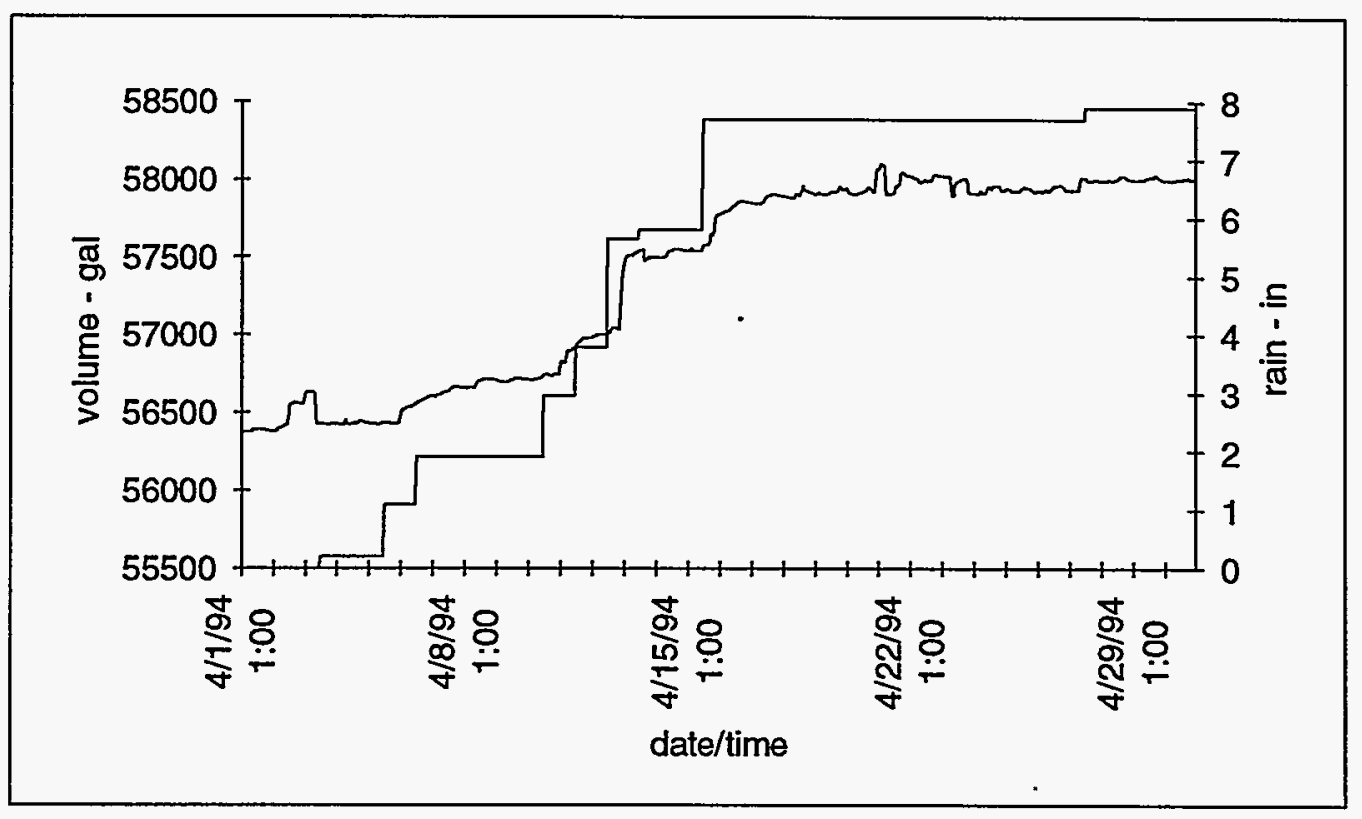

Fig. 4.13. Time series plot of volume in W-8 and rainfall at ORNL (1 to 30 April 1994). 


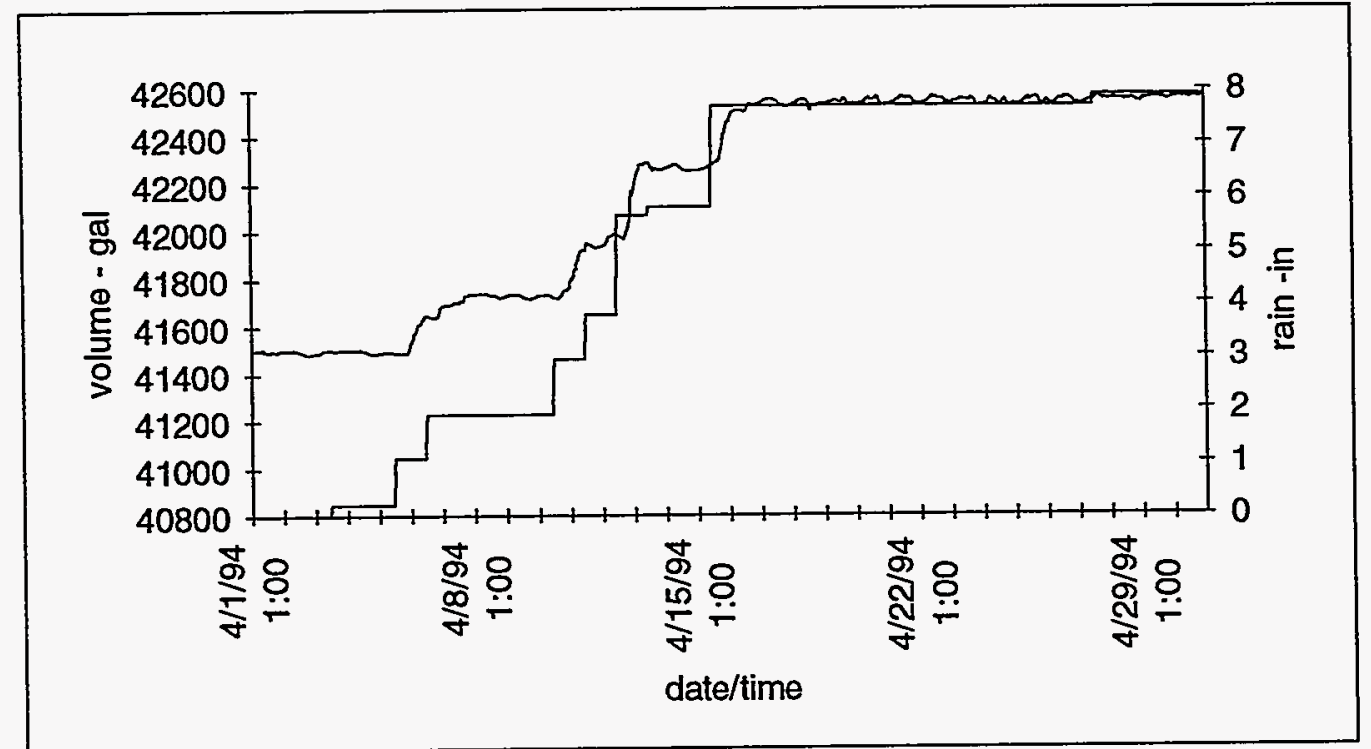

Fig. 4.14. Time series plot of volume in W-9 and rainfall at ORNL (1 to 30 April 1994). 
correlation of 0.83 . Figure 4.14 shows the $\mathrm{W}-9$ volume and rainfall time series data. The detrend analysis showed that this tank had a rain influence coefficient of $129 \mathrm{gal} / \mathrm{in}$., with a regression correlation of 0.90 .

The rain-volume detrend analysis for Tanks $W-6, W-7$, and $W-10$ gave poorer results. In the case of W-6 and W-10, while a positive rain volume correlation was obtained, the volume time series suggested that the level sensor was "stuck" at certain levels, or that there was some other problem in the data system. This is illustrated in Fig. 4.15, which shows the cumulative rain and volume data for Tank W-10 for April 1994. It is seen in these data that the volume measure appears to change only once in April, and in exactly a 1,000 gal increment; this indicates an instrument or data problem.

In the case of Tank W-7, while the sensor appears to be working normally and a rain influence was obtained (32 gal/in.), the regression correlation is very poor (0.43), suggesting that the rain influence coefficient is not reliable in predicting tank volume. This is illustrated in Fig. 4.16, which shows the W-7 volume history during April 1994 along with the cumulative rain for this period. It is seen in the volume history that while there was some increase in volume during the rainy period, it was not very well timecorrelated with the rainfall events. Further, the volume in W-7 appears to decrease during the period when it was not raining.

The rain influence for Tanks W-3 and W-4 could not be determined because these tanks were instrumented with level sensors only from late June through early August and because little rain fell during this period. What little rain did fall in the summer of 1995 , however, appeared to have no effect on the liquid volumes in W-3 or W-4.

This analysis shows that the volume increases (leakage into the tank) observed in Tanks W-5, W-8, and W-9 are largely due to local rainfall events, and the effect can be quantified. W-6, W-7, and W-10 also show rain-related leakage into the tanks, but the correlation is too poor to allow the effect to be quantified. Since the data suggest that most leakage into the tanks is due to rainfall, the implication is that, when it is not raining, the data should be relatively free of spurious or anomalous effects and therefore amenable to analysis.

\subsubsection{Statistical Inference Test}

The foregoing discussions reveal that: (1) the groundwater level in the GAAT excavations is below the bottom of the tanks; it is therefore neither a likely contributor to leakage into the tanks, nor will it prevent or mask out-leakage; (2) liquid level in the tanks is free of volume changes due to human intervention (or operations); and (3) level data collected during rainy periods are unsuitable for analysis due to rain-related leakage into the tanks. To further the analysis, a four-month block of GAAT volume data was obtained from WOCC, along with weather data from ORNL's meteorological group, and added to the one-month-long April 1994 database. Together, these data comprised a five-month documented record of the internal liquid level history of Tanks W-5-W-10 and the environmental factors that affected these levels. To gather liquid level data on Tanks W-3 and W-4 for the explicit purpose of assessing liquid integrity, a pressure sensor-type level gauge was installed in the tanks for about one and one-half months.

Figures 4.17-4.24 provide time series plots of the 1995 portion of the volume history of the tanks considered in this study. In the case of the NTF tanks (W-3 and W-4), the data cover the interval from June 22-August 8, 1995. For the STF tanks (W-5-W-10), the data cover the interval from March 28-July 1995. These figures also show, on the right-hand ordinate, the hourly rainfall recorded at ORNL during the same period. (As noted earlier, these data have been hand-edited to remove obvious errors, spikes, and other glitches.) A look at these figures shows that the data from the various tanks exhibit a variety of characteristics. The data from W-3 and W-4, for example, appear to show a resolution-limited characteristic where the volume toggles between two adjacent values. The data also show the points, on June 27 and again on July 21 , at which the level sensor in W-4 was moved, thereby causing an abrupt 


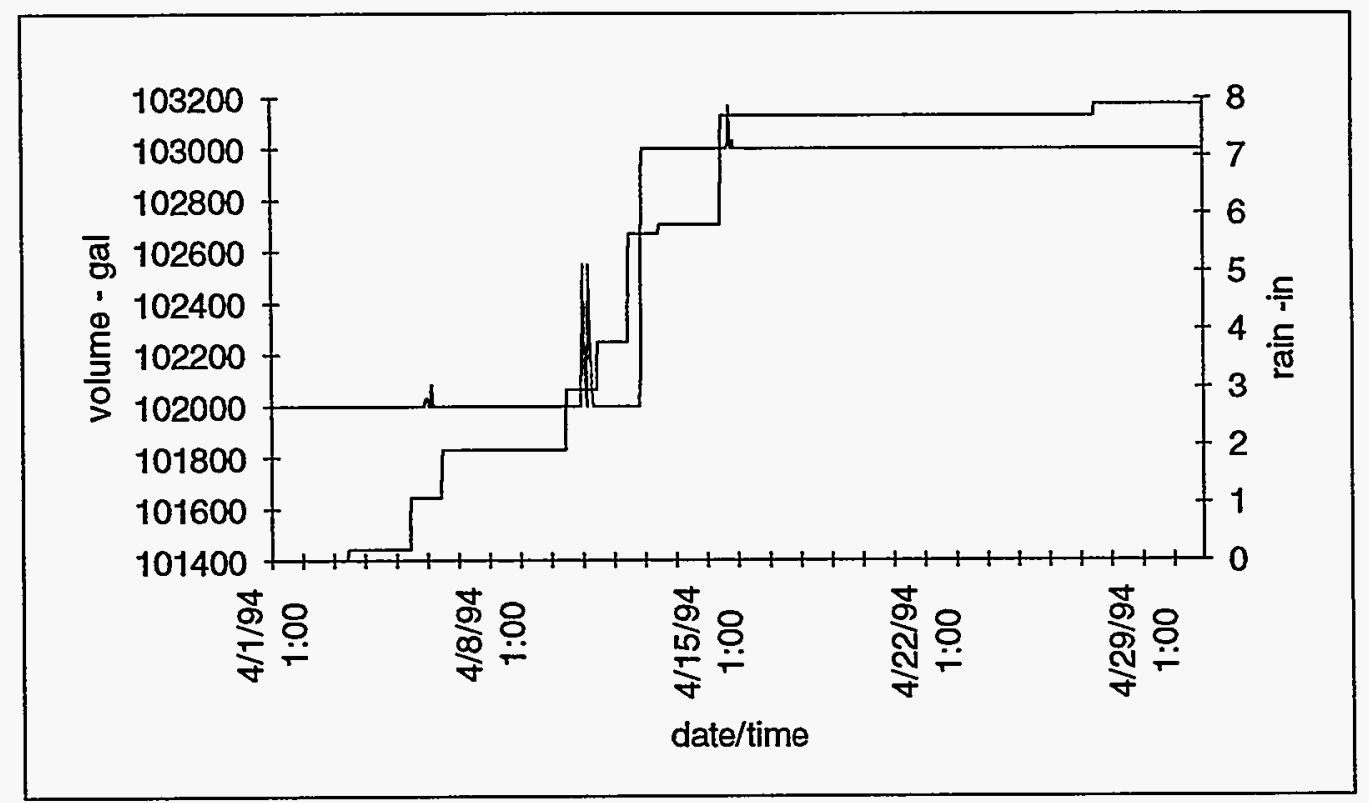

Fig. 4.15. Time series plot of volume in W-10 and rainfall at ORNL ( 1 to 30 April 1994). 


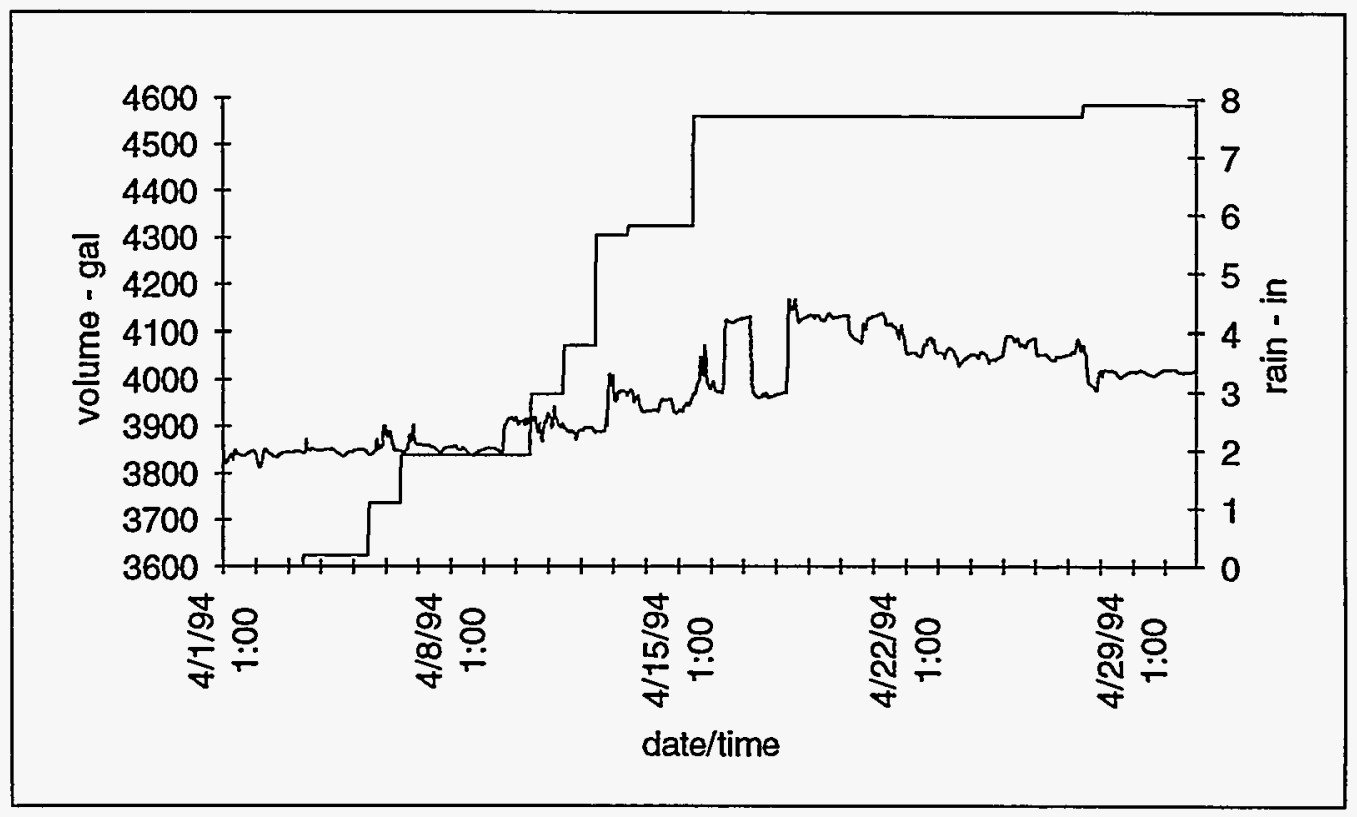

Fig. 4.16. Time series plot of volume in W-7 and rainfall at ORNL ( 1 to 30 April 1994).

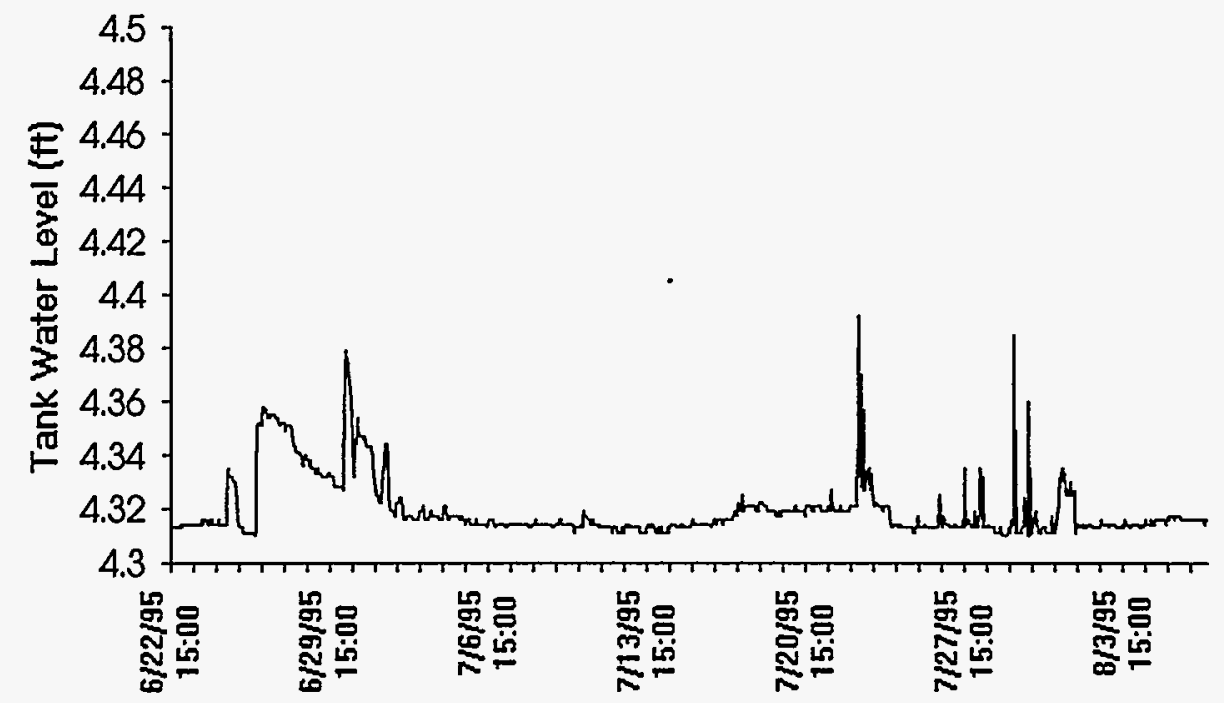

Fig. 4.17. Time series plot of volume in W-3 and rainfall at ORNL (22 June to 8 August 1995). 


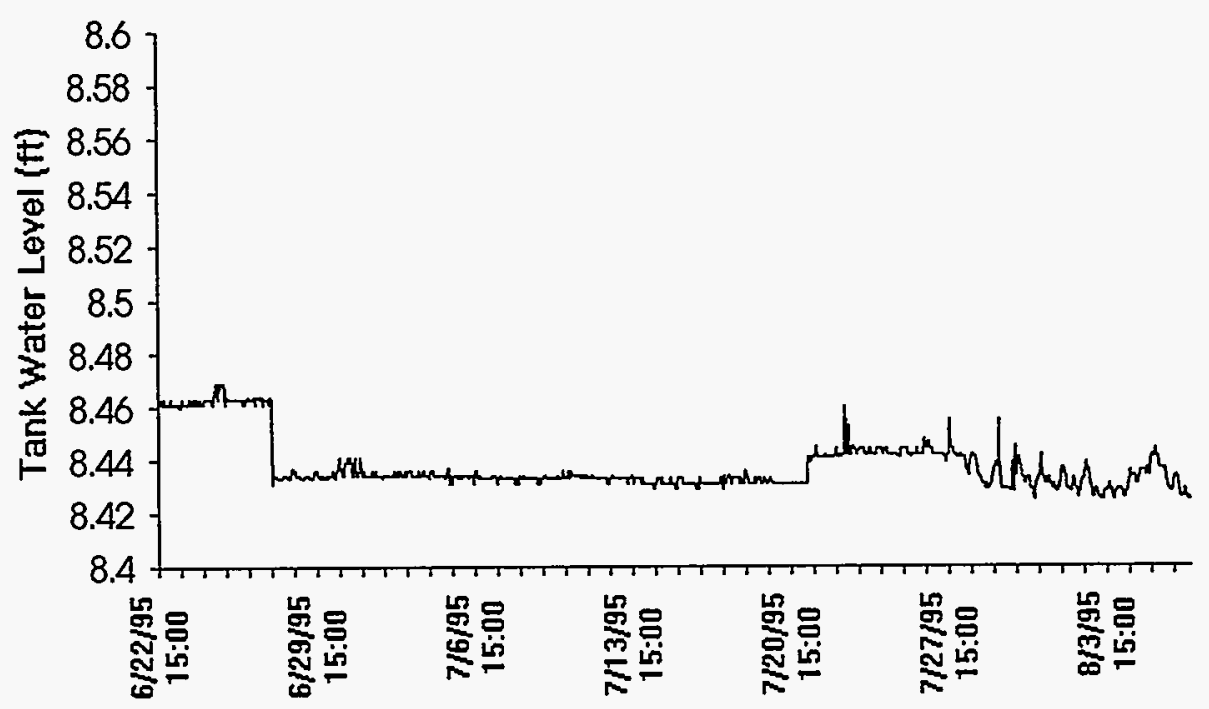

Fig. 4.18. Time series plot of volume in W-4 and rainfall at ORNL (22 June to 8 August 1995).

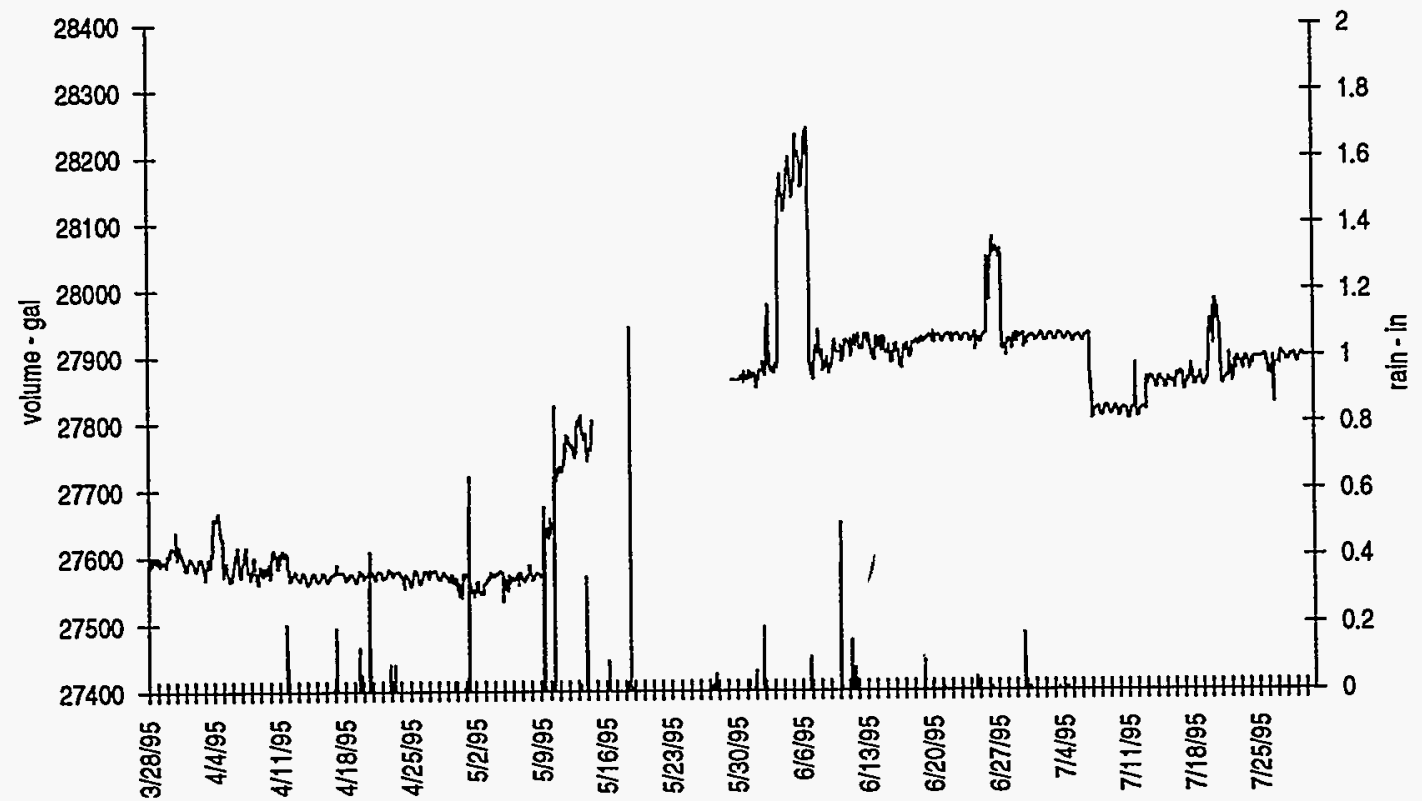

Fig. 4.19. Time series plot of volume in W-5 and rainfall at ORNL (28 March to 30 July 1995). 


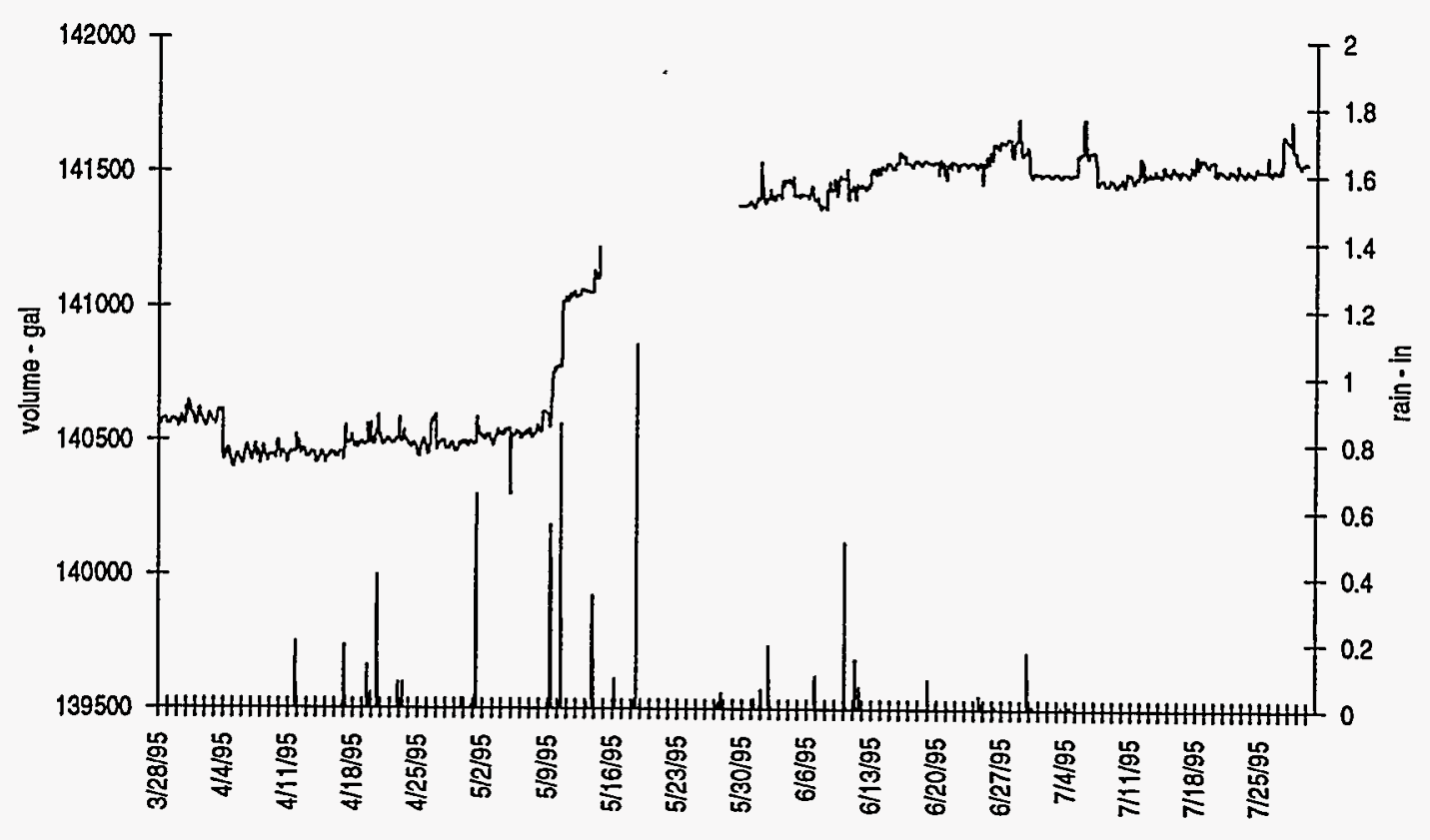

Fig. 4.20. Time series plot of volume in W-6 and rainfall at ORNL (22 June to 8 August 1995).

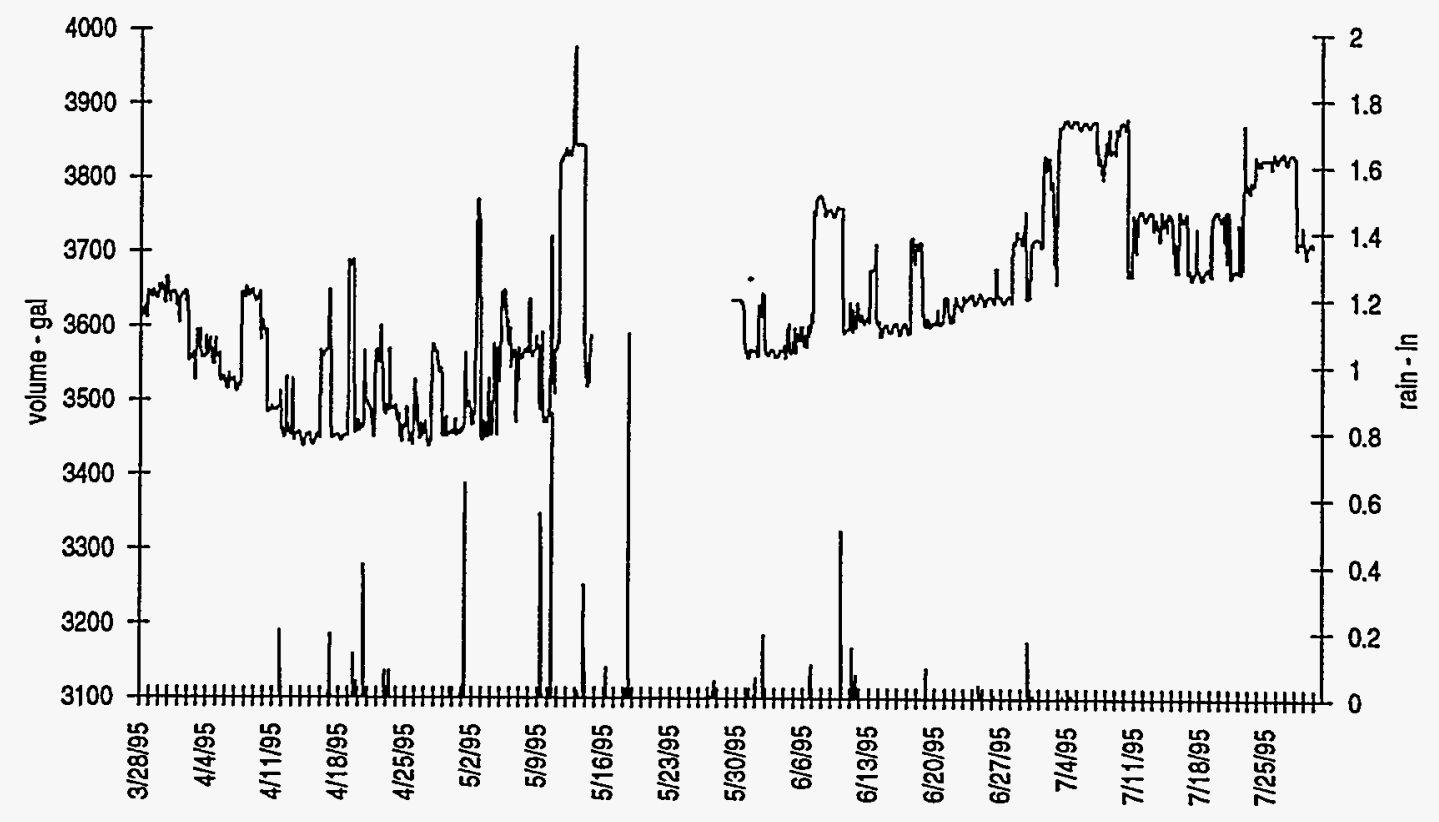

Fig. 4.21. Time series plot of volume in W-7 and rainfall at ORNL (22 June to 8 August 1995). 


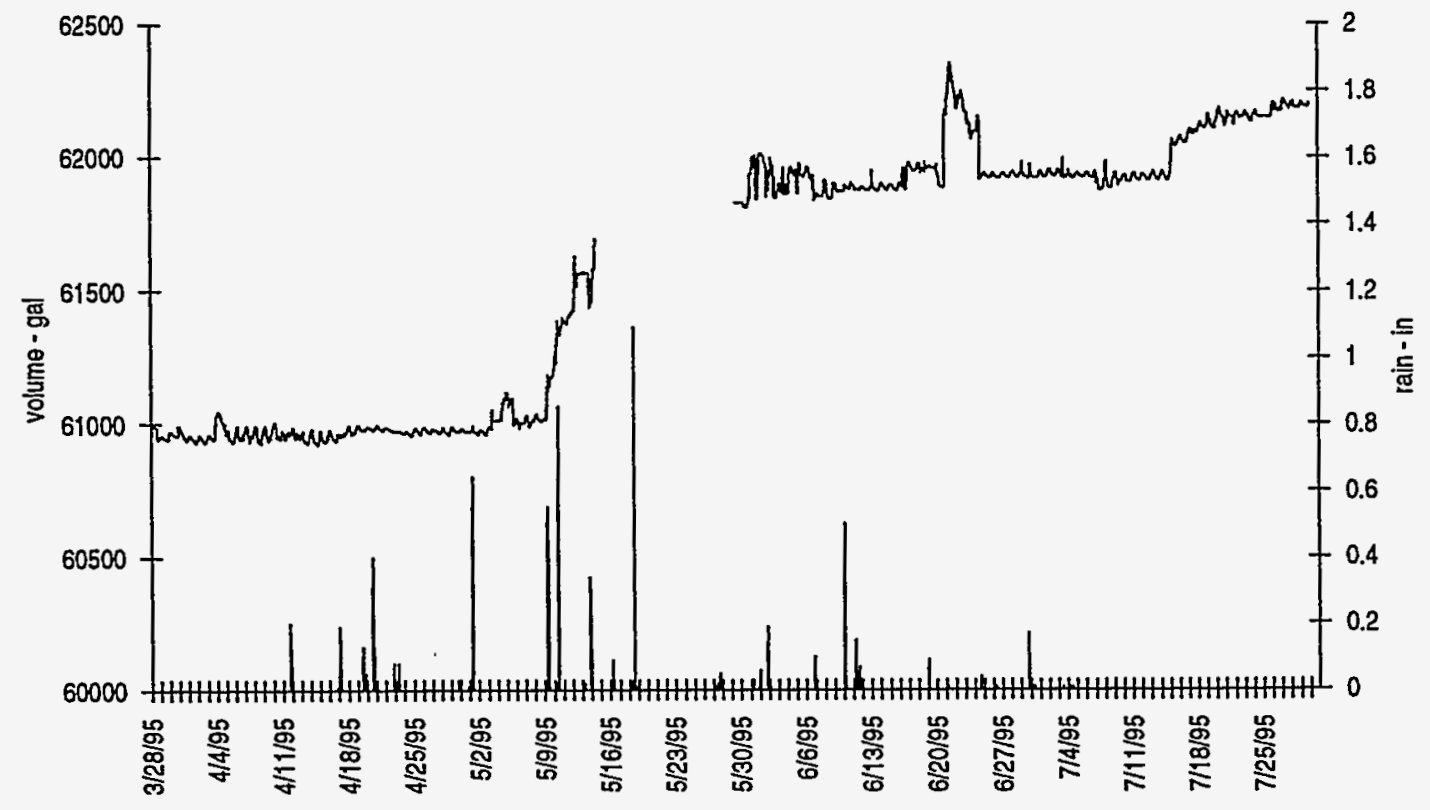

Fig. 4.22. Time series plot of volume in W-8 and rainfall at ORNL (22 June to 8 August 1995).

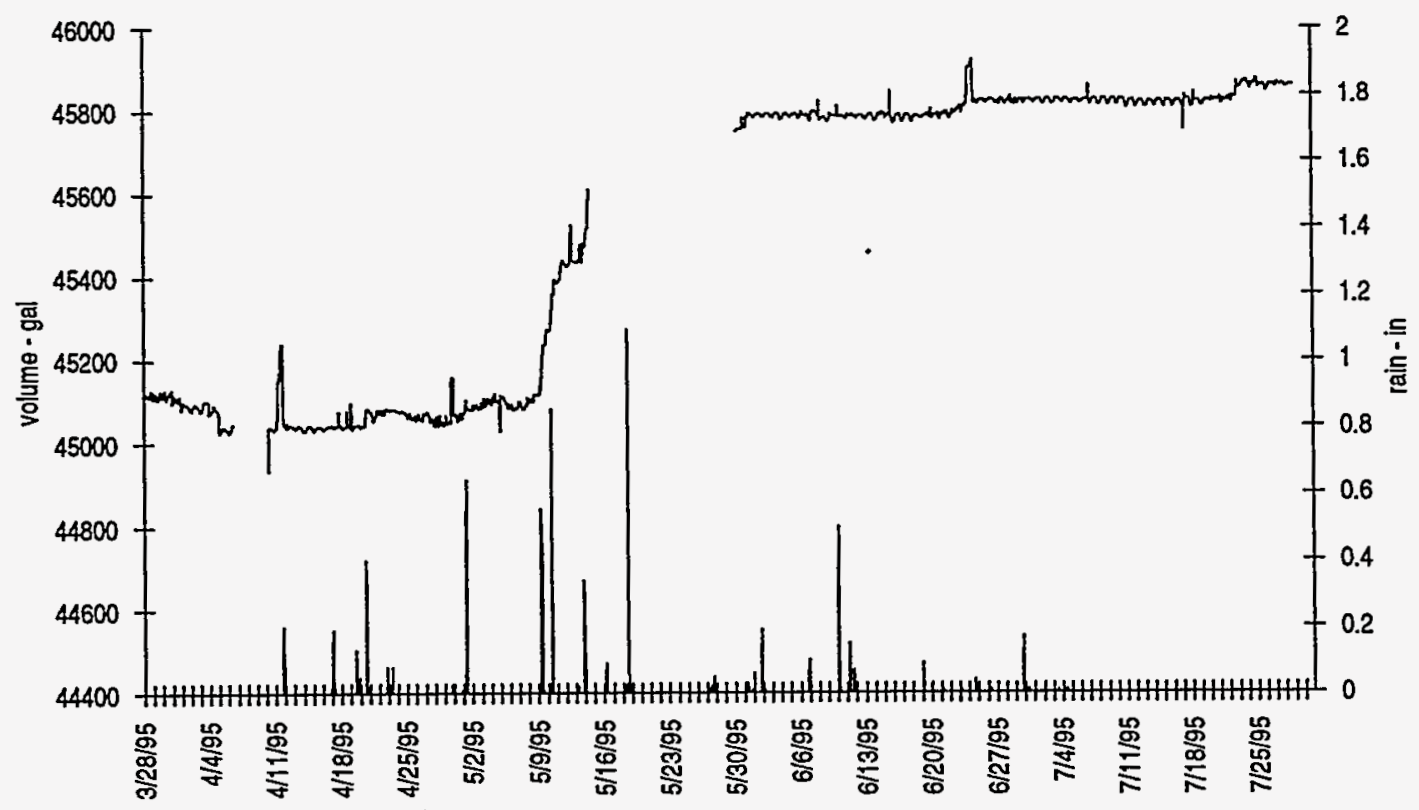

Fig. 4.23. Time series plot of volume in W-9 and rainfall at ORNL (22 June to 8 August 1995). 


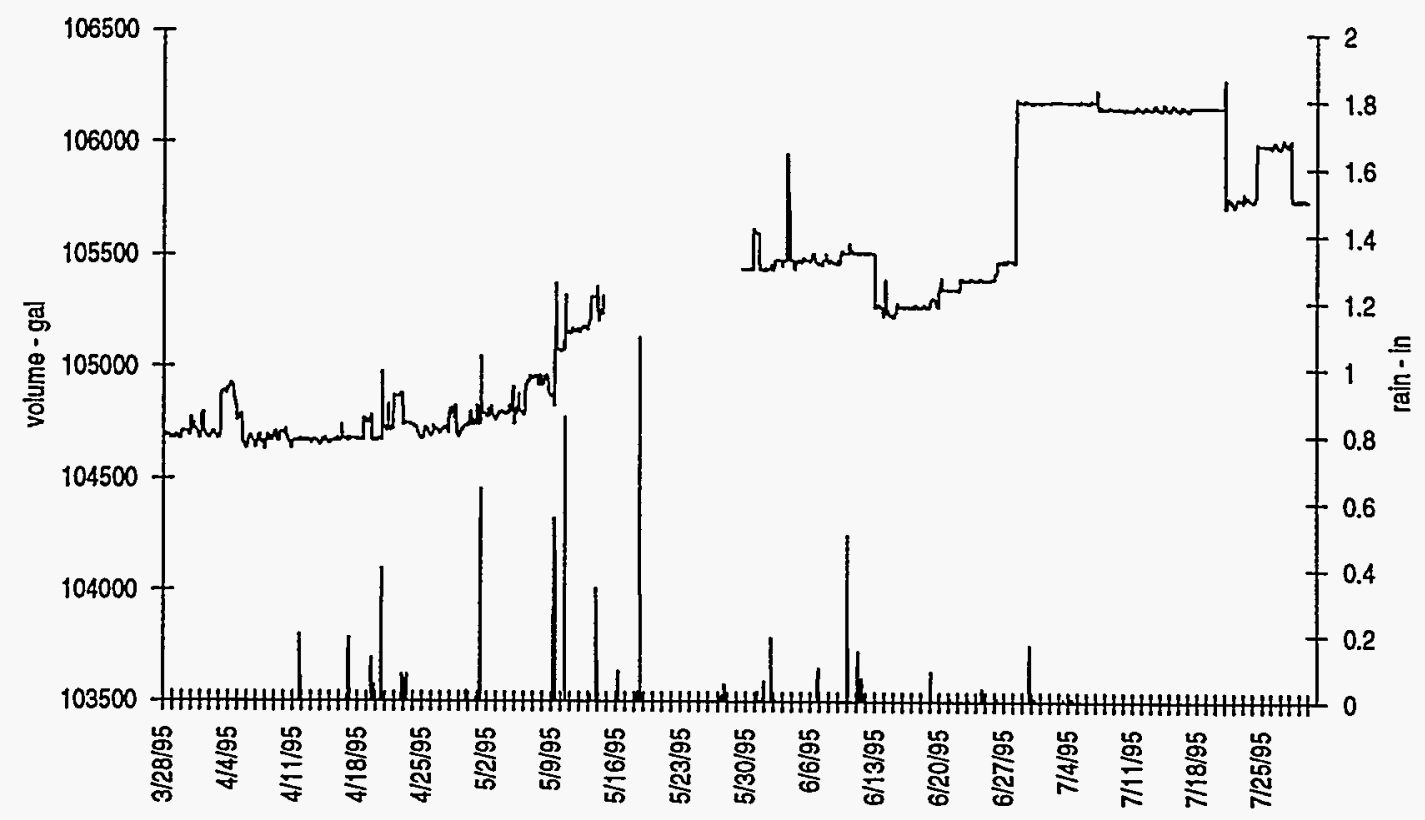

Fig. 4.24. Time series plot of volume in W-10 and rainfall at ORNL (22 June to 8 August 1995). 
change in the measured level. In terms of abstracting portions of the data for analysis, it is clear that the intervals bracketing these periods of abrupt change would not be valid. (Most of the data also show a diurnal volume fluctuation. These fluctuations, an artifact of the level system, which is located outdoors and is influenced by temperature changes, are well understood.)

The data from Tanks W-5-W-10 (Figs. 4.19-4.24) show that the level does not fluctuate between two values and indicate that the measurements were made at a finer resolution than for W-3 and W-4. (This does not necessarily suggest that the STF data have more precision.) A gap is seen in the STF data between May 16 and May 28; we were unable to retrieve data from the WOCC data system for this interval. In addition to this gap, a number of other imperfections can be seen. For example, the data for W-5 between June 4 and 7 show an anomalous level change, where the apparent volume suddenly increases and decreases. These data anomalies, which are certainly not real volume (level) changes, are seen throughout the data, for all of the tanks, to a greater or lesser degree. W-7 is particularly bad in this regard, showing a very noisy volume history. During the data gaps, transition periods, and the noisy and unstable periods, the data are obviously bad and cannot be used for liquid integrity assessment purposes. $^{5}$

The rain influence described in Sect. 4.4.3 for the April 1994 data can also be seen in the 1995 data, particularly around May 9 and 10, and in the few days just before the data loss period. Prior to May 9 , the rain that had fallen (recorded and plotted here in hourly intervals) had been mostly light and intermittent. Though the rain was absorbed, it did not over saturate the soil. On May 9, it rained heavily over an extended period of time, fully saturating the soil and allowing infiltrating rainfall to enter the tank. The next day it rained again, but unlike the rains of May 1 and earlier that were absorbed by the soil, the 10 May rain immediately saturated the already-wet soil, producing an immediate tank-entering runoff. These rainy and rain-influenced data periods must also.be rejected from the suite of data selected for analysis because they do not provide information that relates to the liquid integrity of the LLLW-containing portion of the tank.

The liquid integrity of the GAAT was established using a statistical inference test. The statistical inference was based upon multiple regression analyses of the short-term volume trends in the tanks. The choice of a time interval for the regression analysis is subjective-the best analysis interval is one that is sufficiently long to average through the diurnal and other small-scale fluctuations in the data, yet sufficiently short that many such analysis periods could be abstracted from the data between rainy periods. For the work described here, an analysis period of $48 \mathrm{~h}$ was selected; this duration was chosen for two reasons: first, it met the long-enough/short-enough criteria just discussed, and second, a 48-hour analysis period is what is used in leak testing the FFA Category "C" LLLW tanks at ORNL whose volume capacity is greater than 3,000 gal.

The regression analysis entailed first identifying and abstracting as many usable $48 \mathrm{~h}$ data segments as possible from the five months of available data. ${ }^{6}$ For each of the segments, a least squares fit to the data was made and the regression parameters were tabulated, including the slope of the regression line, $\mathrm{m}$ (in gallons per hour), and the standard deviation of the $y$-estimate, $\sigma_{y}$ (in gallons). Table 4.2 illustrates this analysis, showing the segment starting date, $m$, and $\sigma_{y}$, for Tank W-5; these segments were abstracted from the data shown in Fig. 4.19. This table shows that there were $3148 \mathrm{~h}$ segments

${ }^{5}$ The data shown in the figure have been hand-edited to remove error characters and other large and obviously incorrect artifacts, as described in Sect. 4.1.2. While portions of the edited data shown in the figures may also contain undependable and therefore unusable data (for analysis purposes), these unusable portions cannot be removed from the data because there is no readily supportable physical explanation for them. To remove them would compromise the integrity of the analysis. Therefore, the analysis works around the undependable portions.

${ }^{6}$ Only one and one-half months of data were available for Tanks W-3 and W-4. 
abstracted from the five months of data, or 62 days' worth of data that was deemed usable out of about 150 days of data available.

While these data could have been summarily analyzed, it was likely that there were a few spurious points in the data sets that could be, and should be, rejected. To identify and reject these spurious points in a deterministic way, a data quality index was devised. This index utilized the standard deviation of the $m$ and $\sigma_{y}$ measures and was applied as follows: $\left(m, \sigma_{y}\right)$ pairs that fell outside an ellipse bounded by twice the standard deviation of $m$ on one axis and $\sigma_{y}$ on the other axis would be rejected; $\left(m, \sigma_{y}\right)$ pairs remaining within the ellipse would be retained and used in the inference test. For the data shown above, the standard deviation of the m-values was $0.39 \mathrm{gal} / \mathrm{h}$, and the standard deviation of the $\sigma_{\mathrm{y}}$-values was 5.6 gal. When twice these values are used to construct a bounding ellipse and the $\left(m, \sigma_{y}\right)$ pairs of W-5 data are plotted, an acceptance-rejection envelope plot is constructed, as shown in Fig. 4.25(a). This figure shows that all but three of the $\left(\mathrm{m}, \sigma_{\mathrm{y}}\right)$ pairs of data shown in Table 4.2 are acceptable, leaving 28 pairs of data for the statistical inference test. When these three $\left(m, \sigma_{y}\right)$ pairs are eliminated from the data suite shown in Table 4.2, the residual data have a mean slope (volume rate) of $\langle\mathrm{VR}\rangle=-0.038 \mathrm{gal} / \mathrm{h}$, with a standard deviation, $\sigma_{\mathrm{m}}$ of $0.307 \mathrm{gal} / \mathrm{h}$. A scatter plot of the W-5 data considered to be valid in this analysis is shown in Fig. 4.25(b). This plot shows that the 28 individual volume rate points are more or less uniformly scattered about $0 \mathrm{gal} / \mathrm{h}$. As a rule of thumb, normally distributed random data will have a peak-to-peak value that is about three times the standard deviation of the data set. This rule of thumb is seen to be valid when applied to the data shown in Fig. 4.25(b), suggesting that the data points are what would be expected from a normal population of values that had the mean and standard deviation of the W-5 data set.

The statistical significance of the $-0.038 \mathrm{gal} / \mathrm{h}$ volume rate and $0.307 \mathrm{gal} / \mathrm{h}$ standard deviation can be tested using the null hypothesis test. The $\mathrm{N}=28$ points of $\mathrm{W}-5$ data shown in Fig. 4.25 (b) has $\mathrm{N}-1$ $=27$ degrees of freedom, df. From these values, a t-statistic can be calculated as

$$
t_{s}=N^{1 / 2}<V R>/ \sigma_{m}=(28)^{1 / 2} \times(-0.038) /(0.307)=-0.655 \text {. }
$$

From a Student's $t$-distribution table, the critical value, $t_{c}$ corresponding to a $t$ with 27 degrees of freedom and a one-sided $5 \%$ significance level is 1.703 . Since $\left|t_{8}\right|<t_{c}$, we accept the null hypothesis and conclude that the measured average volume rate, $\langle\mathrm{VR}\rangle$, for $\mathrm{W}-5$ is the same as $0 \mathrm{gal} / \mathrm{h}$.

This same analysis was conducted on the remaining seven tanks of interest here. The appendix shows accept-reject diagrams, together with a scatter plot of the valid volume rate data summary, for each of the tanks. Table 4.3 summarizes the results of the inference test performed on each of the tanks. This table shows that we accept the null hypothesis that the average volume rate is $0 \mathrm{gal} / \mathrm{h}$ for all of the tanks, indicating that the tanks are therefore tight, except for W-7. For W-7, we conclude that the average 

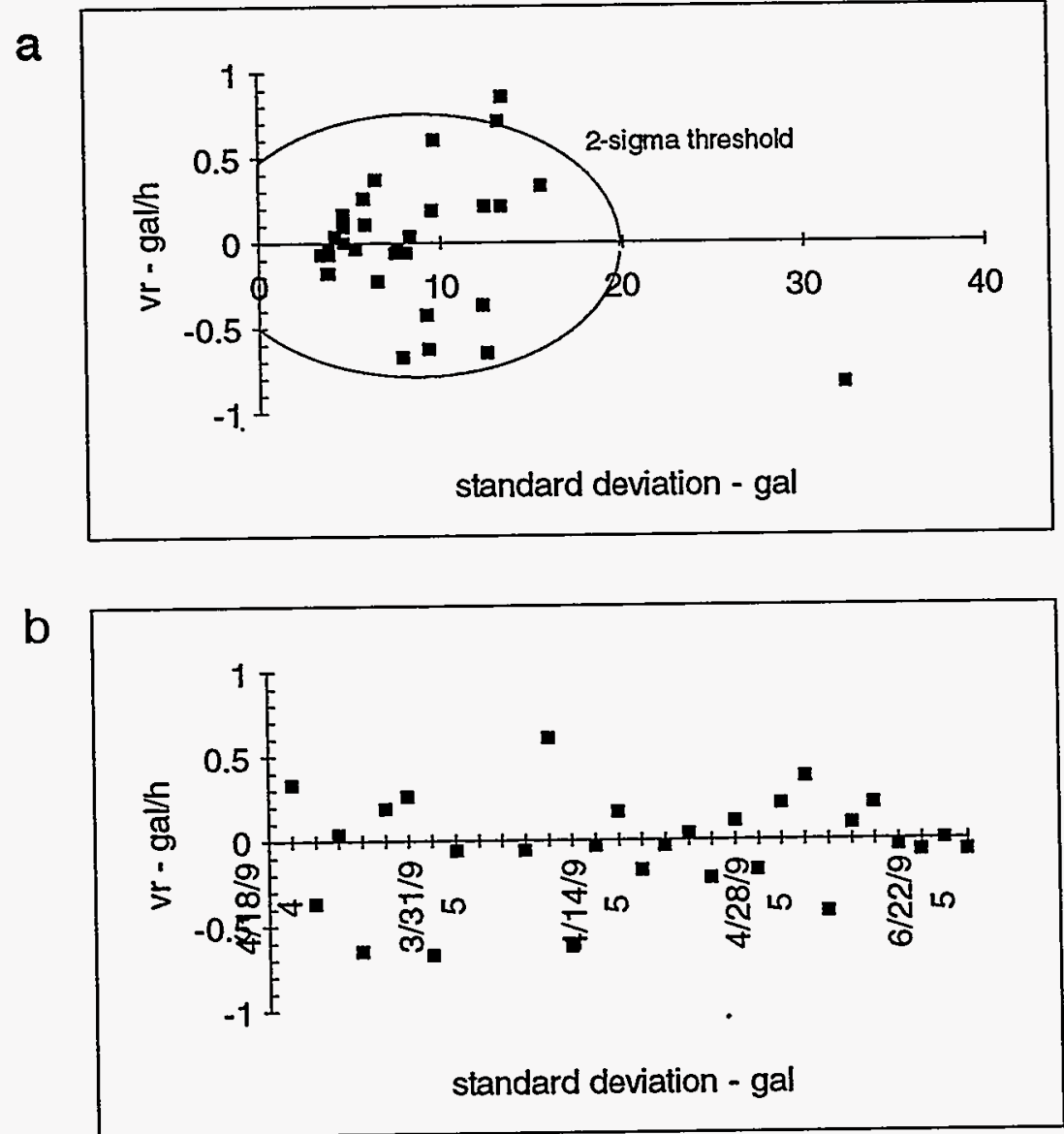

Fig. 4.25. Tank W-5: (a) CVR and noise analysis; (b) scatter plot of valid volume rate estimates. 
55

Table 4.2. Regression statistics for Tank W-5

\begin{tabular}{|c|c|c|}
\hline Segment Date & $\underset{(\mathrm{gal} / \mathrm{h})}{\mathrm{m}}$ & $\begin{array}{r}\sigma_{y} \\
\text { (gal) }\end{array}$ \\
\hline $04 / 18 / 94$ & 0.85 & 13.4 \\
\hline $04 / 20 / 94$ & 0.33 & 15.6 \\
\hline $04 / 22 / 94$ & -0.37 & 12.3 \\
\hline $04 / 24 / 94$ & 0.04 & 8.3 \\
\hline $04 / 26 / 94$ & -0.65 & 12.5 \\
\hline $04 / 28 / 95$ & 0.19 & 9.5 \\
\hline $03 / 29 / 95$ & 0.26 & 5.8 \\
\hline $03 / 31 / 95$ & -0.67 & 7.9 \\
\hline $04 / 02 / 95$ & -0.06 & 7.5 \\
\hline $04 / 04 / 95$ & -0.83 & 32.2 \\
\hline $04 / 28 / 95$ & 0.19 & 9.5 \\
\hline $03 / 29 / 95$ & 0.26 & 5.8 \\
\hline $03 / 31 / 95$ & -0.67 & 7.9 \\
\hline $04 / 02 / 95$ & -0.06 & 7.5 \\
\hline $04 / 04 / 95$ & -0.83 & 32.2 \\
\hline $04 / 18 / 94$ & 0.85 & 13.4 \\
\hline $04 / 20 / 94$ & 0.33 & 15.6 \\
\hline $04 / 22 / 94$ & -0.37 & 12.3 \\
\hline $04 / 24 / 94$ & 0.04 & 8.3 \\
\hline $04 / 26 / 94$ & -0.65 & 12.5 \\
\hline $04 / 28 / 95$ & 0.19 & 9.5 \\
\hline $03 / 29 / 95$ & 0.26 & 5.8 \\
\hline $03 / 31 / 95$ & -0.67 & 7.9 \\
\hline $04 / 02 / 95$ & -0.06 & 7.5 \\
\hline $04 / 04 / 95$ & -0.83 . & 32.2 \\
\hline $04 / 06 / 95$ & 0.71 & 13.3 \\
\hline $04 / 08 / 95$ & -0.06 & 8.1 \\
\hline $04 / 10 / 95$ & 0.60 & 9.8 \\
\hline $04 / 12 / 95$ & -0.63 & 9.3 \\
\hline $04 / 14 / 95$ & -0.03 & 5.3 \\
\hline $04 / 16 / 95$ & 0.17 & 4.7 \\
\hline $04 / 18 / 95$ & -0.18 & 3.8 \\
\hline $04 / 20 / 95$ & -0.03 & 7.7 \\
\hline $04 / 22 / 95$ & 0.04 & 4.2 \\
\hline $04 / 24 / 95$ & -0.23 & 6.5 \\
\hline
\end{tabular}


56

Table 4.2. (continued)

\begin{tabular}{ccc}
\hline Segment Date & $\begin{array}{c}\mathbf{m} \\
\text { (ga//h) }\end{array}$ & $\begin{array}{c}\boldsymbol{\sigma}_{\mathbf{y}} \\
\text { (gal) }\end{array}$ \\
\hline $04 / 26 / 95$ & 0.11 & 5.9 \\
$04 / 28 / 95$ & -0.18 & 3.9 \\
$04 / 30 / 95$ & 0.21 & 12.4 \\
$05 / 02 / 95$ & 0.37 & 6.4 \\
$05 / 04 / 95$ & -0.43 & 9.2 \\
$05 / 06 / 95$ & & \\
$05 / 08 / 95$ & 0.10 & 4.7 \\
$06 / 20 / 95$ & 0.21 & 13.3 \\
$06 / 22 / 95$ & -0.04 & 3.9 \\
$06 / 30 / 95$ & -0.07 & 3.4 \\
$07 / 02 / 95$ & 0.00 & 4.7 \\
\hline
\end{tabular}

volume rate measured over the five months of data used in the analysis is statistically different from zero. It is noted here that this analysis does not suggest that W-7 is leaking, only that the apparent volume change (volume losses, in this case) is greater than would be expected from the noise or uncertainty in the volume measurement over the five months of data analyzed.

Table 4.3. Summary of results from statistical inference test

\begin{tabular}{ccccccc}
\hline Tank ID & $\mathbf{N}$ & $<$ VR $>$ & $\sigma_{\mathbf{m}}$ & $\mathbf{t}_{\mathbf{s}} \mid$ & $\mathbf{t}_{\mathbf{c}}$ & $\begin{array}{c}\text { t-test result } \\
\text { (at 5\% conf.) }\end{array}$ \\
\hline W-3 & 10 & 0.021 & 0.14 & 0.474 & 1.833 & accept \\
W-4 & 10 & -0.017 & 0.06 & 0.896 & 1.833 & accept \\
W-5 & 28 & -0.038 & 0.307 & 0.655 & 1.703 & accept \\
W-6 & 21 & -0.085 & 0.574 & 0.679 & 1.725 & accept \\
W-7 & 27 & -0.483 & 1.336 & 1.879 & 1.706 & reject \\
W-8 & 29 & 0.228 & 0.723 & 1.698 & 1.701 & accept \\
W-9 & 25 & 0.102 & 0.389 & 1.311 & 1.711 & accept \\
W-10 & 23 & 0.347 & 1.35 & 1.233 & 1.717 & accept \\
\hline
\end{tabular}

\subsubsection{Minimum Detectable Leak}

To be useful, a liquid integrity monitoring program should be able to detect a loss (or change) in liquid integrity in a timely fashion. The analysis of the data used to assess the external (conductivity) method showed that this method could be used as a sensitive release detection scheme, provided that any 
LLLW released from a tank drained into an instrumented dry well. To gain a sense of the utility and practicality of the internal (level change) method, the performance of the internal method can be estimated from the results of the regression analysis performed on the GAAT, such as that shown in Table 4.2. These data can be used to estimate the minimum leak that could be detected in each tank for specified performance criteria, based on a $48 \mathrm{~h}$ data segment, and using the in-tank instrumentation "as is," following the procedures developed by the Environmental Protection Agency (EPA) to evaluate the performance of leak detection methods.

For methods used to test underground storage tanks for leaks, the EPA requires a probability of false alarm $\left(\mathrm{P}_{\mathrm{FA}}\right)$ of no more than $5 \%$ and a probability of detection $\left(\mathrm{P}_{\mathrm{D}}\right)$ of at least $95 \%$ against some specified leak rate (usually $0.2 \mathrm{gal} / \mathrm{h}$ in the case of monthly testing). Using these $\mathrm{P}_{D}$ and $\mathrm{P}_{\mathrm{FA}}$ values as the desired performance for the internal liquid integrity assessment method, the EPA shows that the threshold, $\mathrm{T}$, required to obtain a $\mathrm{P}_{\mathrm{FA}}$ of $5 \%$ can be determined from a data set as follows:

$$
\mathrm{P}\{\mathrm{t} \geq(\mathrm{T}-\mathrm{B} / \mathrm{\sigma}\}=0.05,
$$

where $B$ is the bias of the data used for the estimate, $\sigma$ is the standard deviation of the data, and $t$ is the one-sided t-statistic for $\mathrm{N}-1$ degrees of freedom. For the regression statistics obtained for W-5 (see Table 4.2), the bias is essentially zero; therefore, $T_{05}=$ to, or $T_{05}=(1.703)(0.307)=0.523 \mathrm{gal} / \mathrm{h}$ to achieve a $P_{F A}$ of $5 \%$ on a single test.

The EPA shows that the minimum detectable leak rate with a $P_{D}$ of $95 \%$ is twice the calculated threshold, $\mathrm{T}_{05}$. When these calculations are applied to the valid, 48-h data segments shown in Table 4.2, performance estimates can be developed for each tank. The results of these calculations are shown in Table 4.4. This table indicates that the pressure sensors installed in W-3 and W-4 for this assessment achieved a level of performance that is comparable to that demanded by the EPA for USTs, while the conductivity sensors on Tanks W-5, W-6, and W-9 gave results that are close to $1 \mathrm{gal} / \mathrm{h}$. The sensors on Tanks W-7 and W-10, however, were much noisier, resulting in poor performance and a minimum detectable leak rate of almost $5 \mathrm{gal} / \mathrm{h}$.

Table 4.4. Performance estimates for $48 \mathrm{~h}$ integrity tests using the GAAT instrumentation

\begin{tabular}{ccc}
\hline Tank ID & $\begin{array}{c}\text { Threshold } \\
\left(\mathbf{P}_{\mathbf{r A}}=\mathbf{5 \%}\right) \\
(\mathrm{gal} / \mathbf{h})\end{array}$ & $\begin{array}{c}\text { Minimum Detectable Leak Rate } \\
\left.\mathbf{P}_{\mathbf{D}}=95 \%\right) \\
(\mathrm{gal} / \mathbf{h})\end{array}$ \\
\hline W-3 & 0.25 & 0.51 \\
W-4 & 0.11 & 0.22 \\
W-5 & 0.52 & 1.05 \\
W-6 & 0.99 & 1.98 \\
W-7 & 2.28 & 4.56
\end{tabular}


Table 4.4. (continued)

\begin{tabular}{ccc}
\hline Tank ID & $\begin{array}{c}\text { Threshold } \\
\left(\mathbf{P}_{\mathrm{FA}}=\mathbf{5} \%\right) \\
(\mathrm{gal} / \mathrm{h})\end{array}$ & $\begin{array}{c}\text { Minimum Detectable Leak Rate } \\
\left(\mathbf{P}_{\mathrm{D}}=95 \%\right) \\
(\mathrm{gal} / \mathrm{h})\end{array}$ \\
\hline W-8 & 1.23 & 2.46 \\
W-9 & 0.67 & 1.33 \\
W-10 & 2.32 & 4.64 \\
\hline
\end{tabular}

\subsubsection{Evaporation and Condensation}

As described in Chap. 2, the GAAT are ventilated by means of an air vent and a HOG system. Maintaining a weak vacuum on the tank, the HOG system draws air into the tank through the surface vent and exhausts that air into a process system that traps any airborne radioactive particles. Since air is exchanged between the inside of the tank and the outside of the tank, there is also an opportunity for water to be exchanged through the process of evaporation and condensation. For example, cold, dry air entering the headspace of a tank containing warmer water would be expected to absorb some of the water vapor in the tank before it was exhausted, because the air entering the tank could hold more moisture as it warmed, thereby evaporating some liquid. Similarly, warm, moist air entering the headspace of a tank containing cooler water, which could not hold as much moisture as it cooled, would be expected to condense some liquid into the tank before it was exhausted. The amount of evaporation or condensation depends upon several quantities, including the inlet and outlet air temperatures, inlet and outlet relative humidities, and the air sweep rate.

Since water in liquid form can be exchanged as a result of evaporation and condensation in the GAAT, it will have an effect on the water level in these tanks. Accordingly, it would be useful to measure the amount of evaporation and condensation that actually does occur and use those data to compensate the observed volume changes. However, since the GAAT are not equipped with the instrumentation necessary to make the needed measurements, the evaporation.and condensation can only be estimated by making a few assumptions and using the Clausius-Clapeyron equation,

$$
e_{s}=10^{(11.40-2353 / T)}
$$

where $e_{3}$ is the saturation vapor pressure, $r$ is relative humidity, and $T$ is air temperature in degrees Kelvin. The mass flow rate, $\Delta \mathrm{M}_{\mathrm{w}}$ can be calculated as

$$
\Delta M_{w}=\left(\frac{r_{0} e_{0}}{T_{o}}-\frac{r_{i} e_{i}}{T_{i}}\right)\left(\frac{F}{R_{m w}}\right)
$$

where $F$ is the volumetric flow rate of the air sweep system, $R_{\operatorname{mw}}$ is the gas constant for water vapor $\left(462 \mathrm{~J} \mathrm{~kg}^{-1} \mathrm{~K}^{-1}\right.$ ), and $\mathrm{i}$ and o denote inlet and outlet, respectively.

The assumptions that are needed are: (1) that the exhaust air is $100 \%$ saturated (i.e., there is $100 \%$ 
relative humidity) when it leaves the tank and that it does not condense back into the tank; (2) that the liquid in the tank presents a large and stable thermal mass to the air; and (3) that the exhaust air has come into equilibrium with the thermal mass. To the extent we also know or make a reasonable guess at the sweep rate and the water temperature in the tank, we can estimate the quantity of liquid exchanged in the air sweep by measuring the temperature and relative humidity of the inlet air.

By approximating a tank's inlet air temperature and relative humidity as that measured at ORNL's X-10 Met Tower, an estimate of evaporation and condensation can be made. In Fig. 4.26, the Met Tower data from March 27-July 30, 1995, were used, together with an assumed sweep rate of $40 \mathrm{scfm}$, to estimate the evaporation and condensation that could occur from one of the GAAT if all of the assumptions were valid. This plot, whose time span overlaps the 1995 volume time history data used in the inference test (Sect. 4.4.4), shows that during the spring of 1995, evaporation of up to about $0.2 \mathrm{gal} / \mathrm{h}$ would have been the dominant exchange mode, with condensation beginning to occur in early May as the inlet air warmed up and could hold more water. From about the middle of May through the end of July, the plot shows that evaporation losses were about matched by condensation gains. The heavy line in Fig. 4.26 shows the integrated or cumulative water loss over the four-month data interval. This curve shows a relatively steady evaporative loss from March 27 on, reaching about 130 gal around May 8. From this date through July 30 , the alternating evaporation and condensation cycles kept further volume losses small, totalling about 160 gal over the entire period.

While the evaporation/condensation calculations are not meant to be predictive in nature, they do illustrate that some liquid will be lost from the LLLW tanks over time and some liquid will be gained at other times. Since these losses and gains will be recorded as volume losses and gains in the tank, they should be accounted for in any attempt to precisely monitor the changes in liquid level in the tanks. The cumulative volume change data compared with the apparent volume change in W-7 (shown in Fig. 4.26) demonstrates that the losses and gains in W-7 are closely matched in both time and quantity with the evaporation/condensation calculations for a set of assumed conditions. Although this analysis is not intended to explain the losses in W-7 over time, and since it is speculated that the losses would exceed the gains over long (yearly) time intervals at ORNL, evaporation may be a significant factor in the longterm volume changes observed in W-7. The level changes in Tank W-7 were further analyzed by means of a separate file kept on the inactive tanks. The data in this file, which are maintained in a database, are recorded daily at $07: 00$ by the WOCC operator. Figure 4.27, a plot of the level (volume) changes in Tank W-7 from August 30, 1993-November 1,1995, clearly shows a seasonal cycle that could be related to evaporation/condensation processes. 


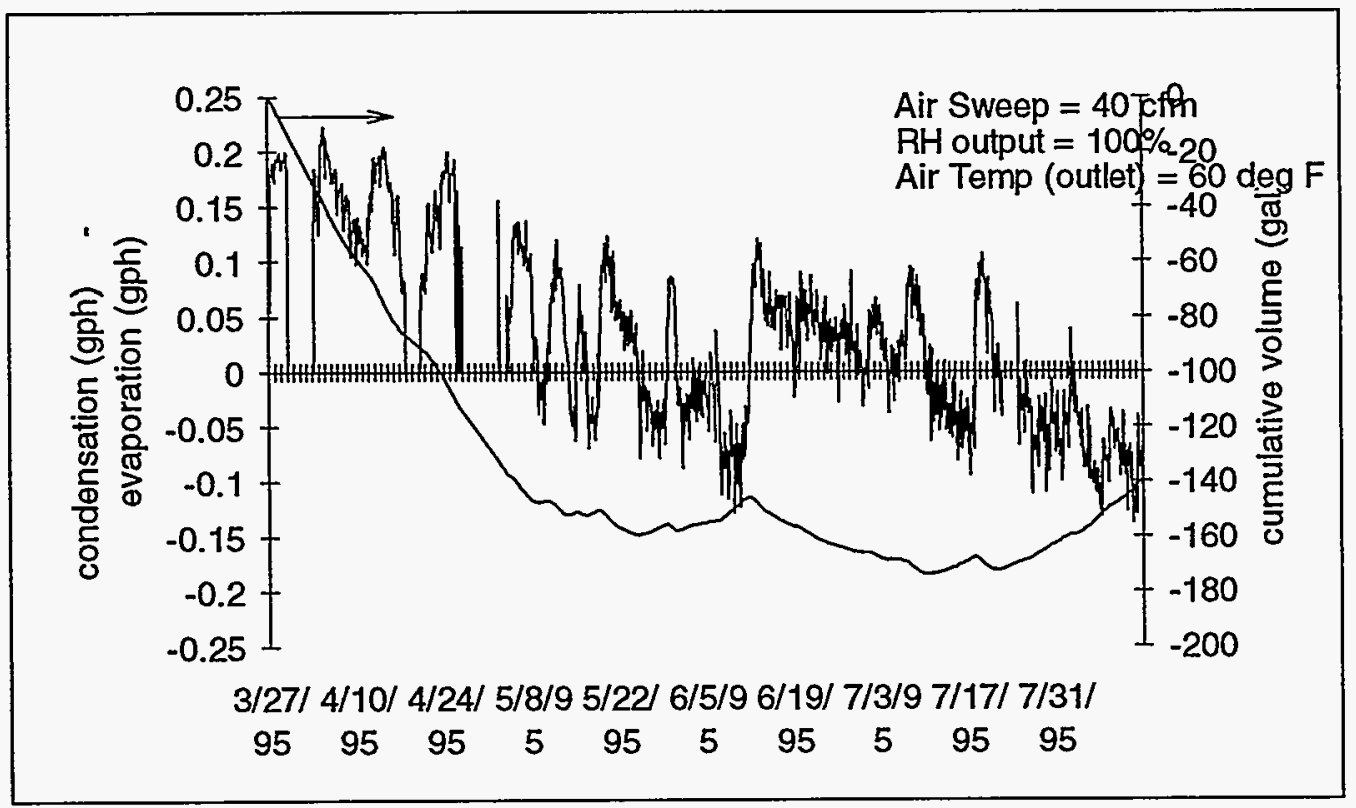

Fig. 4.26. Evaporation and condensation as modeled in an LLLW tank at ORNL (27 March to 30 July 1995).

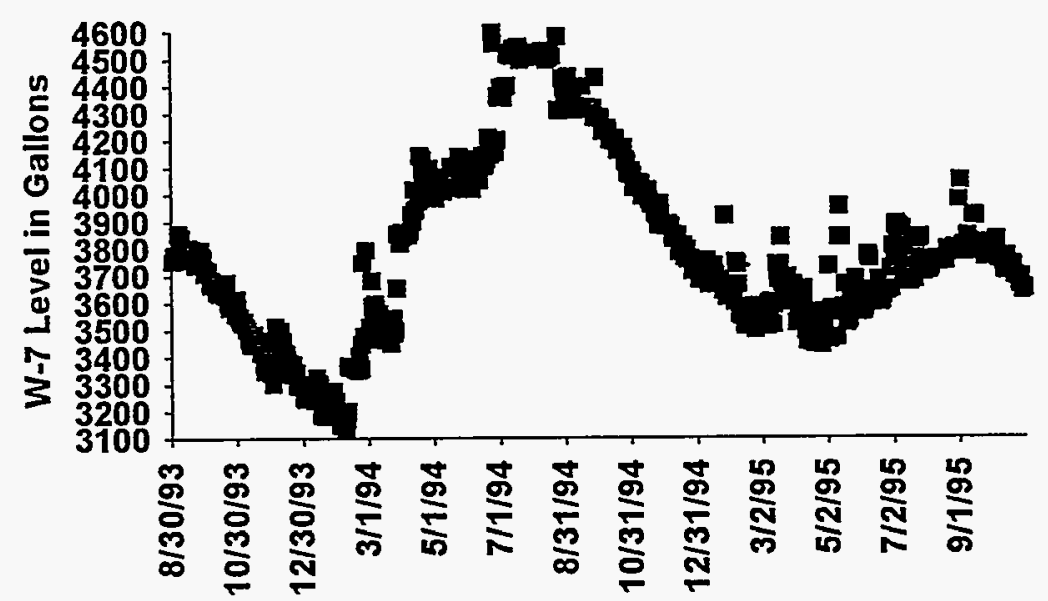

Fig. 4.27. Tank W-7 level (1 September 1993 through 1 November 1995). 


\section{CONCLUSIONS AND RECOMMENDATIONS}

The work described in this report examined the potential for monitoring the liquid integrity of the Gunite and associated tanks as part of the treatability study, utilizing an internal method and an external method. It was concluded from this work that the external method could be used to detect releases as small as 0.5 gal from each tank by means of sensors installed semi-permanently in the dry wells. It was also concluded that the internal method could be used to detect releases as small as 0.2 to $0.5 \mathrm{gal} / \mathrm{h}$ in two of the tanks and slightly higher in the other tanks, with sensors that are either presently installed or that can be installed. Further, the analysis indicated that at least seven of the GAAT (W-3, W-4, W-5, W-6, W-8, W-9, and W-10) show no signs of leakage.

The external method relies on the detection of a significant change in the electrical conductivity of the water in the dry well adjacent to a tank; the detection of such a change would be indicative of a release. For the preliminary evaluation of this method, conductivity, temperature and water level sensors were installed in three tanks (W-3, W-4, and W-8) and in the three dry wells associated with these tanks (D-3, D-4, and D-8). Data from the sensors were collected and analyzed over a four-month period in order to assess the potential of the external method, backed up with additional data such as video inspections of the dry wells. The work showed that the dry wells can in principle be instrumented with the necessary probes and that the sensitivity of the method is very good. A release as small as 0.5 gal of LLLW from a tank would be enough to cause a statistically significant change in the conductivity of the water in the dry well, taking into account fluctuations in both groundwater and LLLW conductivity data and assuming both a fully captured release and a slow and fully mixed flow through the dry well. The performance of the method may be degraded, however, during rainy periods or when water is entering the dry well sump from sources other than the concrete pad under the tank. The evaluation also showed that the current physical condition of some of the dry wells makes instrumentation installation and monitoring difficult. Dry Well D-4 had a layer of sediment at the bottom, and D-8 contained some rubble. In both cases, the amount of material at the bottom was enough to prevent the probes from being installed below the water level. In addition, D-8 had several shallow drain pipes that contributed water during rainfall events. Accordingly, it is likely that at least some of the dry wells, particularly in the STF, will need to be cleaned out or otherwise modified before the external method can be successfully applied to them. In December 1995, with a bucket auger being utilized to move the sediment aside, the conductivity and level instruments in D-3 and D-4 were successfully reinstalled.

The internal method for assessing the liquid integrity of the GAAT relies on precise measurements of the change in volume in each tank over time. Six of the tanks are equipped with level sensors. The data from these sensors are recorded and archived at ORNL and are available for immediate analysis. The data from two of these six tanks exhibited high noise, which limited the certainty of the analysis results. Two of the tanks required that a pressure sensor be installed for the purpose of this assessment. It was determined from an examination of data on groundwater levels that, at both the NTF and STF, the drain system appears to keep groundwater below the level of the tanks. Accordingly, groundwater is not a factor in any leakage in or out that is identified in this analysis. It was also determined during the analysis that most of the tanks exhibit a pronounced correlation between observed volume change and rainfall events, leading to the conclusion that in the case of at least three tanks almost all of the volume increases can be attributed to rain-related leakage into the tank. Based on a statistical inference test on data segments abstracted from dry (non-rainy) periods spanning five months' worth of tank level data, it was determined that all of the tanks except W-7 were tight insofar as leakage from the tank was concerned. Tank W-7 showed a slight volume loss over the assessment period, and W-10 showed an anomalous leakage into the tank that did not seem to be rain-related. Because of the sensor noise, however, the 
results from W-7 and W-10 are tentative, and further investigation is needed before a conclusive result can be reached. Evaporation and instrument calibration factors may contribute to the observed volume changes. These are examples of such factors.

Based upon this work, the following recommendations are made:

- Finalize the evaluation of the feasibility of the external dry well monitoring method. To accomplish this, the following activities should be conducted in the near term:

- Undertake visual and videotape inspections of Dry Wells D-5, D-6, D-7, D-9, and D-10 so as to determine the amount of fill material at the bottom of each and to assess the efficacy of the drain system leading away from each dry well.

- Select one or more of the dry wells in the STF (for example, D-7 or D-8) for an investigation of the practicality of removing the bottom materials or otherwise clearing or modifying the dry wells, to allow the installation of the necessary equipment.

- Install instrumentation in the STF dry wells that can be cleared or modified relatively easily.

- Begin data collection on D-3 and D-4 as well as dry wells in the STF that can be easily instrumented.

- Conduct routine external dry well monitoring to further assess instrument performance and develop a database of baseline conditions in the dry wells.

- To futher validate the method, devise and implement a demonstration that would involve a simulated release from a tank and subsequent detection in a dry well. ased on conditions, resources and program requirements, instrument plans for additional dry wells in the STF.

- Make a final assessment of tank integrity using available data.

- Investigate and correct excessive W-7 and W-10 level sensor noise..

- Finalize assessment criteria.

- Investigate the feasibility of installing relative humidity, temperature, and flow sensors into the hot off-gas duct in order to quantify the effects of evaporation and condensation.

- Implement the internal/external integrity assessment method as soon as practical before the in-tank operations begin, so as to establish a set of baseline data. 


\section{REFERENCES}

BNI (Bechtel National), and MMES (Martin Marietta Energy Systems, Inc.) 1982. "ORNL Observational Approach Workshop On Inactive LLLW Tanks," presented in October 1992 at ORNL (Oak Ridge National Laboratory), Oak Ridge, Tenn.

EPA (U.S. Environmental Protection Agency), Office of Underground Storage Tanks 1990. Standard Test Procedures for Evaluating Leak Detection Methods: Automatic Tank Gauging Systems, EPA/530/UST-90/006, Midwest Research Institute, Falls Church, Va.

EPA, DOE (U.S. Dept. Of Energy), and TDEC (Tennessee Department of Environment and Conservation) 1992. Federal Facility Agreement for the Oak Ridge Reservation, DOE/OR-1014, MMES. Oak Ridge, Tenn.

Fleagle, R. G., and J. A. Businger 1980. An Introduction to Atmospheric Physics, Academic Press, Orlando, Fla.

LMES and Vista Research, 1995. Detailed Leak Detection Test Plan and Schedule for Oak Ridge National Laboratory Liquid Low-Level Waste Active Tanks, DOE/OR/01-1129\&D2. LMES, Oak Ridge, Tenn. 
- 


\section{Appendix \\ ACCEPT/REJECT DIAGRAMS AND \\ DATA USED IN STATISTICAL INFERENCE TEST}


W-3: 48-hour Regression Analysis

\begin{tabular}{cccccc}
\hline & $\mathrm{m}$ & $\sigma_{n}$ & $r^{2}$ & $F$ & $\sigma_{y}$ \\
\hline $6 / 22 / 95$ & 0.16 & 0.03 & 0.47 & 40.2 & 2.4 \\
$7 / 3 / 95$ & 0.06 & 0.06 & 0.03 & 1.3 & 5.5 \\
$7 / 5 / 95$ & -0.22 & 0.04 & 0.43 & 35.3 & 3.6 \\
$7 / 7 / 95$ & 0.01 & 0.02 & 0.01 & 0.36 & 1.7 \\
$7 / 9 / 95$ & 0.07 & 0.05 & 0.04 & 2 & 4.9 \\
$7 / 11 / 95$ & -0.21 & 0.04 & 0.4 & 30.3 & 3.7 \\
$7 / 13 / 95$ & 0.04 & 0.04 & 0.02 & 0.73 & 4.3 \\
$7 / 15 / 95$ & 0.18 & 0.03 & 0.47 & 40 & 2.7 \\
$7 / 19 / 95$ & 0.15 & 0.03 & 0.27 & 17.4 & 3.4 \\
$8 / 2 / 95$ & -0.03 & 0.02 & 0.03 & 1.7 & 2.4 \\
\hline & & & & & \\
N: & 10 & & & & \\
Mean: & 0.021 & & & & 3.46 \\
Std Dev: & 0.1413 & & & & 1.199259 \\
2-sigma min: & -0.2616 & & & & 1.061482 \\
2-sigma max: & 0.303599 & & & & 5.858518
\end{tabular}




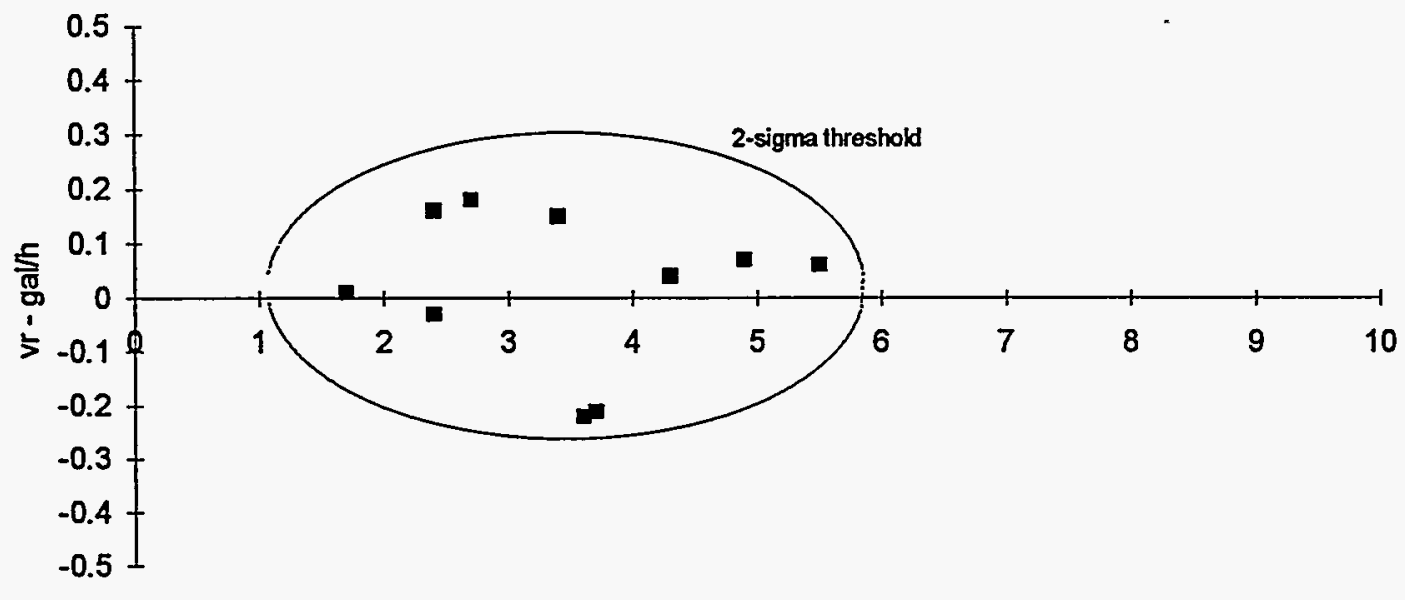

standard deviation - gal

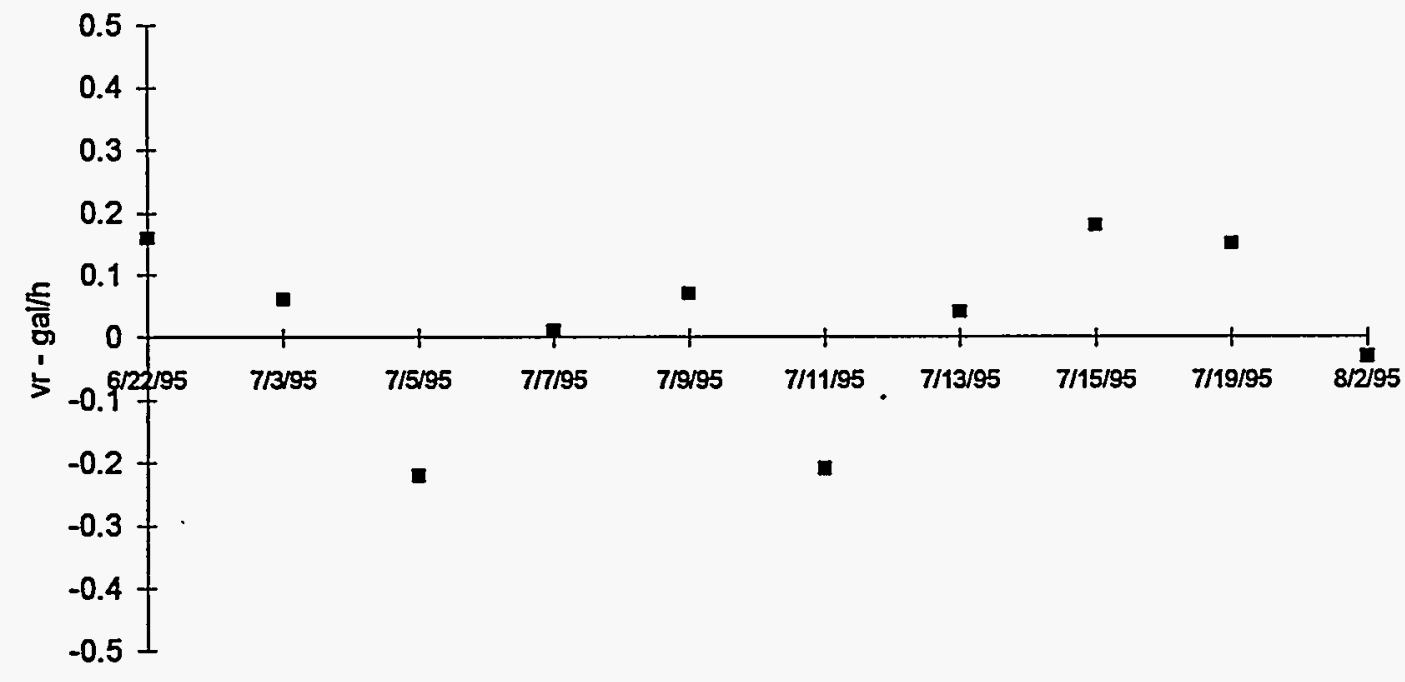


T-4: 48-hour Regression Analysis

\begin{tabular}{|c|c|c|c|c|c|}
\hline & $\mathrm{m}$ & $\sigma_{n}$ & $r^{2}$ & $F$ & $\sigma_{n}$ \\
\hline $6 / 22 / 95$ & 0 & 0.04 & 0 & 0 & 3.6 \\
\hline $6 / 24 / 95$ & -0.09 & 0.09 & 0.02 & 1 & 8.9 \\
\hline $6 / 28 / 95$ & 0.01 & 0.04 & 0 & 0.04 & 3.9 \\
\hline $6 / 30 / 95$ & 0.1 & 0.1 & 0.02 & 0.9 & 9.6 \\
\hline $7 / 2 / 95$ & 0.05 & 0.03 & 0.06 & 2.8 & 3 \\
\hline $7 / 4 / 95$ & -0.09 & 0.04 & 0.09 & 4.5 & 4 \\
\hline $7 / 6 / 95$ & -0.08 & 0.03 & 0.11 & 5.4 & 3.3 \\
\hline $7 / 8 / 95$ & 0.02 & 0.03 & 0.01 & 0.47 & 2.5 \\
\hline $7 / 10 / 95$ & 0.01 & 0.03 & 0 & 0.13 & 2.9 \\
\hline $7 / 12 / 95$ & 0 & 0.03 & 0 & 0 & 2.6 \\
\hline $7 / 14 / 95$ & 0.04 & 0.04 & 0.01 & 0.7 & 4.1 \\
\hline $7 / 16 / 95$ & 0.17 & 0.04 & 0.29 & 18.7 & 3.8 \\
\hline $7 / 18 / 95$ & -0.13 & 0.06 & 0.09 & 4.8 & 5.6 \\
\hline $\mathbf{N}:$ & 13 & & & & \\
\hline Mean: & 0.000769 & & & & 4.446154 \\
\hline Std Dev: & 0.083213 & & & & 2.281672 \\
\hline 2-sigma min: & -0.16566 & & & & -0.11719 \\
\hline 2-sigma max: & 0.167195 & & & & 9.009497 \\
\hline
\end{tabular}


A-6

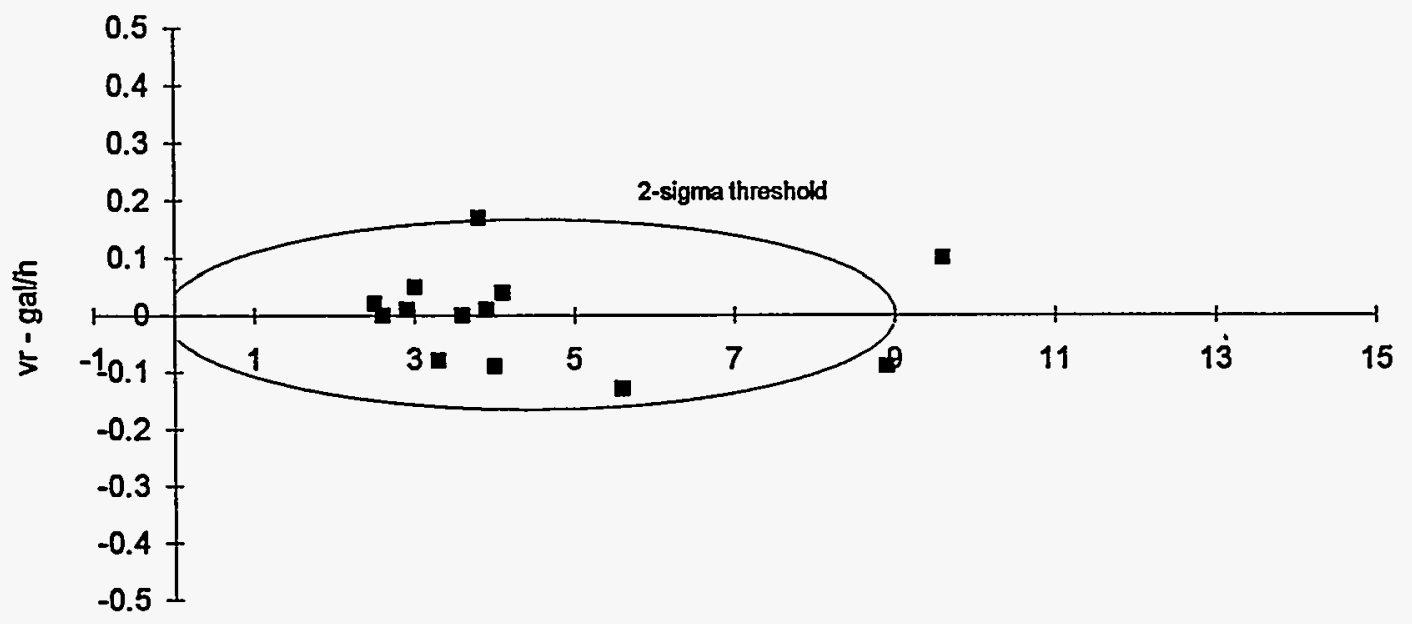

standard deviation - gal

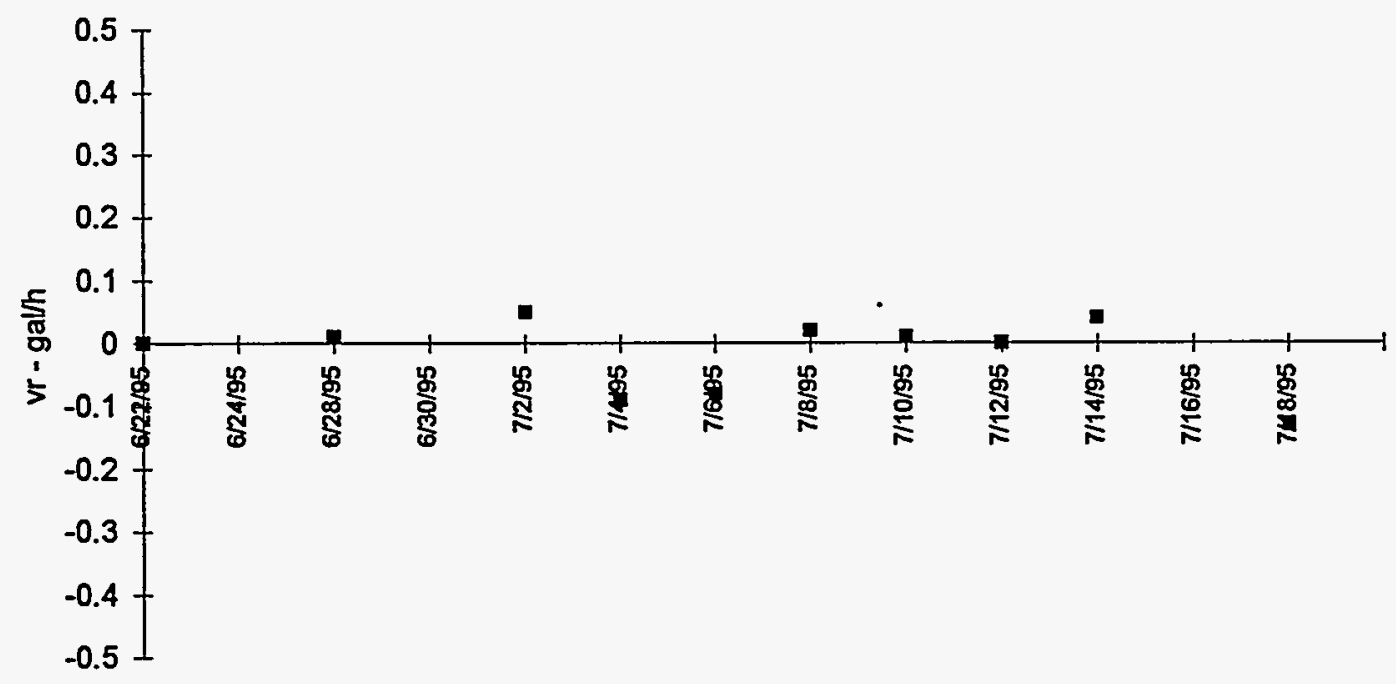


W-5: 48-hour Regression Analysis

\begin{tabular}{|c|c|c|c|c|c|c|}
\hline & $\mathrm{m}$ & $\mathrm{m}$ & $\sigma_{n}$ & $r^{2}$ & $F$ & $\sigma_{y}$ \\
\hline $4 / 18 / 94$ & 0.85 & 0.85 & 0.14 & 0.45 & 37.6 & 13.4 \\
\hline $4 / 20 / 94$ & 0.33 & 0.33 & 0.16 & 0.08 & 4.1 & 15.6 \\
\hline $4 / 22 / 94$ & -0.37 & -0.37 & 0.13 & 0.15 & 8.3 & 12.3 \\
\hline $4 / 24 / 94$ & 0.04 & 0.04 & 0.09 & 0 & 0.19 & 8.3 \\
\hline $4 / 26 / 94$ & -0.65 & -0.65 & 0.13 & 0.36 & 25.3 & 12.5 \\
\hline $4 / 28 / 94$ & 0.19 & 0.19 & 0.1 & 0.08 & 3.6 & 9.5 \\
\hline 3/29/95 & 0.26 & 0.26 & 0.06 & 0.28 & 18.4 & 5.8 \\
\hline 3/31/95 & -0.67 & -0.67 & 0.08 & 0.6 & 67.7 & 7.9 \\
\hline $4 / 2 / 95$ & -0.06 & -0.06 & 0.08 & 0.02 & 0.78 & 7.5 \\
\hline $4 / 4 / 95$ & -0.83 & -0.83 & 0.34 & 0.11 & 6.1 & 32.2 \\
\hline $4 / 6 / 95$ & 0.71 & 0.71 & 0.14 & 0.37 & 26.5 & 13.2 \\
\hline $4 / 8 / 95$ & -0.06 & -0.06 & 0.09 & 0.01 & 0.49 & 8.1 \\
\hline 4/10/95 & 0.6 & 0.6 & 0.1 & 0.43 & 34.9 & 9.7 \\
\hline 4/12/95 & -0.63 & -0.63 & 0.1 & 0.48 & 43.4 & 9.3 \\
\hline 4/14/95 & -0.03 & -0.03 & 0.06 & 0.01 & 0.4 & 5.3 \\
\hline 4/16/95 & 0.17 & 0.17 & 0.05 & 0.21 & 12.1 & 4.7 \\
\hline 4/18/95 & -0.18 & -0.18 & 0.04 & 0.32 & 21.7 & 3.8 \\
\hline $4 / 20 / 95$ & -0.03 & -0.03 & 0.08 & 0 & 0.2 & 7.7 \\
\hline 4/22/95 & 0.04 & 0.04 & 0.04 & 0 & 0.7 & 4.2 \\
\hline $4 / 24 / 95$ & -0.23 & -0.23 & 0.07 & 0.19 & 11.2 & 6.5 \\
\hline $4 / 26 / 95$ & 0.11 & 0.11 & 0.06 & 0.07 & 3.4 & 5.9 \\
\hline 4/28/95 & -0.18 & -0.18 & 0.04 & 0.29 & 10.1 & 3.9 \\
\hline $4 / 30 / 95$ & 0.21 & 0.21 & 0.13 & 0.05 & 2.7 & 12.4 \\
\hline $5 / 2 / 95$ & 0.37 & 0.37 & 0.07 & 0.41 & 31.5 & 6.4 \\
\hline $5 / 4 / 95$ & -0.43 & -0.43 & 0.1 & 0.31 & 20.6 & 9.2 \\
\hline $5 / 6 / 95$ & 0.1 & 0.1 & 0.05 & 0.1 & 3.7 & 4.7 \\
\hline $5 / 8 / 95$ & 0.21 & 0.21 & 0.14 & 0.05 & 2.3 & 13.3 \\
\hline 6/20/95 & -0.04 & -0.04 & 0.04 & 0.03 & 1.3 & 3.9 \\
\hline $6 / 22 / 95$ & -0.07 & -0.07 & 0.03 & 0.1 & 4.9 & 3.4 \\
\hline $6 / 30 / 95$ & 0 & 0 & 0.05 & 0 & 0 & 4.7 \\
\hline $7 / 2 / 95$ & -0.07 & -0.07 & 0.04 & 0.05 & 2.6 & 3.9 \\
\hline
\end{tabular}

$\begin{array}{ccc}\text { N: } & 31 & 31 \\ \text { Mean: } & -0.01097 & -0.01097 \\ \text { Std Dev: } & 0.386948 & 0.386948 \\ \text { 2-sigma } & -0.78486 & -0.78486 \\ \text { min: } & & \\ \text { 2-sigma } & 0.762929 & 0.762929 \\ \text { max: } & & \end{array}$




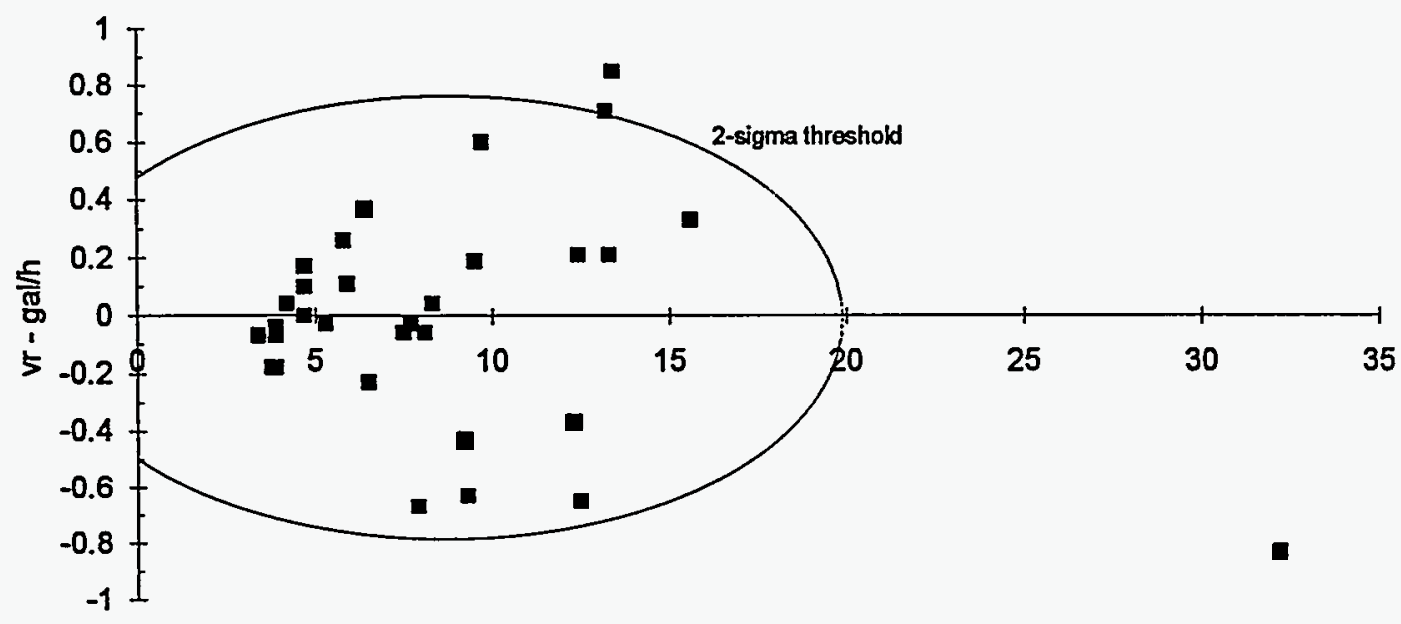

standard deviation - gal

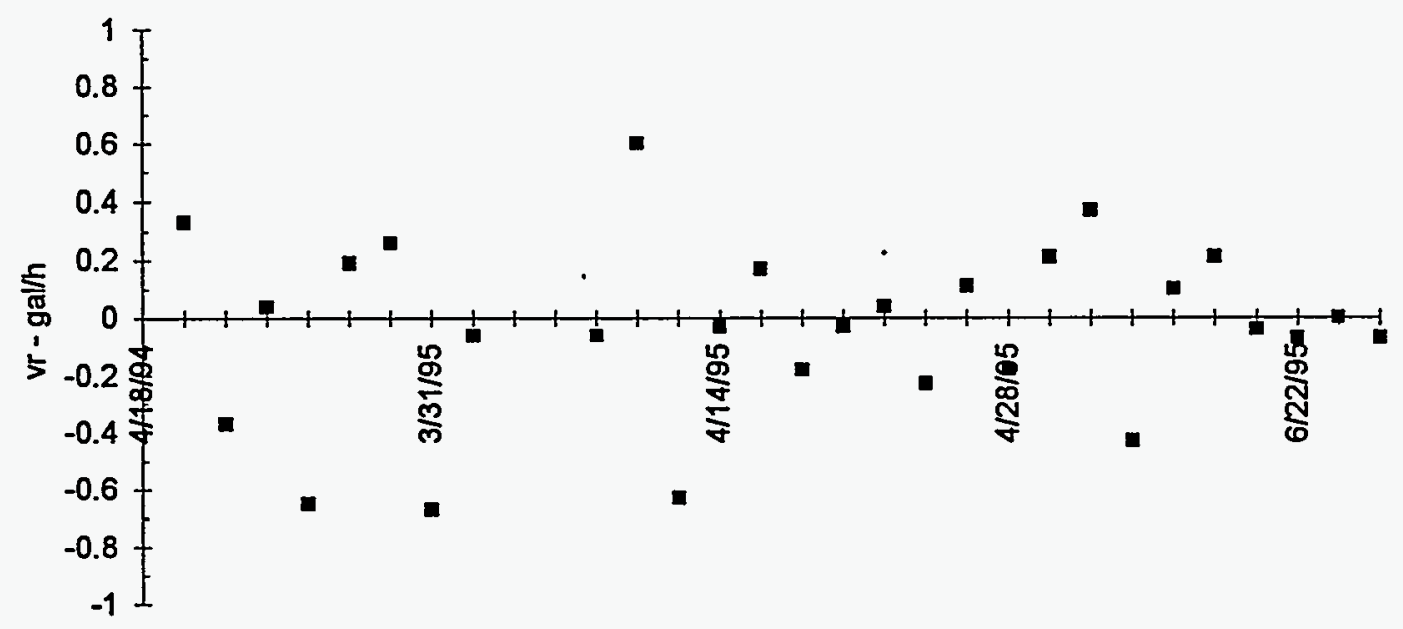

standard deviation - gal 
W-6: 48-hour Regression Analysis

\begin{tabular}{cccccc}
\hline & $\mathrm{m}$ & $\sigma_{n}$ & $r^{2}$ & $\mathrm{~F}$ & $\sigma_{y}$ \\
\hline $3 / 29 / 95$ & -0.05 & 0.09 & 0 & 0.4 & 8.7 \\
$3 / 31 / 95$ & 0.13 & 0.26 & 0 & 0.3 & 24.8 \\
$4 / 2 / 95$ & 0.34 & 0.15 & 0.1 & 5.5 & 14 \\
$4 / 4 / 95$ & -3.96 & 0.5 & 0.6 & 62 & 48.3 \\
$4 / 6 / 95$ & 0.77 & 0.2 & 0.25 & 15.4 & 18.9 \\
$4 / 8 / 95$ & -0.18 & 0.15 & 0.03 & 1.5 & 14.1 \\
$4 / 10 / 95$ & -0.28 & 0.19 & 0.04 & 2.1 & 18.4 \\
$4 / 12 / 95$ & -0.8 & 0.16 & 0.34 & 23.9 & 15.7 \\
$4 / 14 / 95$ & -0.11 & 0.13 & 0.01 & 0.7 & 12.4 \\
$4 / 16 / 95$ & 1.1 & 0.2 & 0.4 & 30.3 & 19.7 \\
$4 / 18 / 95$ & -0.16 & 0.07 & 0.1 & 4.8 & 7.2 \\
$4 / 20 / 95$ & -0.27 & 0.28 & 0.02 & 0.9 & 27.2 \\
$4 / 22 / 95$ & 0.41 & 0.4 & 0.16 & 6.6 & 15.2 \\
$4 / 24 / 95$ & -0.78 & 0.15 & 0.36 & 25.6 & 14.7 \\
$4 / 26 / 95$ & 0.56 & 0.46 & 0.03 & 1.4 & 44.6 \\
$4 / 28 / 95$ & -0.45 & 0.12 & 0.25 & 15.3 & 11.1 \\
$4 / 30 / 95$ & 0.85 & 0.2 & 0.3 & 19 & 18.7 \\
$5 / 2 / 95$ & -0.39 & 0.1 & 0.25 & 15.3 & 9.6 \\
$5 / 4 / 95$ & -0.63 & 0.49 & 0.03 & 1.6 & 47 \\
$5 / 6 / 95$ & -0.05 & 0.1 & 0 & 0.39 & 8.9 \\
$5 / 8 / 95$ & 2.35 & 0.31 & 0.55 & 57.3 & 29.9 \\
$6 / 20 / 95$ & -0.34 & 0.2 & 0.1 & 3 & 19.1 \\
$6 / 22 / 95$ & -0.01 & 0.07 & 0 & 0.02 & 7 \\
$6 / 30 / 95$ & -1.4 & 0.26 & 0.38 & 28 & 25.4 \\
$7 / 2 / 95$ & -0.12 & 0.05 & 0.11 & 6 & 4.8 \\
\hline & & & & &
\end{tabular}

N: $\quad 25$

Mean: $\quad-0.1388$

19.416

Std Dev: 1.08356

12.13685

2-sigma min: -2.30592

$-4.85769$

2-sigma max: 2.02832

43.68969 
A- 10
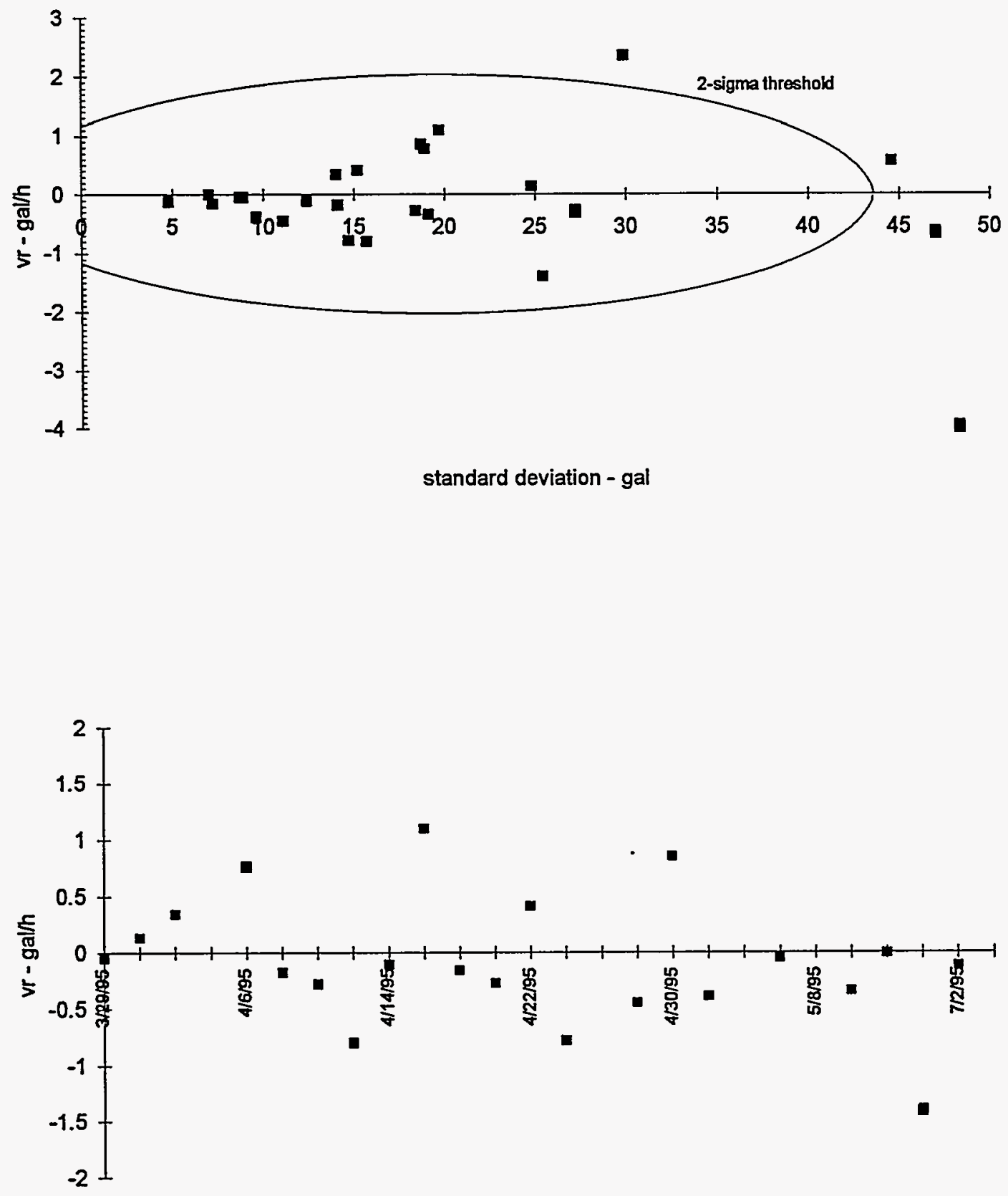


\section{A-11}

W-7: 48-hour Regression Analysis

\begin{tabular}{|c|c|c|c|c|c|}
\hline & $\mathrm{m}$ & $\sigma_{n}$ & $r^{2}$ & $F$ & $\sigma_{y}$ \\
\hline 4/19/94 & -0.76 & 0.16 & 0.32 & 21.5 & 15.8 \\
\hline $4 / 21 / 94$ & -1.8 & 0.19 & 0.67 & 91.5 & 18.1 \\
\hline $4 / 23 / 94$ & 0.25 & 0.08 & 0.16 & 8.9 & 8 \\
\hline $4 / 25 / 94$ & -0.97 & 0.12 & 0.59 & 66.3 . & 11.5 \\
\hline $4 / 27 / 94$ & -1.24 & 0.25 & 0.36 & 25.5 & 23.6 \\
\hline $4 / 29 / 94$ & 0.05 & 0.04 & 0.03 & 1.48 & 3.8 \\
\hline 3/29/95 & 0.53 & 0.08 & 0.48 & 43.7 & 7.8 \\
\hline 3/31/95 & -0.34 & 0.1 & 0.19 & 10.4 & 10.1 \\
\hline $4 / 2 / 95$ & -1.6 & 0.32 & 0.35 & 24.7 & 31.2 \\
\hline $4 / 4 / 95$ & -3.6 & 0.13 & 0.14 & 7.6 & 12.7 \\
\hline 4/6/95 & -0.21 & 0.06 & 0.21 & 12.5 & 5.6 \\
\hline 4/8/95 & 0.78 & 0.28 & 0.14 & 7.4 & 27.7 \\
\hline $4 / 10 / 95$ & -3.8 & 0.3 & 0.78 & 166 & 28.9 \\
\hline $4 / 12 / 95$ & -0.23 & 0.29 & 0.01 & 0.6 & 28.4 \\
\hline $4 / 14 / 95$ & -0.19 & 0.05 & 0.2 & 11.4 & 5.4 \\
\hline $4 / 16 / 95$ & 0.89 & 0.66 & 0.03 & 1.8 & 64 \\
\hline $4 / 18 / 95$ & 5.8 & 0.68 & 0.61 & 71.9 & 65.8 \\
\hline $4 / 20 / 95$ & 0.38 & 0.35 & 0.02 & 1.1 & 34.1 \\
\hline $4 / 22 / 95$ & -0.29 & 0.47 & 0.01 & 0.37 & 45.4 \\
\hline 4/24/95 & -0.63 & 0.14 & 0.31 & 20.5 & 13.4 \\
\hline $4 / 26 / 95$ & -0.57 & 0.21 & 0.14 & 7.4 & 20.1 \\
\hline $4 / 28 / 95$ & -1.6 & 0.48 & 0.19 & 11.4 & 46.5 \\
\hline $4 / 30 / 95$ & 0.89 & 0.19 & 0.31 & 21 & 18.7 \\
\hline $5 / 2 / 95$ & 0.38 & 1.2 & 0 & 0.1 & 115 \\
\hline $5 / 4 / 95$ & 4.6 & 0.35 & 0.79 & 177 & 33.5 \\
\hline $5 / 6 / 95$ & -1.2 & 0.28 & 0.27 & 16.7 & 27.2 \\
\hline $5 / 8 / 95$ & -1.4 & 0.34 & 0.26 & 16.9 & 32.4 \\
\hline 6/20/95 & 0.56 & 0.1 & 0.41 & 31.9 & 9.5 \\
\hline $6 / 22 / 95$ & 0.59 & 0.1 & 0.61 & 70.9 & 6.8 \\
\hline $6 / 30 / 95$ & 2.47 & 0.34 & 0.53 & 51.8 & 32.9 \\
\hline $7 / 2 / 95$ & -4.31 & 0.27 & 0.85 & 254 & 26 \\
\hline
\end{tabular}

\footnotetext{
$\mathrm{N}: \quad 31$

Mean: $\quad-0.21194$

Std Dev: $\quad 2.03997$

2-sigma $\quad-4.29187$

min:

2-sigma 3.868004

max:
}

26.77097

22.85586

$-18.9407$

72.48268 
A-12

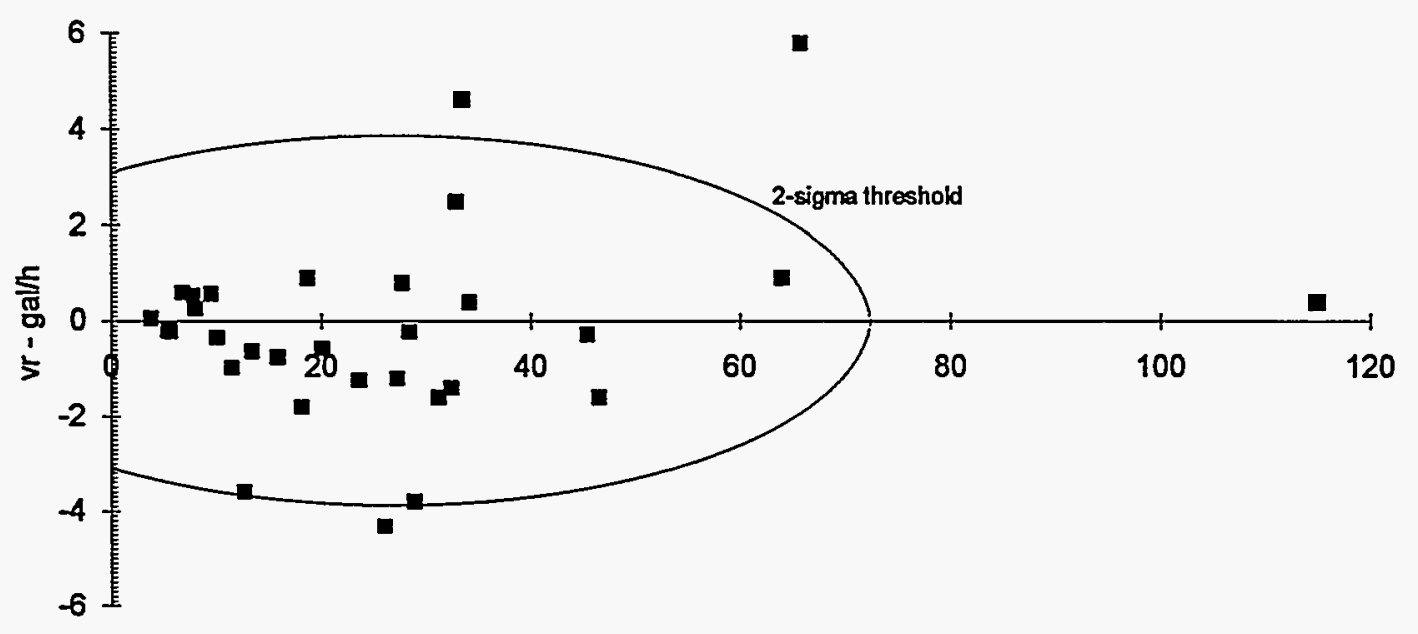

standard deviation - gal

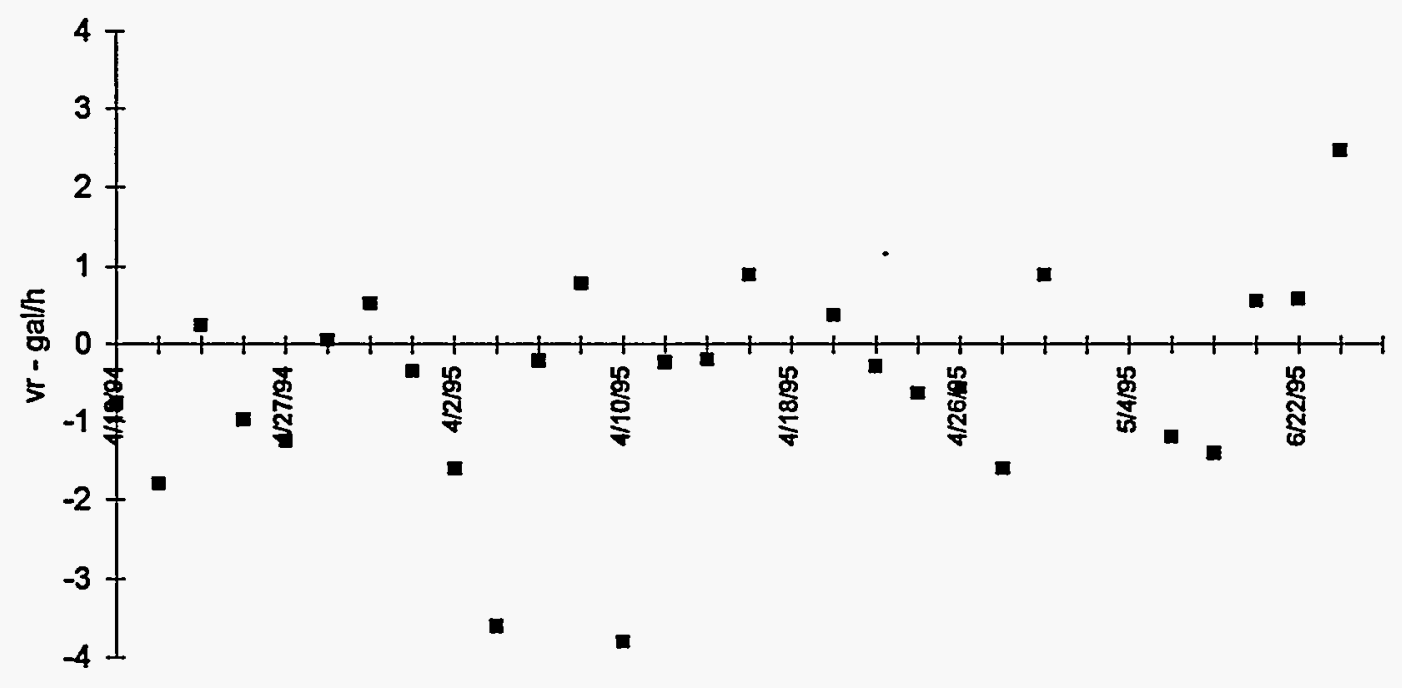


A-13

W-8: 48-hour Regression Analysis

\begin{tabular}{|c|c|c|c|c|c|}
\hline & $\mathrm{m}$ & $\sigma_{n}$ & $r^{2}$ & $F$ & $\sigma_{y}$ \\
\hline $4 / 19 / 94$ & 0.91 & 0.24 & 0.23 & 13.9 & 23.4 \\
\hline $4 / 21 / 94$ & 0.18 & 0.54 & 0 & 0.11 & 52 \\
\hline $4 / 23 / 94$ & -1.5 & 0.37 & 0.25 & 15.8 & 36.25 \\
\hline $4 / 25 / 94$ & 0.34 & 0.13 & 0.13 & 7.1 & 12.3 \\
\hline $4 / 27 / 94$ & 1.38 & 0.2 & 0.5 & 46.5 & 19.4 \\
\hline $4 / 29 / 94$ & 0.08 & 0.09 & 0.02 & 0.8 & 8.7 \\
\hline $3 / 29 / 95$ & -0.01 & 0.14 & 0 & 0 & 13 \\
\hline 3/31/95 & -0.42 & 0.11 & 0.23 & 13.8 & 11 \\
\hline $4 / 2 / 95$ & 0.25 & 0.09 & 0.14 & 7.8 & 8.5 \\
\hline $4 / 4 / 95$ & -0.33 & 0.38 & 0.01 & 0.7 & 37 \\
\hline $4 / 6 / 95$ & 0.59 & 0.18 & 0.19 & 10.7 & 17.4 \\
\hline $4 / 8 / 95$ & 0.31 & 0.21 & 0.04 & 2.1 & 20.6 \\
\hline $4 / 10 / 95$ & -0.15 & 0.19 & 0.01 & 0.6 & 18.1 \\
\hline 4/12/95 & -0.4 & 0.12 & 0.2 & 11.6 & 11.3 \\
\hline $4 / 14 / 95$ & 0.04 & 0.17 & 0 & 0 & 16.6 \\
\hline 4/16/95 & 0.22 & 0.12 & 0.06 & 2.9 & 12.1 \\
\hline 4/18/95 & 0.44 & 0.1 & 0.29 & 19.1 & 9.7 \\
\hline $4 / 20 / 95$ & 0.17 & 0.05 & 0.22 & 13.2 & 4.5 \\
\hline $4 / 22 / 95$ & -0.23 & 0.04 & 0.4 & 30.8 & 4.1 \\
\hline $4 / 24 / 95$ & 0.15 & 0.08 & 0.08 & 3.9 & 7.4 \\
\hline 4/26/95 & 0.15 & 0.07 & 0.09 & 4.6 & 6.6 \\
\hline $4 / 28 / 95$ & 0.14 & 0.08 & 0.06 & 3 & 8 \\
\hline $4 / 30 / 95$ & 0.06 & 0.04 & 0.04 & 2.1 & 4.3 \\
\hline $5 / 2 / 95$ & 0.71 & 0.16 & 0.31 & 20.7 & 15 \\
\hline $5 / 4 / 95$ & 2.4 & 0.22 & 0.73 & 122 & 21.1 \\
\hline 5/6/95 & -0.72 & 0.25 & 0.15 & 8.1 & 24.4 \\
\hline $5 / 8 / 95$ & 1.69 & 0.35 & 0.33 & 22.9 & 34 \\
\hline $6 / 20 / 95$ & 7.2 & 1.1 & 0.5 & 44.8 & 103 \\
\hline $6 / 22 / 95$ & -3.5 & 0.33 & 0.71 & 114 & 31.7 \\
\hline 6/30/95 & 0.11 & 0.12 & 0.02 & 1.1 & 11.1 \\
\hline $7 / 2 / 95$ & 0.06 & 0.09 & 0.01 & 0.5 & 9.2 \\
\hline
\end{tabular}

$\mathrm{N}: \quad 31$

Mean: $\quad 0.332903$

19.73387

Std Dev: $\quad 1.600144$

19.13781

2-sigma min: $\quad-2.86739$

$-18.5418$

2-sigma max: 3.533192

58.0095 
A-14

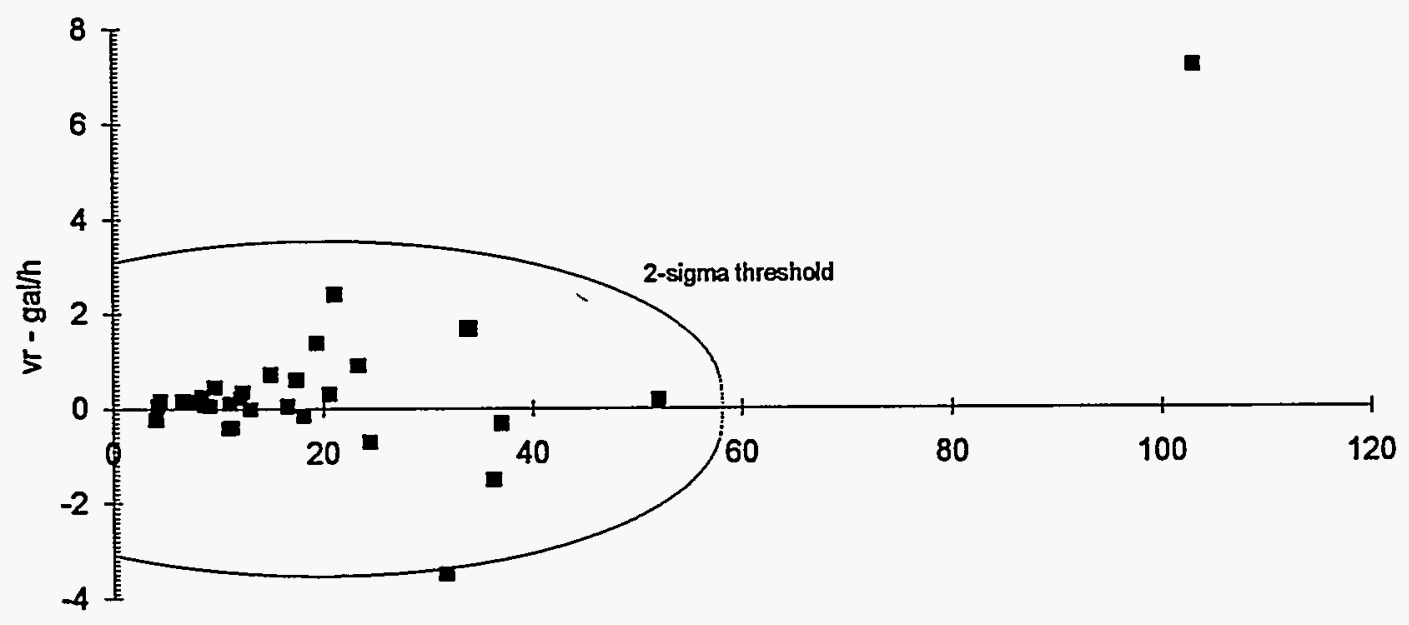

standard deviation - gal

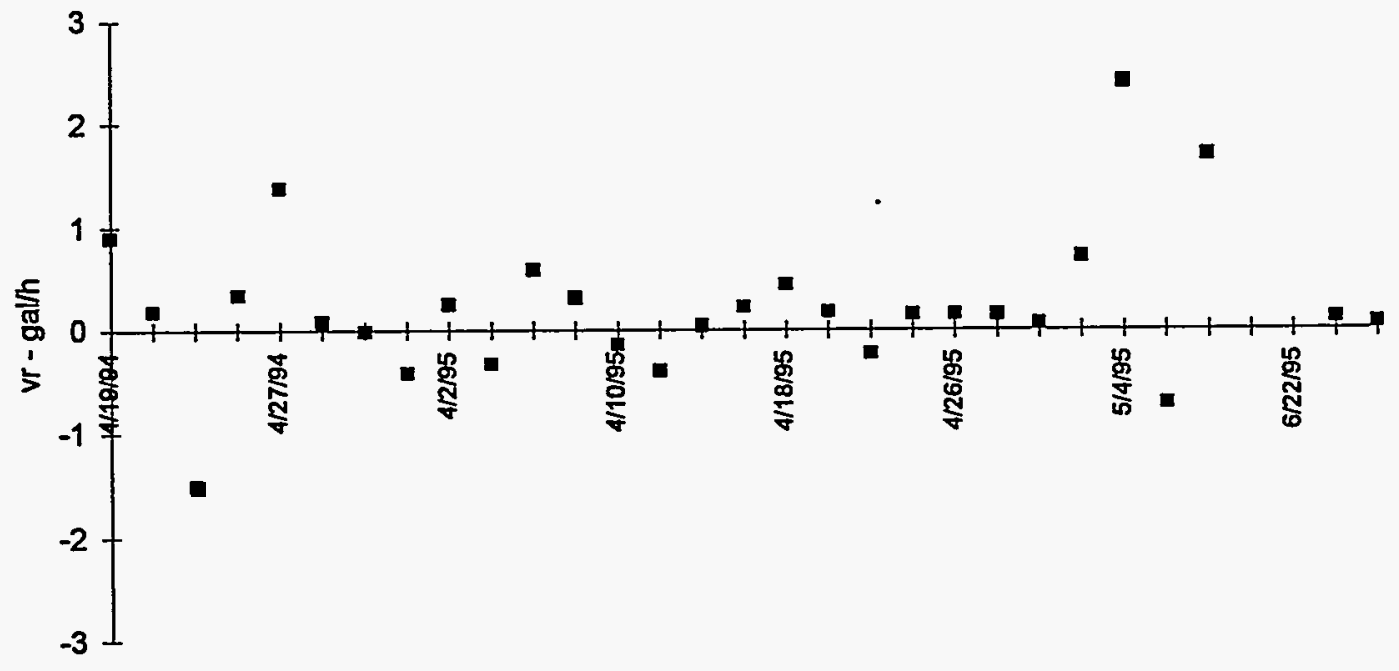


W-9: 48-hour Regression Analysis

\begin{tabular}{|c|c|c|c|c|c|}
\hline & $\mathrm{m}$ & $\sigma_{n}$ & $r^{2}$ & $\mathbf{F}$ & $\sigma_{y}$ \\
\hline 4/19/94 & 0.09 & 0.09 & 0.02 & 1.1 & 8.7 \\
\hline $4 / 21 / 94$ & 0.19 & 0.11 & 0.06 & 2.8 & 10.8 \\
\hline $4 / 23 / 94$ & -0.23 & 0.1 & 0.1 & 5.6 & 9.3 \\
\hline $4 / 25 / 94$ & 0.27 & 0.1 & 0.13 & 6.7 & 9.9 \\
\hline $4 / 27 / 94$ & 0.24 & 0.08 & 0.16 & 9.1 & 7.6 \\
\hline $4 / 29 / 94$ & 0.17 & 0.04 & 0.25 & 15 & 4.3 \\
\hline 3/29/95 & -0.12 & 0.07 & 0.07 & 3.2 & 6.5 \\
\hline 3/31/95 & -0.64 & 0.07 & 0.6 & 75.7 & 7.1 \\
\hline $4 / 2 / 95$ & 0.03 & 0.07 & 0 & 0.23 & 6.3 \\
\hline $4 / 4 / 95$ & -1.5 & 0.15 & 0.67 & 95.4 & 14.9 \\
\hline \multicolumn{6}{|l|}{$4 / 6 / 95$} \\
\hline \multicolumn{6}{|l|}{$4 / 8 / 95$} \\
\hline \multicolumn{6}{|l|}{$4 / 10 / 95$} \\
\hline $4 / 12 / 95$ & -3.1 & 0.54 & 0.41 & 32.4 & 51.8 \\
\hline 4/14/95 & -0.05 & 0.05 & 0.02 & 0.97 & 4.7 \\
\hline $4 / 16 / 95$ & 0.07 & 0.03 & 0.09 & 4.71 & 2.9 \\
\hline $4 / 18 / 95$ & 0.02 & 0.15 & 0 & 0.01 & 14 \\
\hline 4/20/95 & 0.88 & 0.13 & 0.49 & 43.8 & 12.7 \\
\hline $4 / 22 / 95$ & 0.35 & 0.05 & 0.56 & 59.2 & 4.38 \\
\hline $4 / 24 / 95$ & -0.36 & 0.03 & 0.78 & 161 & 2.7 \\
\hline $4 / 26 / 95$ & 0.23 & 0.06 & 0.25 & 15.5 & 5.6 \\
\hline $4 / 28 / 95$ & 0 & 0.08 & 0 & 0 & 7.4 \\
\hline $4 / 30 / 95$ & -0.51 & 0.33 & 0.05 & 2.3 & 32.2 \\
\hline $5 / 2 / 95$ & 0.32 & 0.06 & 0.4 & 31.5 & 5.5 \\
\hline $5 / 4 / 95$ & 0.14 & 0.14 & 0.02 & 1 & 13.1 \\
\hline $5 / 6 / 95$ & -0.16 & 0.06 & 0.12 & 6.5 & 5.8 \\
\hline $5 / 8 / 95$ & 1.3 & 0.13 & 0.69 & 101 & 12.2 \\
\hline $6 / 20 / 95$ & -0.4 & 0.04 & 0.02 & 0.9 & 4.3 \\
\hline $6 / 22 / 95$ & 0.33 & 0.06 & 0.42 & 32.8 & 5.6 \\
\hline $6 / 30 / 95$ & -0.01 & 0.04 & 0 & 0.24 & 3.5 \\
\hline $7 / 2 / 95$ & -0.12 & 0.05 & 0.13 & 6.7 & 4.3 \\
\hline
\end{tabular}

N: $\quad 28$

Mean: $\quad-0.09179$

9.931429

Std Dev: $\quad 0.76434$

10.05743

2-sigma $\quad-1.62047$

$-10.1834$

min:

2-sigma 1.436894

30.04629

max: 


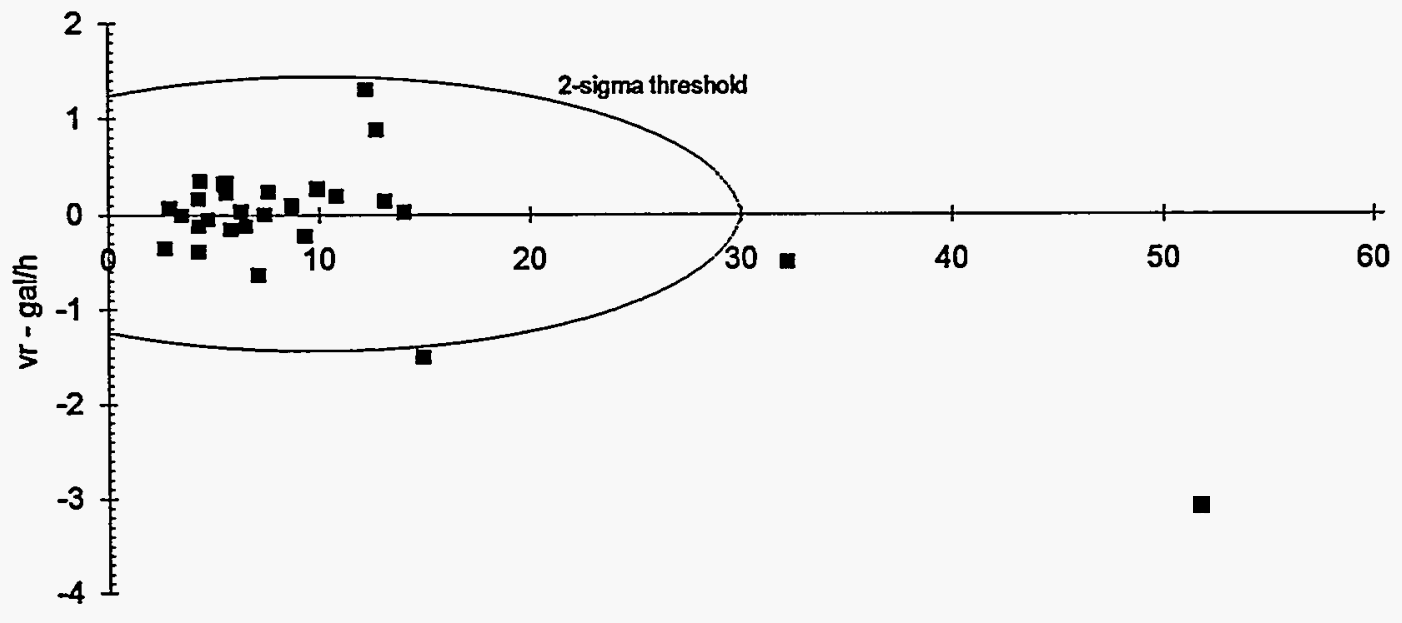

standard deviation - gal

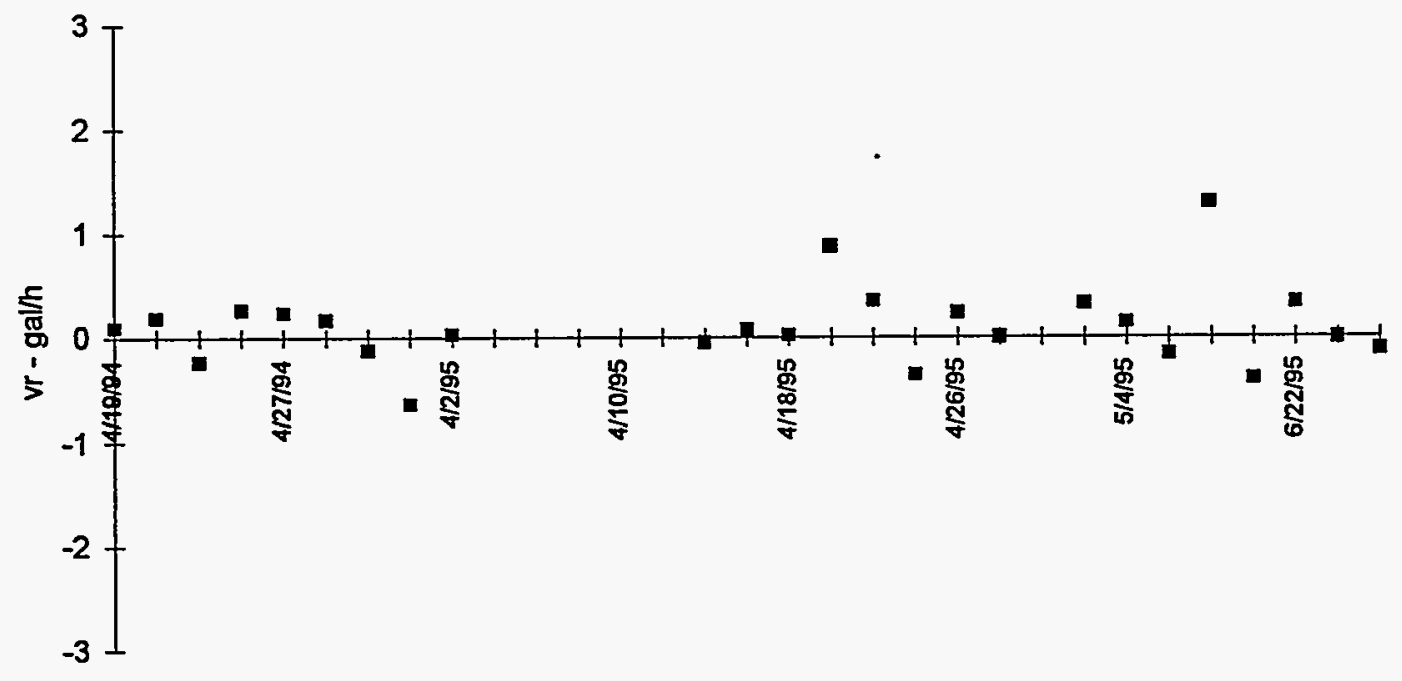




\section{A-17}

W-10: 48-hour Regression Analysis

\begin{tabular}{cccccc}
\hline & $\mathrm{m}$ & $\sigma_{n}$ & $r^{2}$ & $F$ & $\sigma_{y}$ \\
\hline $3 / 29 / 95$ & 0.53 & 0.09 & 0.41 & 32.7 & 8.8 \\
$3 / 31 / 95$ & 0.56 & 0.34 & 0.05 & 2.7 & 32.4 \\
$4 / 2 / 95$ & 3 & 0.56 & 0.38 & 27.7 & 54.2 \\
$4 / 4 / 95$ & -3.2 & 0.36 & 0.63 & 78 & 35 \\
$4 / 6 / 95$ & -0.31 & 0.33 & 0.02 & 0.87 & 31.9 \\
$4 / 8 / 95$ & 0.77 & 0.16 & 0.34 & 24.1 & 15.1 \\
$4 / 10 / 95$ & -1.06 & 0.17 & 0.46 & 38.8 & 16.4 \\
$4 / 12 / 95$ & -0.03 & 0.04 & 0.02 & 0.75 & 3.6 \\
$4 / 14 / 95$ & 0.11 & 0.08 & 0.04 & 2 & 7.8 \\
$4 / 16 / 95$ & 0.12 & 0.11 & 0.03 & 1.2 & 10.1 \\
$4 / 18 / 95$ & 2.5 & 0.24 & 0.7 & 108 & 23.1 \\
$4 / 20 / 95$ & 2.03 & 0.56 & 0.22 & 13.17 & 53.9 \\
$4 / 22 / 95$ & -0.27 & 0.71 & 0 & 0.15 & 67 \\
$4 / 24 / 95$ & -1.18 & 0.18 & 0.49 & 44.7 & 16.9 \\
$4 / 26 / 95$ & 0.38 & 0.11 & 0.19 & 11.2 & 10.8 \\
$4 / 28 / 95$ & -1.14 & 0.5 & 0.1 & 5.19 & 48.1 \\
$4 / 30 / 95$ & 2.01 & 0.49 & 0.27 & 16.9 & 47 \\
$5 / 2 / 95$ & -0.18 & 0.12 & 0.04 & 2.3 & 11.7 \\
$5 / 4 / 95$ & 0.845 & 0.36 & 0.1 & 5.4 & 35 \\
$5 / 6 / 95$ & 4.25 & 0.38 & 0.73 & 123.5 & 36.8 \\
$5 / 8 / 95$ & 1.72 & 1.05 & 0.05 & 2.7 & 101 \\
$6 / 20 / 95$ & 1.19 & 0.24 & 0.35 & 24.8 & 23.1 \\
$6 / 22 / 95$ & 1.21 & 0.12 & 0.68 & 96.5 & 11.8 \\
$6 / 30 / 95$ & 0.09 & 0.03 & 0.14 & 7.5 & 3.2 \\
$7 / 2 / 95$ & 0.02 & 0.02 & 0.04 & 2 & 1.5 \\
\hline & & & & &
\end{tabular}

$\begin{array}{cc}\text { N: } & 25 \\ \text { Mean: } & 0.5586 \\ \text { Std Dev: } & 1.525478 \\ \text { 2-sigma min: } & -2.49236 \\ \text { 2-sigma max: } & 3.609555\end{array}$

28.248

23.70535

$-19.1627$

75.65869 

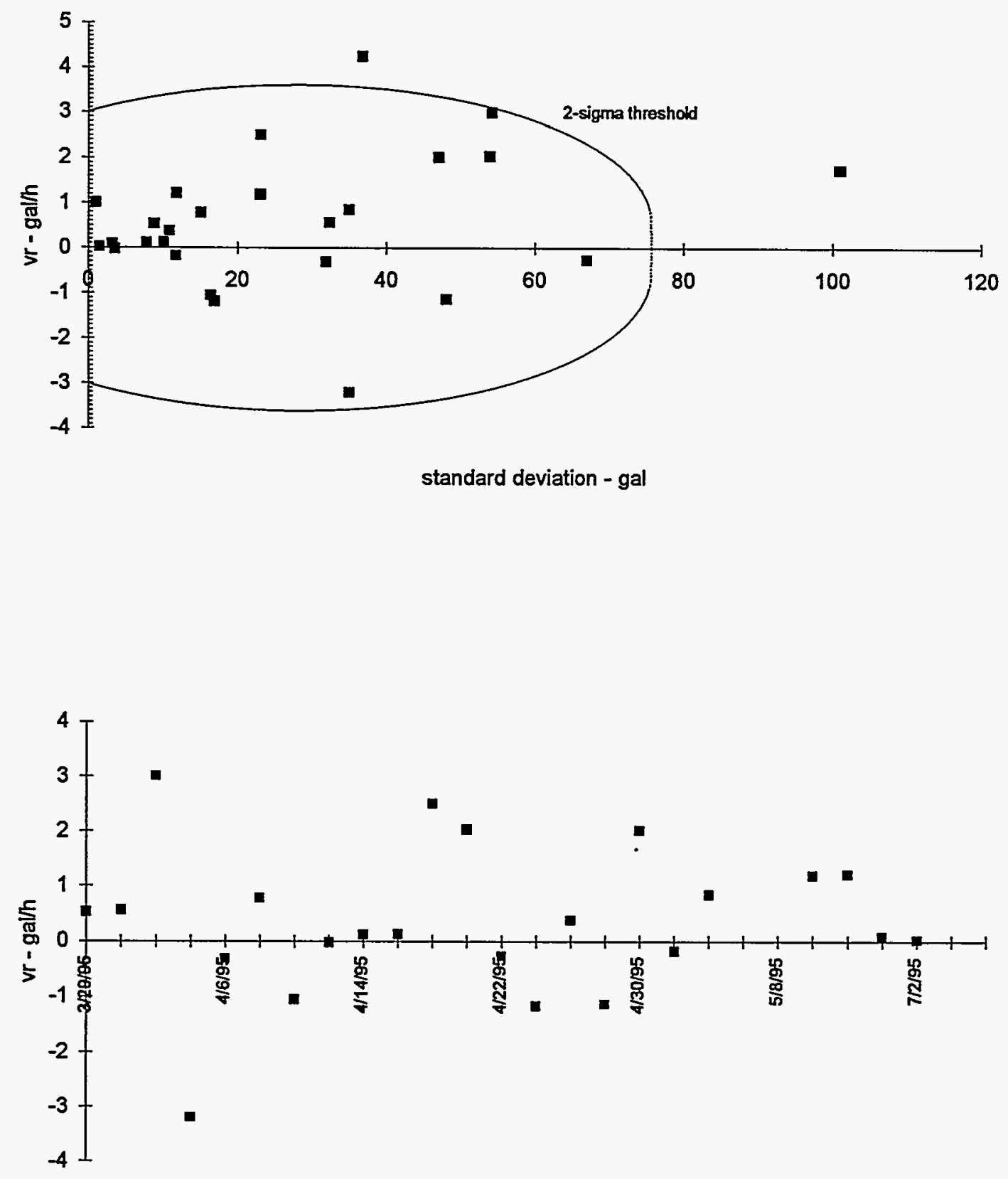


\section{DISTRIBUTION}

1. J.F. Alexander

2. L. V. Asplund

3. H. L. Boston

4. W. B. Brickeen

5. B. L. Burks

6 J. A. Carr

7. D. D. Falter

8. J. R. Frantz

9. B. A. Frederick

10. K. E. Fricke

11. D. H. Gray

12. O.W. Hale

13. L. Holder

14. G. R. Hudson

15. M. A. Johnson

16. B. E. Lewis

17. D. M. Matteo

18. J. C. Miller

19. C. Mims

20. R. R. Morgan

21-22. P. T. Owen

23. J. H. Platfoot

24. W. R. Reed

25. A. D. Reynolds

26. P. A. Schrandt

27. M. Slater

28. J. L. Snyder

29. D. K. Stair

30. W. T. Thompson

31. S. D. Van Hoesen

32. D. Walton

33. C. O. Wiles

34. Central Research Library

35. ER Document Management Center-RC.

36. Office of Scientific and Technical Information, P.O. Box 62, Oak Ridge, TN 37831

37. R. E. Depew, Advanced Systems Technology, Inc., 11217 Outlet Dr., Knoxville, TN 37032

38. S. P. duMont, HAZMED, 667 Emory Valley Road, Suite A, Oak Ridge, TN 37830

39. K. S. Redus, MACTEC, 189 Lafayette Drive, Suite C, Oak Ridge, TN 37830

40. V. A. Rule, XI Associates, 667 Emory Valley Road, Suite C, Oak Ridge, TN 37830 


,

